\title{
REVIEW
}

\section{Recent studies of cements and concretes by synchrotron radiation crystallographic and cognate methods}

\author{
Miguel A.G. Aranda* \\ ALBA Synchrotron, Ctra, BP1413 km. 3,3, Cerdanyola del Vallès, Barcelona 08290, Spain
}

(Received 22 May 2015; accepted 4 July 2015)

\begin{abstract}
The portfolio of available synchrotron radiation techniques is increasing notably for cements and pastes. Furthermore, sometimes the terminology is confusing and an overall picture highlighting similarities and differences of related techniques was lacking. Therefore, the main objective of this work is to review recent advances in synchrotron techniques providing a comprehensive overview. This work is not intended to gather all publications in cement chemistry but to give a unified picture through selected examples. Crystallographic techniques are used for structure determination, quantitative phase analyses and microstructure characterization. These studies are not only carried out in standard conditions but synchrotron techniques are especially suited to non-ambient conditions: high temperatures and pressures, hydration, etc., and combinations. Related crystallographic techniques, like Pair Distribution Function, are being used for the analysis of ill-crystalline phase(s). Furthermore, crystallographic tools are also employed in imaging techniques including scanning diffraction microscopy and tomography and coherent diffraction imaging. Other synchrotron techniques are also reviewed including X-rays absorption spectroscopy for local structure and speciation characterizations; small angle X-ray scattering for microstructure analysis and several imaging techniques for microstructure quantification: full-field soft and hard X-ray nano-tomographies; scanning infrared spectro-microscopy; scanning transmission and fluorescence X-ray tomographies. Finally, a personal outlook is provided.
\end{abstract}

Keywords: synchrotron techniques; quantitative phase analysis; imaging and mapping; binders; cement hydration; cement paste microstructure; $\mathrm{C}-\mathrm{S}-\mathrm{H}$ and $\mathrm{C}-\mathrm{A}-\mathrm{S}-\mathrm{H}$ gels

\section{Contents}

\section{A very brief introduction to Portland cement and concretes}

2. A very brief introduction to synchrotron radiation and properties 5

3. Uses of synchrotron radiation for cements, pastes and concretes 7

3.1. Diffraction for characterizing crystalline phases (long-range order) 10

3.2. Techniques for characterizing amorphous phases 10

3.2.1. Total scattering techniques for studying short-range order 10

3.2.2. X-ray absorption techniques for studying short-range order and chemical states

3.3. Diffraction for quantifying crystalline phases and in many cases phase evolution(s)

*Emails: g.aranda@cells.es; g_aranda@uma.es 
3.3.2. Quantitative phase analysis of hydrating binders

3.4. Variable-temperature diffraction to characterize phase evolution(s) and reactions 15

3.4.1. In-situ thermal formation and decomposition studies at moderate temperatures

3.4.2. In-situ clinkering studies at very high temperatures

3.5. Diffraction under pressure to characterize phases and chemical reactions

3.5.1. Chemical reactions at relatively low pressures in capillary cells (hydrothermal conditions)

3.5.2. Hydrating reactions at medium pressures and temperatures 18

$\begin{array}{ll}\text { 3.5.3. Phase characterization at very high pressures in diamond-anvil-cells } & 18\end{array}$

3.6. Small angle X-ray scattering for microstructural characterization of building materials

3.7. Imaging building materials at different length scales and with different photon energies

3.7.1. Full-field soft X-ray nano-tomography

3.7.2. Full-field hard X-ray micro-tomography

3.7.3. Scanning synchrotron radiation microscopies 28

3.7.4. Hard X-ray coherent diffraction imaging 34

\section{Outlook}

\section{Acknowledgments}

Disclosure statement

References

\section{Nomenclature, Acronyms}

Cement nomenclature

AFm

Aft

ASR

CSA

C-S-H

DTA/TGA

MIP

OPC

PCE

SCM

w/c

AChX-nCT

AChX- $\mu \mathrm{CT}$

ACsX-nCT

ACsX-nM

BCDI

BL

CAT
$\mathrm{C}=\mathrm{CaO}, \underline{\mathrm{C}}=\mathrm{CO}_{2}, \mathrm{~S}=\mathrm{SiO}_{2}, \underline{\mathrm{S}}=\mathrm{SO}_{2}, \mathrm{~A}=\mathrm{Al}_{2} \mathrm{O}_{3}, \mathrm{~F}=\mathrm{Fe}_{2} \mathrm{O}_{3}, \mathrm{M}=\mathrm{MgO}$, $\mathrm{K}=\mathrm{K}_{2} \mathrm{O}, \mathrm{N}=\mathrm{Na}_{2} \mathrm{O}$ and $\mathrm{H}=\mathrm{H}_{2} \mathrm{O}$. Therefore, for instance, $\mathrm{Ca}_{3} \mathrm{SiO}_{5}$ is $\mathrm{C}_{3} \mathrm{~S}, \mathrm{CaCO}_{3}$ is $\mathrm{CC}$, and $\mathrm{CaSO}_{4} \cdot 2 \mathrm{H}_{2} \mathrm{O}$ is $\mathrm{CS}_{2} \mathrm{H}_{2}$. ' $\mathrm{Al}_{2} \mathrm{O}_{3}-\mathrm{Fe}_{2} \mathrm{O}_{3}$-mono sulphate' (set of phases)

' $\mathrm{Al}_{2} \mathrm{O}_{3}-\mathrm{Fe}_{2} \mathrm{O}_{3}$-tri sulphate' (aka, ettringite)

alkali silica reaction

calcium sulphoaluminate cement

calcium-silicate-hydrate amorphous gel

differential thermal analysis/thermo gravimetric analysis

mercury intrusion porosimetry

ordinary Portland cement

polycarboxylate ether

supplementary cementitious materials

water-to-cement mass ratio

absorption-contrast hard X-ray nano-computed tomography

absorption-contrast hard X-ray micro-computed tomography

absorption-contrast soft X-ray nano-computed tomography

absorption-contrast soft X-ray nano-microscopy

Bragg coherent diffraction imaging

beam line

computed axial tomography (aka, computed tomography) 


\begin{tabular}{|c|c|c|}
\hline 101 & CDI & coherent diffraction imaging (aka, lensless imaging) \\
\hline 102 & CRL & compound refractive lenses \\
\hline 103 & $\mathrm{DAC}$ & diamond anvil cell \\
\hline 104 & EXAFS & extended X-ray absorption fine structure \\
\hline 105 & FCDI & forward coherent diffraction imaging \\
\hline 106 & FoV & field of view \\
\hline 107 & FZP & Fresnel zone plate \\
\hline 108 & IR & infrared \\
\hline 109 & $\mathrm{~KB}$ & Kirkpatrick-Baez (elliptically-bent double-focusing mirrors) \\
\hline 110 & $\mathrm{PChX}-\mu \mathrm{CT}$ & phase-contrast hard X-ray micro-computed tomography \\
\hline 111 & PDF & pair distribution function \\
\hline 112 & PFCDI-nCT & $\begin{array}{l}\text { ptychographic forward coherent diffraction imaging nano-computed } \\
\text { tomography }\end{array}$ \\
\hline 114 & RQPA & Rietveld quantitative phase analysis \\
\hline 115 & SANS & small-angle neutron scattering \\
\hline 116 & SAS & small-angle scattering \\
\hline 117 & SAXS & small-angle X-ray scattering \\
\hline 118 & SCXRD & single crystal X-ray diffraction \\
\hline 119 & SEM & scanning electron microscopy \\
\hline 120 & SFXM & scanning fluorescence X-ray microscopy \\
\hline 121 & SR & synchrotron radiation \\
\hline 122 & STXM & scanning transmission X-ray microscopy \\
\hline $\begin{array}{l}123 \\
124\end{array}$ & SDXM & $\begin{array}{l}\text { scanning diffraction X-ray microscopy (aka, synchrotron microdiffrac- } \\
\text { tion) }\end{array}$ \\
\hline 125 & $\mathrm{SDX}-\mu \mathrm{CT}$ & scanning diffraction X-ray micro-computed tomography \\
\hline 126 & SXRPD & synchrotron X-ray powder diffraction \\
\hline 127 & TEM & transmission electron microscopy \\
\hline $\begin{array}{l}128 \\
129\end{array}$ & XANES & $\begin{array}{l}\text { X-ray absorption near edge structure (aka, NEXAFS near-edge } X_{\Lambda} \text {-ray } \\
\text { absorption fine structure) }\end{array}$ \\
\hline 130 & XAS & X-ray absorption spectroscopy \\
\hline 131 & XFEL & X-ray free electron laser \\
\hline 132 & XRPD & X-ray powder diffraction \\
\hline
\end{tabular}

\section{A very brief introduction to Portland cement and concretes}

138 The term cement (building material) may be used for almost any type of binder, with chemistry 139 ranging from fully organic to totally inorganic. The oldest organic 'cements' were made from 140 plant extracts like starch. The oldest pure inorganic cements were based on muds and subsequently on gypsum plasters. However, since the development of Portland cement about 180 years ago (http://en.wikipedia.org/wiki/Portland_cement), it has become the dominant binder used in concrete (http://en.wikipedia.org/wiki/Concrete) for construction. Concrete is a hierarchically complex hardened composite material formed from the mixing of water and aggregates (both fine and coarse) with Portland cement. Some other additions and admixtures may be added depending upon the type of concrete.[1] Portland cements are used as poorly soluble but highly reactive powders in water. The initial suspension, named as fresh cement paste, firstly undergoes setting and on hardening yields the cementitious matrix. The use of water for achieving the hardening 149 results in the term 'hydraulic binders', to highlight that the reaction of cement with water yields the concrete which can harden even underwater. 
151

152

153

154

155

156

157

158

159

160

161

162

163

164

165

166

167

168

169

170

171

172

173

174

175

176

177

178

179

Q1 180

181

182

183

184

185

186

187

188

189

190

191

192

193

194

195

196

197

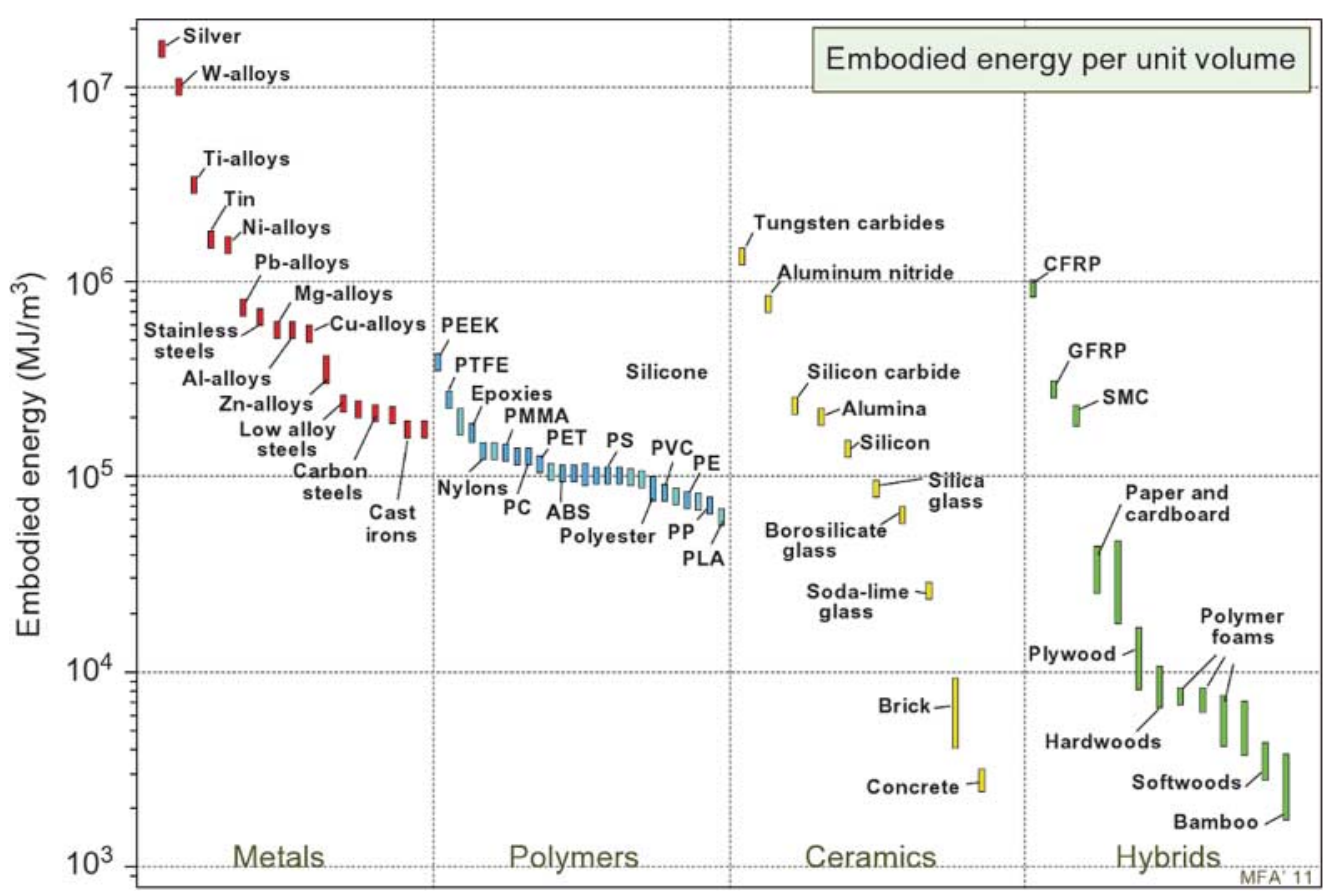

Figure 1. Embodied energy for different types of materials normalized to the unit volume. Reprinted from Materials and the Environment: Eco-informed Material Choice, Second Edition, M. F. Ashby, Chapter 6: Eco-data: Values, sources, precision, Figure 6.11. Copyright (2013), with permission from Elsevier.

Praised for its versatility, durability, fire-resistance, on-site casting and economic value, Portland concrete is receiving recognition also for its relatively low embodied energy compared to other building materials (see Figure 1). Furthermore, because of its use of local materials, by which there is reduction in energy and pollution costs associated with material transport, it is also an important asset. Annual worldwide Portland cement production is approaching 3 Gt.[2] World yearly consumption of concrete is well over $6 \mathrm{~km}^{3}$; its magnitude may be, perhaps, better perceived by referring this value to every person in the planet: 2.5 tonnes per person per year. This is just second only to our consumption of fresh water. However and in spite of its universal use, Portland cements are one of the most environmentally contentious materials. Worldwide production of cement accounts for approximately $6 \%$ of the total anthropogenic $\mathrm{CO}_{2}$ production.[3]

Research in cements and concretes has many facets ranging from the understanding of phase assemblage and microstructure to ensure extended durability, to reduce the $\mathrm{CO}_{2}$ footprint of cements to mitigate the current man-increased green-house effect. An overview of the research carried out in cements can be gained from the scientific programme of the International Congress on the Chemistry of Cements which takes place every four years with the last edition taking place in October-2015 at Beijing (www.iccc2015beijing.org/).

Portland cement is manufactured by grinding the Portland clinker with the setting regulator that may be close to $4 \mathrm{wt} \%$ of gypsum. A typical Portland clinker chemical composition is close to $67 \mathrm{wt} \% \mathrm{CaO}, 22 \mathrm{wt} \% \mathrm{SiO}_{2}, 5 \mathrm{wt} \% \mathrm{Al}_{2} \mathrm{O}_{3}, 3 \mathrm{wt} \% \mathrm{Fe}_{2} \mathrm{O}_{3}$ and $3 \mathrm{wt} \%$ of minor components. With this elemental chemistry, OPCs usually contains four major phases: $50-70 \mathrm{wt} \%$ alite, $\mathrm{Ca}_{3} \mathrm{SiO}_{5}$ or $\mathrm{C}_{3} \mathrm{~S}, 15-30 \mathrm{wt} \%$ belite, $\mathrm{Ca}_{2} \mathrm{SiO}_{4}$ or $\mathrm{C}_{2} \mathrm{~S}, 5-10 \mathrm{wt} \%$ tricalcium aluminate, $\mathrm{Ca}_{3} \mathrm{Al}_{2} \mathrm{O}_{6}$ or $\mathrm{C}_{3} \mathrm{~A}$ and 5-15 wt $\%$ tetracalcium aluminoferrite, $\mathrm{Ca}_{4} \mathrm{Al}_{2} \mathrm{Fe}_{2} \mathrm{O}_{10}$ or $\mathrm{C}_{4} \mathrm{AF}$. Most cement compounds are not pure stoichiometric phases but they (may) incorporate many ions as extensively discussed in classical papers and books.[4] 
Finally, some crystalline and amorphous hydrated phases should also be mentioned. AFm are a set of phases with crystalline layered structures. The AFm phase refers to a family of hydrated calcium aluminates based on the hydrocalumite structure, $\mathrm{Ca}_{4} \mathrm{Al}_{2}(\mathrm{OH})_{12} \cdot[\mathrm{Cl}(\mathrm{OH})] \cdot 6 \mathrm{H}_{2} \mathrm{O}$. The archetype AFm phase is $\mathrm{C}_{3} \mathrm{~A} \cdot \mathrm{CaSO}_{4} \cdot 12 \mathrm{H}_{2} \mathrm{O}$ or $\mathrm{Ca}_{4} \mathrm{Al}_{2}(\mathrm{OH})_{12} \cdot\left[\mathrm{SO}_{4}\right] \cdot 6 \mathrm{H}_{2} \mathrm{O}$, known as Kuzelite, but $\mathrm{Al}$ can be partly replaced by $\mathrm{Fe}$ and $\mathrm{SO}_{4}^{2-}$ can be partly or fully replaced by $\mathrm{OH}^{-}, \mathrm{Cl}^{-}$, $\mathrm{CO}_{3}^{2-}$ and several other anions.[5,6] In a similar way, AFt are a set of crystalline tridimensional framework compounds. By far the most common $\mathrm{AFt}$ phase is ettringite which has the stoichiometry $\mathrm{C}_{3} \mathrm{~A} \cdot 3 \mathrm{CaSO}_{4} \cdot 32 \mathrm{H}_{2} \mathrm{O}$ that can also be written as $\mathrm{Ca}_{6} \mathrm{Al}_{2}\left(\mathrm{SO}_{4}\right)_{3}(\mathrm{OH})_{12} \cdot 26 \mathrm{H}_{2} \mathrm{O}$. On the other hand, the principal binding reaction product of cement hydration is amorphous calciumsilicate-hydrate (C-S-H) gel, one of the most complex of all gels.[7] Saturated $\mathrm{C}-\mathrm{S}-\mathrm{H}$ gel has the approximate formula $(\mathrm{CaO})_{1.7} \mathrm{SiO}_{2}\left(\mathrm{H}_{2} \mathrm{O}\right)_{4}$, including liquid water between the particles, but the $\mathrm{Ca} / \mathrm{Si}$ ratio and the water content evolves with time and it depends upon the composition of the starting binder.

\section{A very brief introduction to synchrotron radiation and properties}

Current synchrotron light sources are a particular type of circular particle accelerator designed and built to produce electromagnetic radiation of outstanding properties. These laboratories are user-oriented (both academic and industrial) Large Facilities where staff of very different backgrounds (photon scientists: physicists, chemists, geologists, biologists, physicists, etc.; and sup- Q2 port scientists and technologists: accelerator physicists, mechanical/vacuum/computing/control engineers, technicians, etc.) work together with the final goal of offering the best possible service to the users.

A synchrotron light source usually contains three types of electron accelerators: (i) the linear accelerator (linac), (ii) the booster and (iii) the storage ring. The electrons are produced and initially accelerated in the linac. The electrons from the linac are injected into the booster where they are further accelerated before being kicked into the storage ring. However, some synchrotron light sources inject the electrons directly from the linac into the storage ring which is a circularly shaped accelerator where the kinetic energy of the electrons is kept constant and the desired electromagnetic radiation is generated. The readers are directed to two recent books in order to Q3 learn more about synchrotron light sources.[8-10]

Figure 2 shows some of the most important components in a synchrotron facility from the storage ring of the sample to be studied. The design of beamlines varies tremendously depending on the methods (and wavelength range) to be used. For this reason only a very general overview of a beamline set-up is given in Figure 1. From the user's point of view, everything starts at the photon source where the synchrotron radiation is produced by moving the electrons in the appropriate way within the magnetic device (see Figure 1). The SR produced by the source is pre-conditioned in the front-end before leaving the tunnel to enter into the optic hutch. It must be highlighted that both the energy range and the brightness of the SR strongly depend on the photon source but their discussion is out of the scope of this paper.

The unmonochromatized beam is called a white beam and must be 'conditioned' before it can be used to analyse the sample in the experimental hutch. It is not possible to review all possible optics devices but we can highlight just a few: (i) Mirrors to transport the beam (and sometime to focus it as well as to collimate and reject unwanted radiation); (ii) Monochromators to select a particular wavelength (or set of wavelengths) from the incoming beam; (iii) Focusing optic elements (if needed) to match the size of the beam to the requirements of the employed technique and sample; (iv) Slits, filters, diagnosis elements, etc. Monochromators can select a very narrow energy bandwidth (usually $\Delta \mathrm{E} / \mathrm{E}=10^{-4}$ or smaller) for instance using a double-crystal-monochromator and this radiation is called monochromatic, but it can also select a 
much wider set of wavelengths (f.i. $\Delta \mathrm{E} / \mathrm{E}=1-2 \%$ with a multilayer monochromator) for having higher flux and this type of radiation is commonly named pink beam.

The conditioned SR is then used in the experimental hutch to analyse the sample. The appropriate sample answer is recorded in the detector that for combined studies can be more than one. Most of the synchrotron BLs are in the hard X-ray domain (roughly between $4 \mathrm{keV}$ and $50 \mathrm{keV}$ ) or soft X-ray domain (roughly between $200 \mathrm{eV}$ and $4000 \mathrm{eV}$ ). The optics (and sample set-ups) of soft and hard X-ray BLs are quite different as low-energy implies vacuum which places a lot of restraints in many experiments. It must also be mentioned that IR spectro-microscopy BLs are also starting to play a role in cement studies.

The sample (as well as some optics elements) must be positioned with high mechanical accuracy. Hence, high resolution mechanical and piezoelectric stages are commonly used. Custom-made sample environments also allow in-situ experiments. This term should be understood to include, but not be limited to, time-resolved works (under the influence of external parameters like chemical gradients (water, $\mathrm{CO}_{2}$, etc.), temperature, pressure, etc.; or combinations!) usually in the subsecond to hour timescale which is the relevant scale for building material experiments.

The main properties of SR that benefit building material studies are summarized in Table 1. The outstanding properties of SR have encouraged their uses in many researches related to cements. Comprehensive information regarding the uses of synchrotron can be found in recent books.[7-10] Very useful properties of SR like its intrinsic time structure (that allows following 
Table 1. Main properties of synchrotron radiation of interest for building material studies.

\begin{tabular}{|c|c|}
\hline Property of the SR & Features / uses \\
\hline $\begin{array}{l}\text { Extreme brightness and flux } \\
\text { (combined with high collimation) }\end{array}$ & $\begin{array}{l}\text { - Very high signal-to-noise ratio, allowing high quality data } \\
\text { Fast data collection, including kinetics studies (typ. > } 1 \mathrm{~ms} \text { ) } \\
\text { - Complex sample environments that absorb radiation, for } \\
\text { instance in high temperature, high pressure studies, etc. } \\
\text { Radiation damage }\end{array}$ \\
\hline $\begin{array}{l}\text { Energy tunability (from infrared to } \\
\text { very high-energy X-rays) }\end{array}$ & $\begin{array}{l}\text { Chemical sensitivity through the absorption edges } \\
\text { High-energy minimizes absorption in complex sample } \\
\text { environment experiments } \\
\text { - High energy allows to access to large momentum transfer } \\
\text { values }\end{array}$ \\
\hline $\begin{array}{l}\text { Beam size tunability (from tens of } \\
\mathrm{mm} \text { to tens of } \mathrm{nm} \text { ) }\end{array}$ & $\begin{array}{l}\text { Enable a very large range of imaging techniques from } \mathrm{cm} \text { in } \\
\text { paleontology to } \mathrm{nm} \text { in nanotechnology } \\
\text { Matches the size of the beam to the experiment requirements } \\
\text { Allows to design sample environments with large degree of } \\
\text { freedom }\end{array}$ \\
\hline Parallel geometry & $\begin{array}{l}\text { - Improved full-field reconstruction for imaging } \\
\text { Minimize the errors in powder diffraction } \\
\text { Limited magnification of X-ray beams }\end{array}$ \\
\hline Partial transverse coherence & $\begin{array}{l}\text { - Used in phase contrast imaging techniques } \\
\text { - Allows coherent diffraction imaging }\end{array}$ \\
\hline Stability & - High resolution and high reproducibility \\
\hline
\end{tabular}

Notes: Characteristics in italics note possible drawbacks. Polarization properties and temporal resolution due to the electron bunches are not included as they have not been used in cement studies.

ultra-fast processes in the picosecond to nanosecond range) and polarization features (that allows studying magnetic and chiral samples) are not highlighted in Table 1 as, to the best of my knowledge, they have not yet been used in cement characterization.

Also to the best of my knowledge there is no general review about the uses of synchrotron radiation for characterizing cement binders. I am aware of three focused reviews and they are discussed at the beginning of the next section. However, there are general reviews about the uses of synchrotron radiation applied to other fields like cultural heritage.[11,12] In particular, I found the second, very general, work [12] extremely enlightening. Furthermore, some techniques not treated here (because they have not been applied to building materials) are gathered and discussed there. It must also be noted that the evolution of synchrotron radiation, including its growing importance in crystallography, has also been reviewed [13] and also the starting uses of XFEL.[14]

In this review article, I highlight recent uses of SR applied to a better/deeper characterization of building materials through selected examples. I restrict the discussion to the last decade and references to previous works are only carried out for a few selected cases. I convey my apologies Q5 to these authors whose work(s) are not referenced here but it would not be possible to account for all works dealing with SR and building materials. I have selected examples to show the wide range of applicabilities, and this work is not intended to be a thorough work compiling all references but the updated summary of some key developments.

\section{Uses of synchrotron radiation for cements, pastes and concretes}

There are three recent reviews devoted to the characterization of building materials by synchrotron characterization techniques. Prof. Monteiro's group has reported two reviews $[15,16]$ 


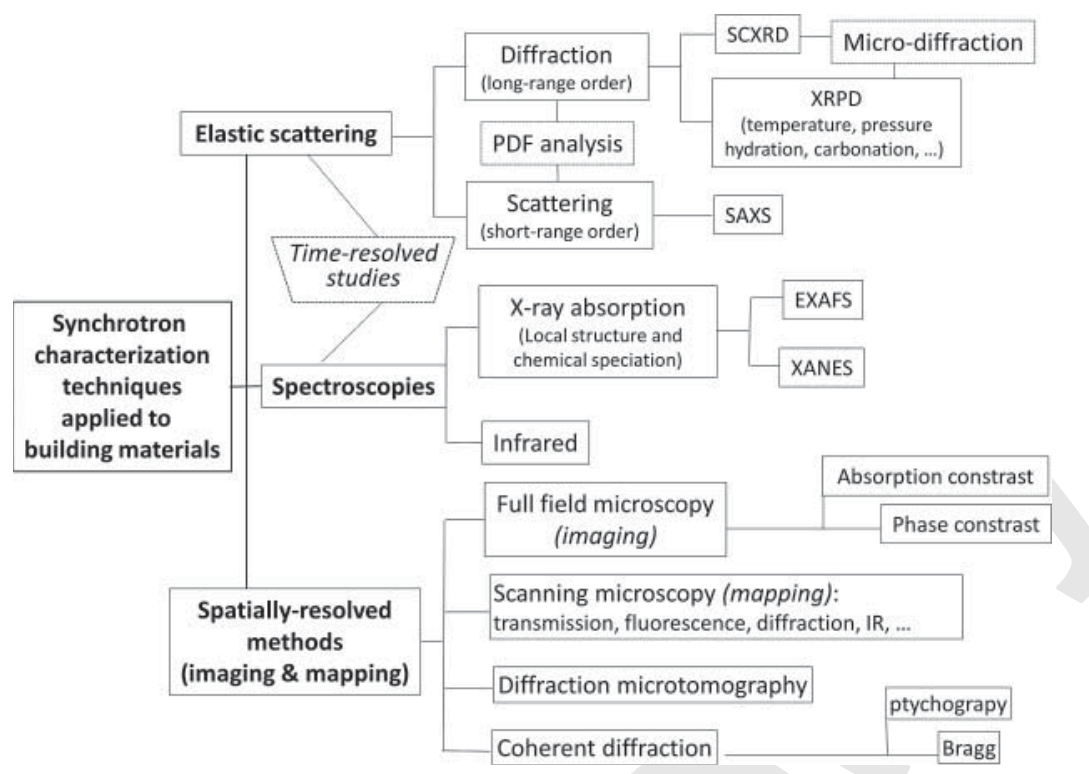

Figure 3. Summary of the different synchrotron techniques employed for characterizing cements and pastes. The interaction of the SR can be elastic where momentum is transferred (yielding the scattering techniques) or inelastic where energy is exchanged (resulting in the spectroscopic techniques). Furthermore, there are many imaging tools profiting from these interactions as well as others like absorption. Moreover, time-resolved studies allow to study kinetics of chemical reactions which are key to follow the evolution in pastes in different time domains. (Acronyms have been defined in the beginning of this paper.)

mainly focused on their own activities covering some techniques: (i) full-field soft X-ray nanotomography; (ii) scanning transmission X-ray microscopy; (iii) scanning X-ray microdiffraction microscopy; and (iv) high pressure X-ray powder diffraction. On the other hand, Prof. Provis's group has also reported one review,[17] mainly focused on their own activities arising from BL-based studies (synchrotron and neutron), dealing with the multiscale understanding of the microstructure and chemistry of geopolymer binders. In this case, the reviewed synchrotron techniques were: (i) scanning infrared spectro-microscopy; (ii) scanning fluorescence X-ray microscopy; and (iii) X-ray nano- and micro-tomographies.

With the information that I have gathered, Figure 3 displays a scheme containing the different SR techniques that have been employed for the characterization of cements and pastes. Figure 4 schematically represents the set-ups used for the main characterization techniques discussed here. As it can be seen from both figures, many synchrotron techniques have been used for the characterization of building materials.

These techniques range from scattering for the analysis of phases as well as phase evolutions to spectroscopic tools for a better characterization of chemical species and elemental compositions. Spatially resolved information can be obtained from a number of approaches. In this context, it is appropriate to distinguish between mapping (or raster-scanning) which consists in the sequential measurement of data from adjacent regions of a sample achieved by moving each region into the photon beam, and (full-field) imaging where an image of the sample is recorded onto an array detector where the signal coming from each region of the sample is measured at each pixel. In addition to the mapping and imaging approaches, hybrid approaches are also being developed. There is no doubt that spatially resolved data are very important in building material characterization as they are being used to reveal the complex hierarchical microstructure of the hydrated pastes without alteration, which is not the case for other characterization techniques like electron microscopies. 
401

402

403

404

405

406

407

408

409

410

411

412

413

414

415

416

417

418

419

420

421

422

423

424

425

426

427

428

429

430

431

432

433

434

435

436

437

438

439

440

441

442

443

444

445

446

447

448

449

450

\section{Scattering \\ techniques}

Spectroscopic
Spectroscopic techniques

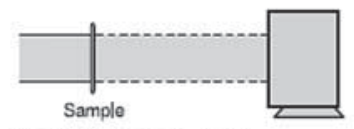

Transmission-XAS
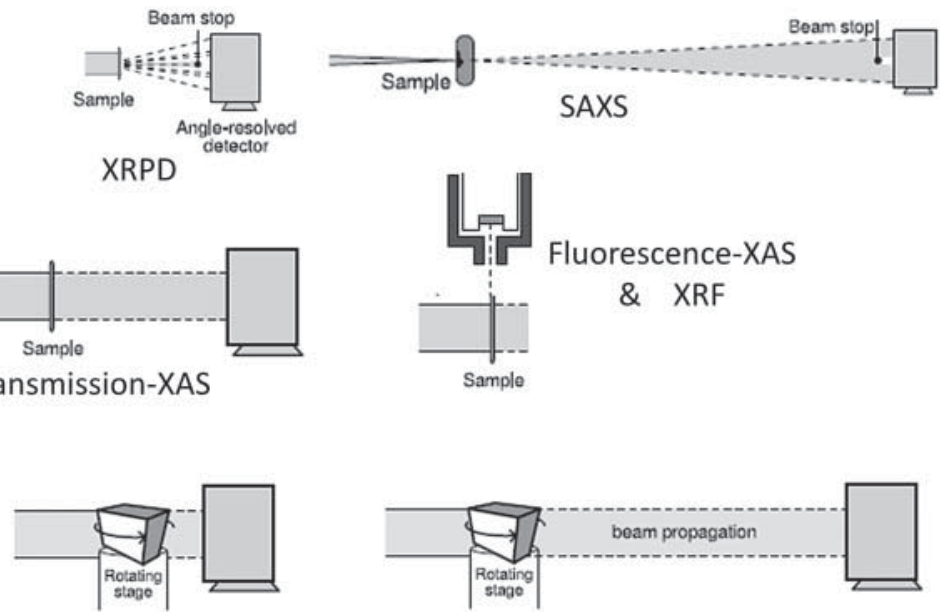

Spatially-resolved techniques

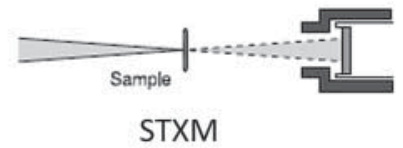

AC full-field microscopy

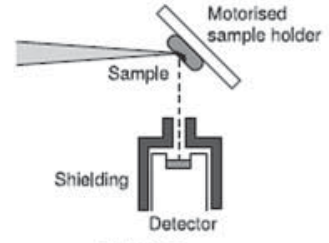

SFXM
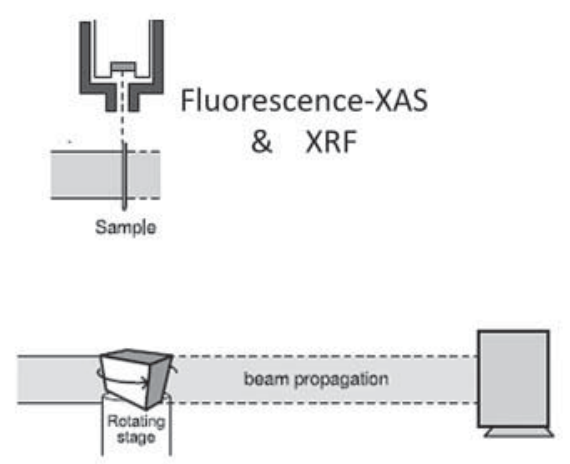

PC full-field microscopy

Figure 4. Schematic representation of the main experimental methods used to study cements and discussed in this paper. Reprinted with modification from reference 10 with permission from Elsevier.

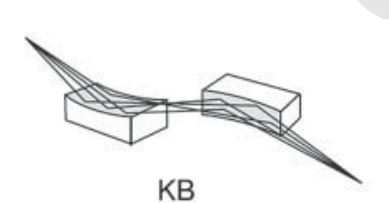

$\mathrm{KB}$

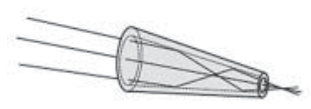

Capillaries

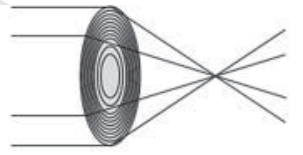

FZP

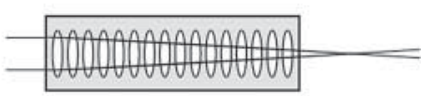

CRL

Figure 5. Main X-ray focusing optics used at synchrotron facilities. KB: Kirkpatrick-Baez mirrors, FZP: Fresnel zone plates, CRL: Compound refractive lenses, Mono and poly-capillaries. KB mirrors and capillary optics are achromatic reflective optics therefore more suited to focus X-rays on wide energy ranges. Reprinted from reference 10 with permission from Elsevier.

For mapping and combined approaches, the synchrotron beam must be focused on a tiny spot of the appropriate size (see Figure 4). However, focusing the synchrotron X-rays is challenging since the optical index $n$ of most materials is close to unity for these energies. This is being circumvented by several approaches and Figure 5 gives the four main types of focusing optics. For a deeper insight, the reader is directed to a recent review [18] where the progress in the development of hard X-ray microscopy techniques for material characterization at the nanoscale was discussed.

Reflective optics (KB mirrors and capillaries) are achromatic, allowing stable beam focusing even when the energy of the incoming X-ray beam varies. Therefore, they are suited to X-ray 
absorption experiments. Some mirrors have a fixed bending, while others use mechanical benders to change the focal spot size (or position). For hard X-rays, the most common configuration used for focusing is the KB system, in which one mirror focuses the beam in the horizontal and a second mirror focuses in the vertical direction. Both mirrors can be moved (and bent)

Diffractive optics use nanostructures to focus the beam. They are called Fresnel lenses and are very effective for soft X-ray energies. At hard X-ray energies, it becomes increasingly difficult to manufacture nanostructures that provide the necessary phase shift although big advances are taking place.[18] FZP optics is chromatic which means that the focal points move with the energy. Therefore, they require adjustments when varying the energy (e.g. $\mu$-XAS in STXM experiments).

Refractive optics work profits from the index of refraction being smaller than one, and so they look like inverted lenses. Since the index of refraction is quite close to 1.0 , many lenses are needed (often more than 10) to provide suitable refraction power. Most lenses are made out of beryllium, although other materials are also used. The main disadvantages of refractive lenses are their chromaticity and the low flux that they provide at soft X-ray energies. For hard X-rays and limited energy ranges, their performances are competitive.

\subsection{Diffraction for characterizing crystalline phases (long-range order)}

SR X-ray diffraction is used to determine the crystal structures of phases present in building materials which develop long range periodic order. These phases can be fine powder, and then the suitable technique is XRPD, or single crystal, and then the right technique would be $\mathrm{SCXRD}_{\perp}$ (see Figure 3). Now, microdiffraction is becoming important as crystals considered powder a decade ago (sizes ranging 1 to $10 \mu \mathrm{m}$ ) can now be studied as single crystals using microdiffraction techniques. To the best of my knowledge, microcrystal synchrotron X-ray diffraction has still not been used to solve crystal structures in the cement field but has been used for imaging samples. This application will be treated in sections 3.7.3.4 and 3.7.3.5.

Examples of crystal structures studied by SXRPD are numerous. I can highlight the $\mathrm{M}_{3}$ superstructure of $\mathrm{C}_{3} \mathrm{~S}$ from synchrotron and neutron powder diffraction, [19] the $\mathrm{T}_{1}$ and $\mathrm{T}_{2}$ polymorphs of $\mathrm{C}_{3} \mathrm{~S},[20]$ the $\mathrm{T}_{3}$ superstructure of $\mathrm{C}_{3} \mathrm{~S}$,[21] an improved structural description for gypsum, [22] cell dimensions and compositional details of mechanochemically prepared $\mathrm{C}-$ $\mathrm{S}-\mathrm{H}$ gels [23] and approximate structural descriptions of 1.0 C-S-H and 1.5 C-S-H gels,[24] wet and dried ettringites,[25] Fe-Si-hydrogarnets (hydroandradite),[26] the pseudo-cubic structure of doped ye'elimite [27] and several AFm-type phases including Fe-hemicarbonate,[28] hemicarboaluminate and carbonated hemicarboaluminate [29] and the double-anion Kuzel salt, $\mathrm{Ca}_{2} \mathrm{Al}(\mathrm{OH})_{6} \cdot\left(\mathrm{Cl}_{0.50}\left[\mathrm{SO}_{4}\right]_{0.25} \cdot 2.5 \mathrm{H}_{2} \mathrm{O}\right) \cdot[30]$

\subsection{Techniques for characterizing amorphous phases}

If the samples are crystalline (periodically ordered in the long range), the suitable technique to characterize the (crystal) structures is diffraction. However, very interesting samples (for instance C-S-H gel) are not crystalline and so alternative methodologies have to be employed to study their local (short-range) structures (see Figure 3). From the set of suitable techniques for characterizing local structures with SR, total scattering techniques and XAS are the most widely used approaches.

\subsubsection{Total scattering techniques for studying short-range order}

Total scattering methods (often referred to as PDF or radial distribution function) have been used since the thirties of the past century to get insight into the disordered structure of liquids and 
501 amorphous materials. The experimental set-up essentially comprises a collimated, monochro-

502

503

504

505

506

507

508

509

510

511

512

513

514

515

516

517

518

519

520

521

522

523

524

525

526

527

528

529

530

531

532

533

534

535

536

537

538

539

540

541

542

543

544

545

546

547

548

549

550 matic beam impinging on a sample and the scattering data are nowadays recorded in a suitable 2D detector. Very short wavelengths (and so highly energetic X-ray photons) allow access to large momentum transfer values as well as to reduce experimental artefacts. The PDF method involves the sine Fourier transform of the measured structure factor over the widest possible momentum transfer range, providing a direct measure of the probability, G(r), of finding an atom surrounding a central atom at a radial distance. The weighting factor of each atomic species is scaled by their concentration and by the number of electrons (for X-rays). The advantage is that average structural information may be obtained when no (sharp) Bragg peaks are present in the measured diffraction pattern and all the scattering data are taken into account (including diffuse scattering), hence the name total scattering. A work that was recently focused on has reviewed the use of total scattering methods in building materials to characterize amorphous and poorly crystalline phases.[31]

The PDF technique was employed to study the local structure of synthetic C-S-H(I) showing nanocrystalline ordering with particle diameter close to $3.5 \mathrm{~nm}$ which are similar to a size-broadened $1.1 \mathrm{~nm}$ tobermorite crystal structure.[32] The C-S-H component in hydrated tricalcium silicate was found to be similar to $\mathrm{C}-\mathrm{S}-\mathrm{H}(\mathrm{I})$; only a slight bend and additional disorder within the $\mathrm{CaO}$ sheets were required to explain its nanocrystalline structure. In a subsequent work, [33] these researchers studied different $\mathrm{C}-\mathrm{S}-\mathrm{H}$ samples with varying $\mathrm{Ca} / \mathrm{Si}$ ratios (between 0.6 and 1.8). The PDF analysis results suggested that the $\mathrm{C}-\mathrm{S}-\mathrm{H}$ structure evolves from tobermorite-like to jennite-like as a function of the increasing $\mathrm{Ca} / \mathrm{Si}$ ratio. Evolution of these short- and medium-range order structural characteristics was associated with the alteration of the $\mathrm{Ca}-\mathrm{O}$ layers and silicate depolymerization.

The PDF approach using SR has also been employed to study several other amorphous (or ill-crystalline) phases in cement research including ASR gel,[34] silica fume,[35] metakaolin [36,37] and geopolymers.[38-40]

\subsubsection{X-ray absorption techniques for studying short-range order and chemical states}

Synchrotron-based XAS techniques provide element-selective complementary information about the local structure and chemical speciation of the selected element by fine-tuning the X-ray photon energy to the absorption edge of the absorber. Most frequently used XAS techniques are XANES and EXAFS. The XANES region covers up to $\approx 50 \mathrm{eV}$ above the absorption edge and it is mainly used to study the oxidation state of the absorber atom and for fingerprinting on the basis of a comparison of reference spectra with the unknown spectrum of the element under study. The first coordination shell (f.i. tetrahedral vs. octahedral coordination) can also be discriminated from the XANES data under some conditions. The EXAFS region can span up to $1 \mathrm{keV}$ above the absorption edge and it can provide information about the local structure (i.e. type of neighbouring atoms, bond length and coordination numbers, second neighbours) of the studied atom. In this case, a deeper mathematical treatment of the recorded signal is needed. Chiefly, in addition to crystalline materials, XAS can be used to study amorphous solids with elements at very low concentrations (detection limit variable but usually lower than a few tens of ppm). In addition, XAS techniques combined with a micro X-ray beam can provide spatially resolved information on the micrometer scale about the speciation of the studied element(s); examples of this mapping approach are given in section 3.7.3.3.

Selected examples of XAS techniques applied to building materials are discussed next. The iron incorporation in hydrated cement phases is always an issue as it can replace a number of elements including aluminium. Hence, iron in carbonate containing AFm phases was studied by SXRPD and EXAFS around the Fe K-edge ( 7120 eV).[28] In a latter study,[41] Fe K-edge EXAFS data were used for studying iron along OPC hydration from very early ages (hours) 
up to one year, with hydration having taken place at $20^{\circ} \mathrm{C}$ and $50^{\circ} \mathrm{C}$. Disregarding anhydrous phases, ferrihydrite was detected during the first hours of the hydration process. After 1 day, the formation of Al- and Fe-siliceous hydrogarnet was observed, while the amount of ferrihydrite decreased. In a subsequent work,[42] it was shown, also from Fe-edge EXAFS data, that at long hydration ages (many years), and upon selective dissolution of the pastes, independent of the chemical compositions of cements, formation of the mixed $\mathrm{Fe}-\mathrm{Al}$ siliceous hydrogarnet is thermodynamically favoured. Other work used Si K-edge $(\sim 1850 \mathrm{eV})$ XANES data to study the silicon environments in two hydrated samples: an OPC paste and a related paste with $35 \mathrm{wt} \%$ of slag as $\mathrm{SCM}_{2}$ which showed no major differences.[43] Ca K-edge $(\sim 4400 \mathrm{eV})$ EXAFS spectra were obtained, in addition to other complementary techniques, to investigate and characterize the structural disorder in $\mathrm{C}-\mathrm{S}-\mathrm{H}$ samples with $\mathrm{Ca} / \mathrm{Si}$ ratios similar to tobermorite.[44] It was shown that $\mathrm{C}-\mathrm{S}-\mathrm{H}$ gels with $\mathrm{Ca} / \mathrm{Si}$ ratio of $\sim 0.8$ are structurally similar to nano-crystalline turbostratic tobermorite. Finally, XANES spectra of Fe K-edge, Ca K-edge and S K-edge $(\sim 2480 \mathrm{eV})$ have been very recently used for investigating the nature of damaged interior walls.[45]

\subsection{Diffraction for quantifying crystalline phases and in many cases phase evolution(s)}

XRPD in general, and SXRPD in particular, is being widely used for quantifying the crystalline (and overall amorphous) phase contents. There are several approaches to analyse the powder diffraction patterns, and thus to derive the phase assemblages. However, the Rietveld method is by far the most commonly employed methodology. Recently, three review articles have been devoted to RQPA of anhydrous Portland cements,[46] Portland cements, blended Portland cements and their hydration products,[47] and building materials in general.[48] In these review articles, results derived from SXRPD analyses were mentioned but the uses of SR were not thoroughly discussed. The main uses of RQPA for giving information about building materials are compiled in Figure 6 and as it can be seen, there are many applications. Most of these uses are attained from laboratory XRPD, but SXRPD provides higher resolution data which are very important for studying very complex samples. SXRPD has also been used to validate analysis protocols later implemented with laboratory data. Furthermore, SXRPD allows very demanding experimental conditions that can hardly be attained with laboratory data (f.i., high pressure studies, very high temperature analyses, etc.). In the next subsections I will focus on the uses of SXRPD for phase quantification (including phase evolution) under a large variety of conditions.

\subsubsection{Quantitative phase analysis of anhydrous building materials}

The initial work on RQPA of a Portland clinker was published in 1993 [49] but it was not until 2001 that SXRPD was applied to the RQPA of OPCs.[50] In this work, the main benefits of using synchrotron radiation were discussed: (i) very high resolution (by using a crystal analyser system in the diffracted beam) for polymorph identification/quantification; and (ii) high-energy radiation $(E=28.2 \mathrm{keV}$, or $0.44 \AA$ ) for sampling a large amount of clinker and thus to have accurate intensities that yield accurate phase quantification. In a subsequent work, these authors focused on the use of SXRPD for establishing the accuracy in RQPA of OPC cements.[51,52] Other authors also compared RQPA results from SXRPD, from neutron powder diffraction data and from laboratory data.[53] The very high resolution data obtained at synchrotron powder diffractometers allowed to establish alite phase coexistence in many clinkers.[54,55] Finally, SR was also employed for the quantification of other cements like calcium aluminate cements [56] and belite cements.[57]

Figure 7 shows a typical Rietveld plot as a visual outcome of a quantitative phase analysis for an OPC clinker.[47] The main peaks due to a given phase are labelled. Furthermore, this figure compares the Rietveld plots for data taken with three powder diffractometers for the same clinker. 
601

602

603

604

605

606

607

608

609

610

611

612

613

614

615

616

617

618

619

620

621

622

623

624

625

626

627

628

629

630

631

632

633

634

635

636

637

638

639

640

641

642

643

644

645

646

647

648

649

650

\section{Main uses of RQPA for OPC materials}

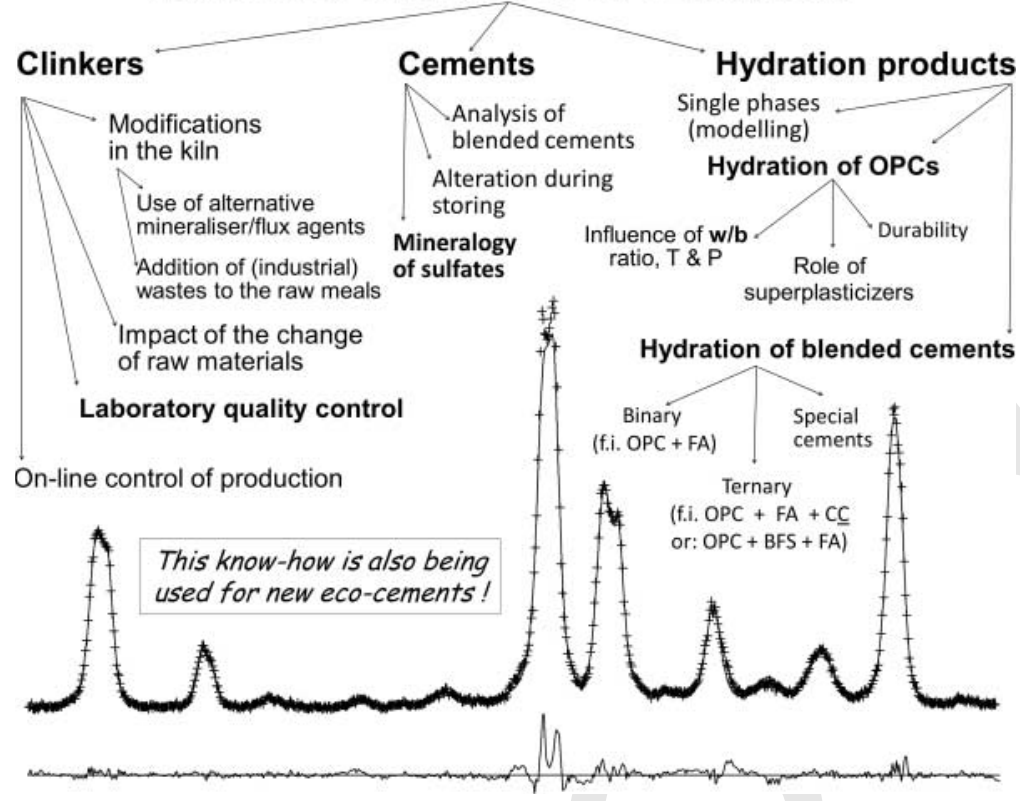

Figure 6. Main uses of Rietveld quantitative phase analysis for studying ordinary Portland clinkers, cements and hydration products. Reprinted from reference 45 with permission from the Mineralogical Society of America.

The high-resolution data provided by SXRPD allowed to clearly establish the coexistence of two alite phases.[55]

\subsubsection{Quantitative phase analysis of hydrating binders}

SXRPD has been used more often for analysing hydrating binders than for characterizing anhydrous clinkers/cements. This is a consequence of the more complex nature of the hydrating building materials where many crystalline phases (and some amorphous ones) can coexist/develop. Therefore, the high-resolution data of SXRPD coupled with the larger penetration of high energy radiation (which leads to better particle averaging and so more accurate powder diffraction intensities) are two key assets. There is no need to say that fast powder diffraction data can be recorded (which depends upon the used detector system). Fast kinetics can be recorded from sub-second [58] to hours - time resolution. Firstly, I will focus on some selected studies of single phase hydration (or artificial mixtures of crystalline phases) and, secondly, I will review key works dealing with hydration of cements.

The hydration of $\mathrm{C}_{3} \mathrm{~A}$ and $\mathrm{C}_{4} \mathrm{AF}$ at variable temperatures, between $25^{\circ} \mathrm{C}$ and $170^{\circ} \mathrm{C}$, was studied by SXRPD. The diffraction pattern evolutions were reported including the identification of intermediate phases but phase quantifications were not carried out.[59] In a related work, energydispersive SXRPD was used to study the hydration of $\mathrm{C}_{4} \mathrm{AF}$ and $\mathrm{CS}_{2}$ at temperatures ranging between $30^{\circ} \mathrm{C}$ and $150^{\circ} \mathrm{C}$. The diffraction peak evolution was again followed, including intermediate phase identification, but phase quantification was not carried out.[60] In a step forward, Rietveld methodology was employed for quantifying the phase development of $\mathrm{C}_{3} \mathrm{~A}+\mathrm{CS}_{\mathbf{S}} \mathrm{H}_{0.5}$ samples with and without superplasticizer. Ettringite was quantified and also its texture evolution was also reported.[61] Rietveld methodology has also been employed to study the role of ye'elimite polymorphism in hydration reactions (and kinetics) by addressing the standard 
651

652

653

654

655

656

657

658

659

660

661

662

663

664

665

666

667

668

669

670

671

672

673

674

675

676

677

678

679

680

681

682

683

684

685

686

687

688

689

690

691

692

693

694

695

696

697

698

699
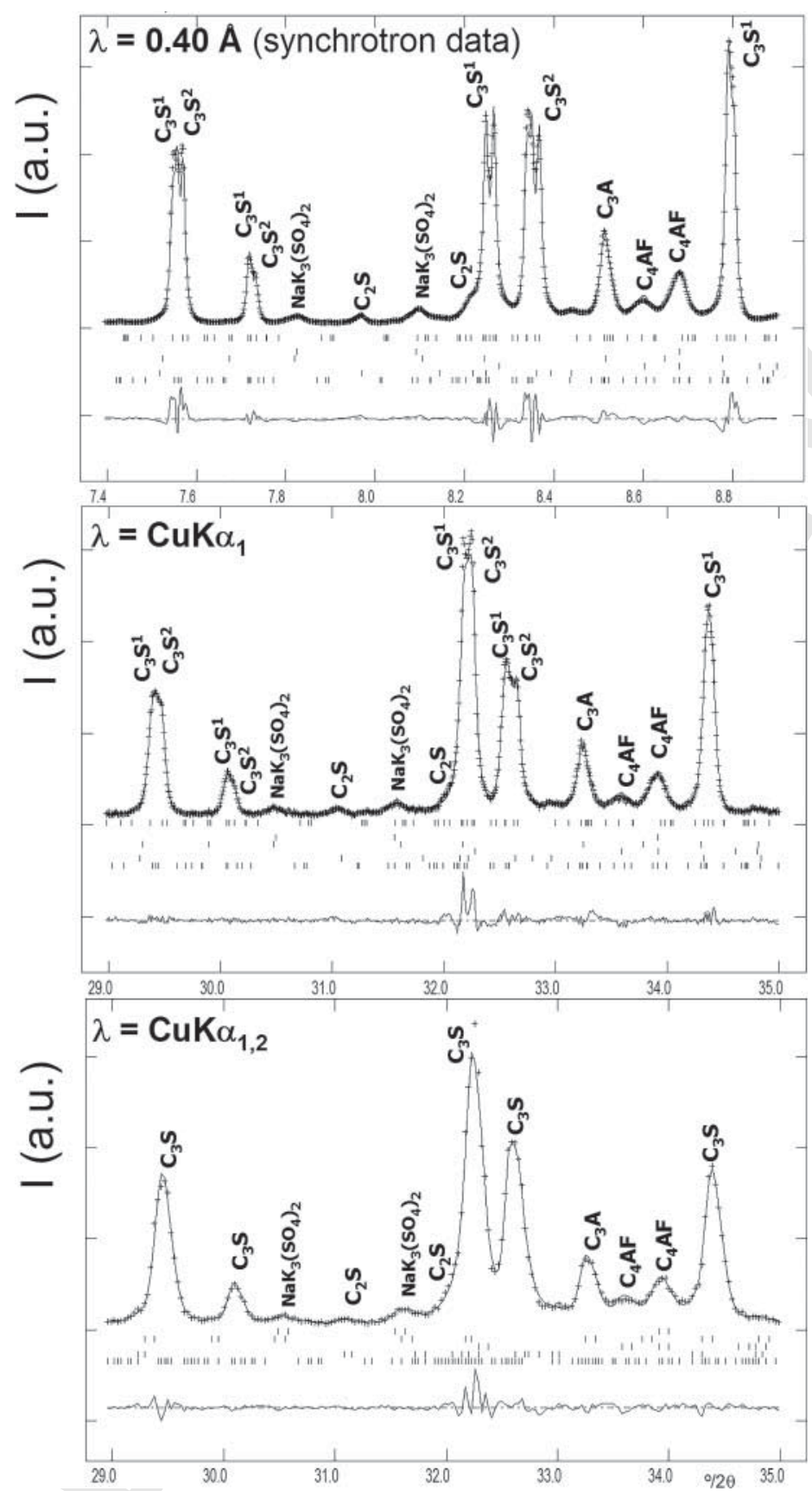

Figure 7. Selected region of the Rietveld plots (three different experimental set-ups) used for quantitative phase analysis of the same commercial Portland clinker. Data were collected at: ID31 diffractometer of ESRF synchrotron (top), a laboratory diffractometer with a $\mathrm{Ge}(111)$ primary monochromator, $\mathrm{CuK} \alpha_{1}$, (middle), and a laboratory diffractometer with a graphite secondary monochromator, $\mathrm{CuK} \alpha_{1,2}$, (bottom). Please note the different resolution in the recorded data. Peaks arising from different phases are labelled. Reprinted from reference 45 with permission from the Mineralogical Society of America. 
701 variables: water-to-ye'elimite ratio and sulphate sources.[62] Very recently, the hydration of

$702 \mathrm{C}_{4} \mathrm{AF}$ has been followed by RQPA of SXRPD at room temperature in different conditions: (i)

703 without gypsum; (ii) with gypsum; (iii) with gypsum and stoichiometric ye'elimite (orthorhom-

704 bic); and iv) with gypsum and doped ye'elimite (pseudo-cubic). Different behaviours have been

705 observed and discussed including a delayed $\mathrm{C}_{4} \mathrm{AF}$ hydration by the presence of ye'elimite, that it

706 is even dependent of the doping content of the ye'elimite phase.[63] To end this section, I would

707 like to highlight that SXRPD can also be used to develop/validate methods for analysis of key

708 phases. This is the case of two reports $[64,65]$ where a method for quantifying portlandite was 709 developed.

710 Concerning the hydration of cements, a first key paper was devoted to monitoring the influ711 ence of cellulose ethers on hydration kinetics of cements with a time resolution of one minute 712 with the first dataset taken only 90 seconds after water mixing.[66] In this work, the ettringite 713 crystallization was followed but quantitative phase contents were not derived. Later, Rietveld methodology was used to extract the phase contents in hydrating OPC pastes with time resolution of minutes.[67] This hydration study was carried out in the presence of additives such as superplasticizers and setting accelerating agents. A similar experimental set-up and analysis methodology were followed to study the hydration of belite and active belite cements.[68] The hydration of eco-cements, including phase content evolution by Rietveld methodology, has also been analysed for aluminium-rich belite sulphoaluminate cements,[69] active sulphobelite cements [70] and active sulphobelite cements at very early ages.[71] SXRPD coupled with the Rietveld method can also be used to characterize the long-term leaching behaviour of concretes by quantifying portlandite dissolution at different hydration times.[72] These results were compared to those obtained by DTA/TGA.

It is also important to discuss some hydration studies where SCM were blended with OPCs. Time-resolved SXRPD coupled with the Rietveld method was used to quantify the early-age hydration and pozzolanic reaction in OPC blended with natural zeolites. One key conclusion of this study was that the addition of natural zeolites accelerates the onset of $\mathrm{C}_{3} \mathrm{~S}$ hydration and precipitation of $\mathrm{CH}$ and Aft.[73] In a subsequent work, these authors enlarged the study by analysing the early-age hydration of OPC blended with micronized zeolitite and quartzite powders.[74]

To conclude this section, not only has OPC been studied but other cementitious systems have been analysed as well. For instance, SXRPD, in combination with other characterization techniques, was used to determine the reaction products of alkali-activated Class $\mathrm{C}$ fly ash-based aluminosilicate materials.[75] Finally, SXRPD and other characterization techniques were used to follow the phase developments and microstructural characteristics of geopolymer binders obtained by alkaline activation of natural pozzolans.[76]

\subsection{Variable-temperature diffraction to characterize phase evolution(s) and reactions}

SXRPD have been also used to characterize cements at quite high temperatures. The main objectives are twofold: on the one hand, to characterize the formation and decomposition products in cement systems and, on the other hand, and at higher temperatures, to study in-situ clinkering processes. These two uses are discussed next.

\subsubsection{In-situ thermal formation and decomposition studies at moderate temperatures}

I will follow the approach already exercised in previous sections. First, I will discuss some examples of the decomposition of single phases of interest in cement chemistry and, second, I will give examples of thermal decomposition of cement pastes.

Calcium sulphates are key phases for regulating the setting behaviour of cement through the control of the soluble sulphate content at very early ages which is of paramount importance for 
aluminate reactivity. Therefore, I highlight the work studying the formation and reactivity of five calcium sulphates studied by SXRPD and the Rietveld method.[77] More complex phases can be studied in-situ, both formation and decomposition. As an example: a slurry of synthetic ettringite was heated to form AFm-14 (and bassanite), at about $115^{\circ} \mathrm{C}$, on saturated water pressure. On further heating, AFm-14 decomposes to yield hydrogartnet above $210^{\circ} \mathrm{C}$. A full transformation pathway was reported by time-resolved SXRPD using a capillary cell.[78] The thermal decomposition of other cement phases has also been studied by SXRPD, like $3 \mathrm{Mg}(\mathrm{OH})_{2} \cdot \mathrm{MgCl}_{2} \cdot 8 \mathrm{H}_{2} \mathrm{O}$, the main phase of Sorel cement.[79]

High-temperature SXRPD has been used to follow the thermal transformations of special cements or mixtures. This is the case of cement-asbestos decomposition studies.[80,81] The highest reported temperature was $900^{\circ} \mathrm{C}$ as the authors used an air blow heating system with the sample within quartz capillaries. This type of preliminary studies is important for safe treatments of asbestos in novel industrial reactors.

\subsubsection{In-situ clinkering studies at very high temperatures}

High-temperature SXRPD can also be used for the in-situ study of the reactions taking place in the clinkering process. These are complex experiments as the temperature can be as high as $1400-1500^{\circ} \mathrm{C}$ with important fraction of the sample melt, and so the capillary must be inert towards this very reactive environment. Using a halogen furnace that can heat up to $1600^{\circ} \mathrm{C}$, the clinkering reactions of active belite clinkers were reported using platinum tubes.[82] The selected wavelength was very short, $\lambda=0.30 \AA$, to go through the highly absorbing Pt capillary. Rietveld methodology was successfully applied to the recorded data to obtain quantitative phase analyses. In a subsequent work, the same experimental conditions were used to study the clinkering reactions of iron-rich belite sulphoaluminate cements, aka sulphobelite.[83] In this study, the high-temperature reactions were established and quantified and the role of borax for activating these cements was also characterized.

Figure 8 shows a sequence of steps to carry out this type of in-situ experiments. First, the precalcined raw material mixtures(s) are loaded into Platinum tubes.[82] A precalcining step is needed to release the $\mathrm{CO}_{2}$ and avoid overpressures in this type of experiments, where the sample is sealed within the capillary. Furthermore, expensive Pt capillaries/tubes are needed because the heated mixtures contain a relatively large fraction of highly reacting liquid (above $1200-1400^{\circ} \mathrm{C}$ ), and so inexpensive ceramic tubes/capillaries cannot be used. The Pt tube is isolated from the diffractometer by an $\mathrm{MgO}$ ceramic bar which is bonded by a refractory glue (dark powder between $\mathrm{Pt}$ and $\mathrm{MgO}$ in Figure 8, top left). The cell is assembled, mounted within the diffractometer axis and the temperature is coarsely controlled by the calibrated voltage applied to the halogen lamps. Then, the SXRPD patterns are collected at (approximate) temperatures. The temperature can be accurately known from the values of the refined unit cell parameters of platinum, as its thermal expansion is well known. Finally, RQPA is carried out based on the pattern regions which contain diffraction peaks from the sample and are not severely overlapped with the Pt diffraction peaks. Under these very tough conditions (high temperatures with samples containing about $30 \mathrm{wt} \%$ of a highly reactive ceramic melt), the SXRPD patterns were of sufficient quality to allow appropriate quantification of the phase evolution.[82,83]

\subsection{Diffraction under pressure to characterize phases and chemical reactions}

In this section, I will review some SXRPD studies of single phases or cements under pressure. I have subdivided this part into three sections depending upon the level of pressure reached in the different approaches. Hydrothermal reactions take place at relatively low pressure, usually 
801

802

803

804

805

806

807

808

809

810

811

812

813

814

815

816

817

818

819

820

821

822

823

824

825

826

827

828

829

830

831

832

833

834

835

836

837

838

839

840

841

842

843

844

845

846

847

848

849

850
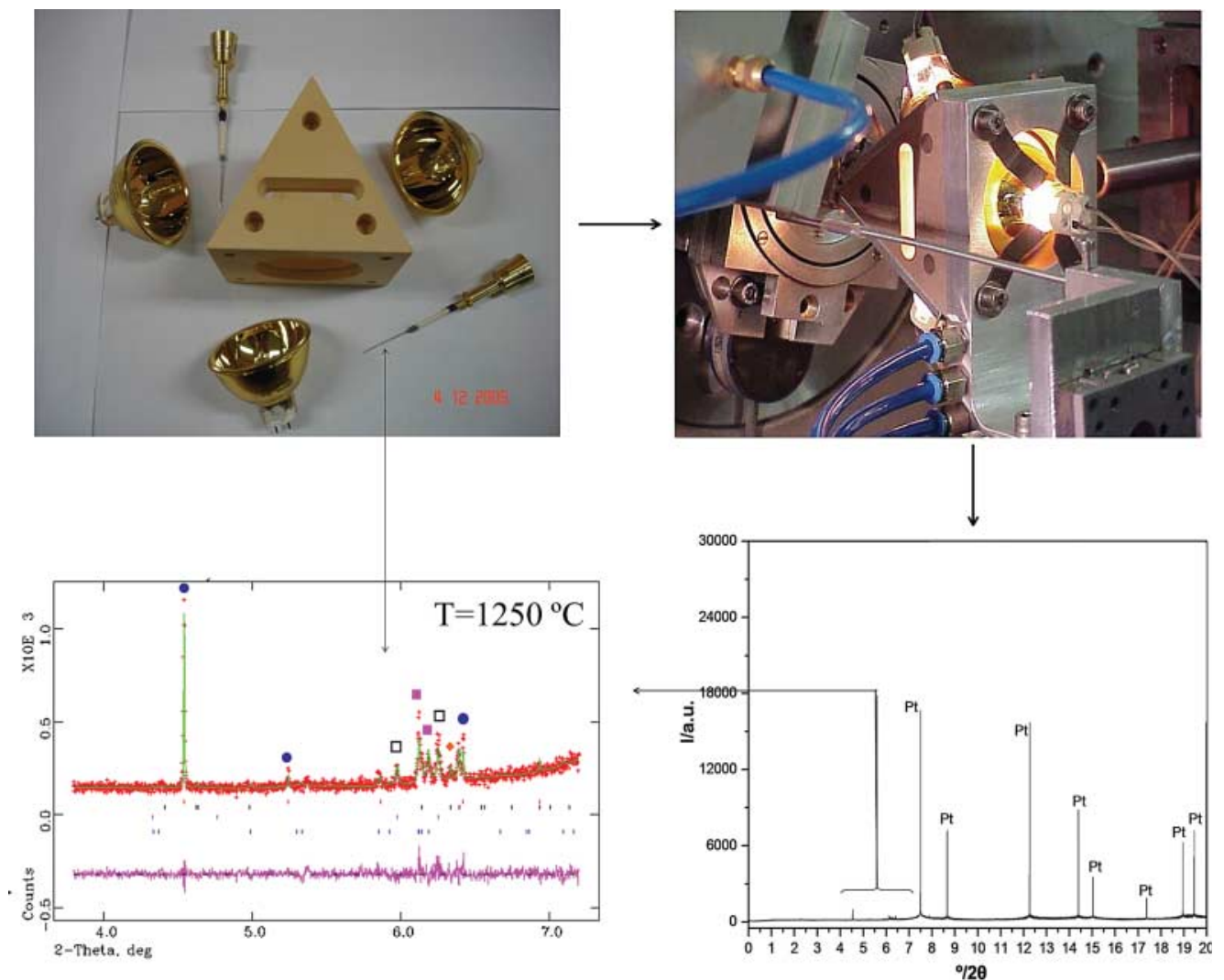

\%20

Figure 8. (Top left) Photography of the disassembled halogen lamp cell that allows in-situ heating up to $1600^{\circ} \mathrm{C}$. Two Pt tubes, loaded with the raw materials, and isolated from the goniometer head mounting system by a $\mathrm{MgO}$ refractory, white ceramic, are also shown. (Top right) Photography of the assembled cell mounted in the ID31 synchrotron powder diffractometer (ESRF). (Bottom right) Raw SXRPD data collected at high temperature where the diffraction peaks of Pt holder (tube) dominate the scattering within the pattern. (Bottom left) Rietveld quantitative plot of the appropriate region of the previous pattern; where the diffraction peaks from the clinker phases are present.

lower than 20 bars (2 MPa). There are capillary cells that can withstand up to 200 bars (20 MPa) and these works are reviewed in the second section. Finally, a DAC can withstand more than 1 Mbar (100 GPa) and is normally used to study the high pressure behaviour of hydrated cement phases to derive mechanical properties like the bulk modulus. These works are reviewed in the last subsection.

\subsubsection{Chemical reactions at relatively low pressures in capillary cells (hydrothermal conditions)}

The formation reactions of AFt and two types of AFm phases were studied by SXRPD and hydrating different calcium aluminate phases in the presence of gypsum.[84] The reactions were investigated with the samples loaded in quartz capillaries, and the maximum internal pressure was 17 bars, which was obtained by supplying $\mathrm{N}_{2}$ gas. The studied temperature range was $25-$ $170^{\circ} \mathrm{C}$, which was obtained by heating the capillary with a hot air flow system. In a second work, [85] these authors studied the hydrothermal transformations of the calcium aluminium oxide hydrates, $\mathrm{CaAl}_{2} \mathrm{O}_{4} \cdot 10 \mathrm{H}_{2} \mathrm{O}$ and $\mathrm{Ca}_{2} \mathrm{Al}_{2} \mathrm{O}_{5} \cdot 8 \mathrm{H}_{2} \mathrm{O}$, to yield crystalline $\mathrm{Ca}_{3} \mathrm{Al}_{2}(\mathrm{OH})_{12}$, and 
where intermediate phases were identified. On the other hand, instead, a capillary cell, an autoclave cell with Be windows was designed and built, allowing the study of cements by SXRPD up to 12 bars and $200^{\circ} \mathrm{C}$.[86] This autoclave cell was initially used for studying the hydrothermal formation of tobermorite under different conditions [86,87] and later it was used for investigating the phase evolutions during the production of autoclaved aerated concretes.[88-90]

\subsubsection{Hydrating reactions at medium pressures and temperatures}

Several hydrothermal reactions take place at pressures up to 20 bars, but there are other conditions where (much) higher pressures apply. For instance, deep oil-well cement slurries can be subject to pressures of up to $1 \mathrm{kbar}$. Therefore, to study cement hydration in the range of 100 200 bars it is very interesting for several applications including oil-well cements which surround metal oil-well liners to form a gas tight seal between the bore wall and the liner. For this type of studies, a cell was designed and built for SXRPD data collection, in optimum conditions, up to 500 bars and $200^{\circ} \mathrm{C}$.[91] Later, this cell, which performs best with sapphire capillaries, has been used for studying a number of hydrating cement slurries including: (i) Class $\mathrm{A}$ and $\mathrm{H}$ oil well cements mixed with variable amounts of $\mathrm{CaCl}_{2}$ for accelerating the hydration [92]; (ii) Class $\mathrm{H}$ oil well cements mixed with silica flour, silica fume and a natural zeolite which are used to improve the mechanical properties of the binder [93]; (iii) White cement, class G and class $\mathrm{H}$ oil well cements, without additives, for analysing the reaction kinetics of the main phases [94]; and (iv) $\mathrm{C}_{3} \mathrm{~S}$ in the presence of several retarders to counterbalance the accelerating behaviour of pressure.[95] These authors have also developed a cell to allow simultaneous measurement of SXRPD data and ultrasound shear-wave reflection data from cement slurries at variable temperatures and pressures.[96]

\subsubsection{Phase characterization at very high pressures in diamond-anvil-cells}

The pressures employed in this type of studies (dozens of GPa equivalent to hundreds of kbars) are much higher than what could exist in cement pastes (mortars or concretes); however these works are important to derive mechanical properties of the hydrated phases as well as to study the stability of cement phases which may help to understand reaction mechanisms. The pressure transmitting medium is important as it should not induce any structural modification to the studied phase and it must be easy to work with. Silicone oil as well as methanol/ethanol mixtures have been used for studying hydrated cement phases at high pressures in DAC systems.

Figure 9 shows a scheme with components of a DAC. There are different types of DACs, but its discussion is out of the scope of the present work. When the sample is loaded within the DAC, the set-up is placed in the diffractometer and the micro-focused beam interacts with the sample. In order to reach higher pressures, smaller samples are employed. The diffracted beam is recorded in an appropriate 2D detector (commonly a CCD detector). Forces are varied with the pressures being measured, commonly, from the fluorescence signal of a ruby chip. Finally (from the data collection point of view), the 2D patterns are radially integrated to transform them to $1 \mathrm{D}$ patterns (see Figure 9) that can be analysed with any Rietveld package.

The DAC approach has been used to study the behaviour of ettringite up to $6 \mathrm{GPa}$. The two main outputs of this study were the isothermal bulk modulus of ettringite, $27 \mathrm{GPa}$, and its transformation to an amorphous phase at pressures above $3 \mathrm{GPa}$.[97] The bulk modulus of gel C-S-H is of utmost importance as it is the main binding component in OPC mortars and concretes. However, as its chemical composition can vary, to report a single number is complicate. In an initial work, two samples were studied, synthetic C-S-H(I) and another gel obtained from the hydration of alkali-activated slag. The powder diffraction patterns were collected up to $4 \mathrm{GPa}$ and the bulk modulus for the two gels were very similar, $\approx 35 \mathrm{GPa}$, showing that Al substitution in 


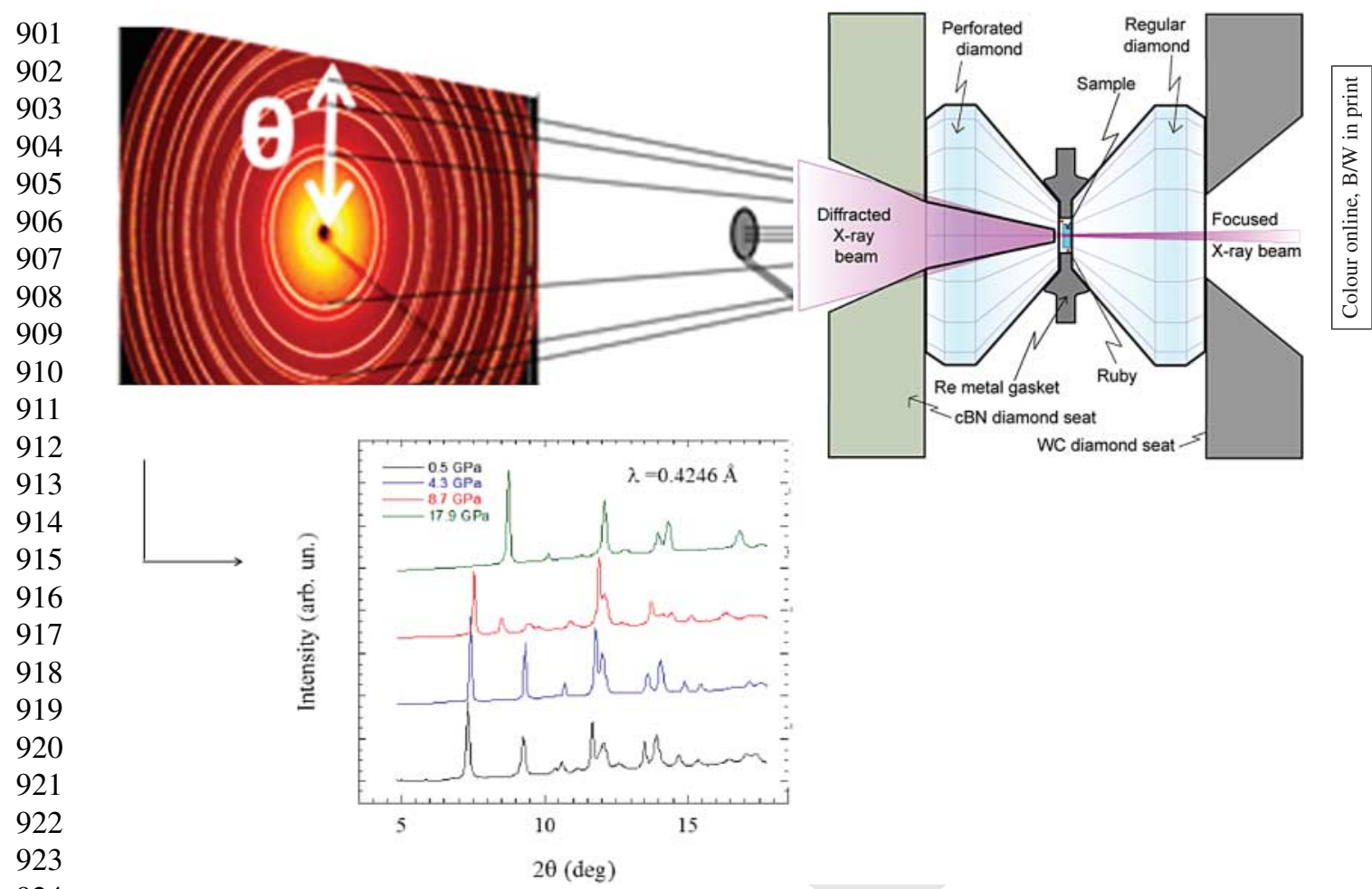

924

Figure 9. Schematic representation showing the experimental work flow in a high-pressure experiment using DAC. (Top right) Scheme of a diamond-anvil-cell with its different components including the ruby chips commonly used to measure the applied pressure. The (micro)focused SR X-ray beam is diffracted by the sample and the high-pressure pattern is collected in a suitable 2D detector. (Top left) A CCD 2-D pattern is collected at a given pressure. Then, the $2 \mathrm{D}$ pattern is integrated to yield the typical intensity versus angle 1D pattern. (Bottom) Finally, several data sets are collected at different pressures and the appropriate information is derived (f.i., unit cell variation, crystal structures, amorphization processes, bulk modulus, etc.).

C-S-H(I) does not significantly affect the bulk modulus of C-S-H(I).[98] On the other hand, the two crystalline phases more similar to the ill-crystalline $\mathrm{C}-\mathrm{S}-\mathrm{H}$ gel are $14 \AA$-tobermorite and jennite. Hence, SXRPD data for $14 \AA$-tobermorite were measured up to $5 \mathrm{GPa}$ and the obtained bulk modulus was $47 \mathrm{GPa}$.[99] A similar study for jennite, measured up to $6 \mathrm{GPa}$, yielded a bulk modulus of $64 \mathrm{GPa}$.[100] The isothermal bulk modulus of aluminium-substituted $11 \AA$-tobermorite from relict lime clasts of 2000-year-old Roman seawater harbour concrete was also measured, yielding $K_{\mathrm{o}}=55 \mathrm{GPa}$ [101]. Other works reported the bulk modulus for selected samples of interest in cement chemistry like stratlingite: $K_{\mathrm{o}}=23 \mathrm{GPa}$, hemicarboaluminate: $K_{\mathrm{o}}=15 \mathrm{GPa}$, monocarboaluminate: $K_{\mathrm{o}}=54 \mathrm{GPa}$ and hydrogarnet: $K_{\mathrm{o}}=70 \mathrm{GPa} \cdot[102,103]$

$\mathrm{X}$-ray diffraction is the standard method for measuring the unit cell volume variation with the pressure of crystalline materials. For a pressure range where the composition of the phase is constant, this directly translates into the density variation with pressure. Using diffraction to determine the density variation of non-crystalline materials is not straightforward, so alternative methods are being investigated. Recent advances have allowed XAS data, taken for an amorphous material loaded in a DAC, to be used to characterize the density variation with pressure. This approach has been successfully used in cement chemistry.[104] The elastic properties of an ASR gel were studied by XAS and Brillouin spectroscopy measurements. XAS was used to determine the density of the gel as a function of pressure, yielding an isothermal bulk modulus 
of $33 \mathrm{GPa}$. Brillouin spectroscopy was applied to measure isentropic bulk (24.9-34.0 GPa) and shear moduli (8.7-10.1 GPa) of the gel.

Finally, SXRPD data collected in DAC as a function of pressure have also been recorded for anhydrous phases of interest in cements. Experimental data were recorded for $\mathrm{C}_{3} \mathrm{~A}$ which yielded an isothermal bulk modulus of $110 \mathrm{GPa}$ which was compared to the results from theoretical calculations.[105] Other elastic properties were also measured and compared to the theoretical results, a second example being ye'elimite. The reported isothermal bulk modulus was $69 \mathrm{GPa}$ [106]

\subsection{Small angle X-ray scattering for microstructural characterization of building materials}

When an X-ray (or a neutron) beam passes through a material, under the appropriate experimental conditions, a component of the direct beam is scattered out at a small angle due to heterogeneities (microstructure) of the sample. The angular profile of the SAXS (or SANS) intensity is effectively a Fourier transform of this microstructure. The recorded data are commonly analysed using appropriate microstructure models, and the microstructures are described/quantified through the resulting parameters. Although SAXS data can be obtained with laboratory sources, the quality of the data from SR instruments is much higher. Therefore, most of the SAS studies are carried out at synchrotron (or neutron) facilities. A focused review was devoted to the applications of SAXS and SANS characterization techniques to C-S-H gel and cement pastes.[107] In this review, the similarities and differences between SAXS and SANS were also highlighted.

SAS (SAXS and SANS) techniques are nondestructive tools for characterizing density fluctuations over a wide range of length scales without altering the sample (sample preparation that may modify the microstructure is not commonly needed). Furthermore, it can probe interfaces of closed as well as open pores, unlike mercury porosimetry where information about the closed pores is not available. SAS provides statistically averaged information over the bulk of a material, unlike microscopy techniques where the information is limited to the local studied part of the sample. However, data treatment is important to extract the appropriate information and data analysis is far from obvious. There are several microstructure models ranging from Guinier approximation to fractal morphologies and full analysis of coherently ordered microstructures.[107,108]

Some examples of uses can be highlighted. By combining SAXS and SANS data with several other techniques, the mean formula and mass density of the nanoscale $\mathrm{C}-\mathrm{S}-\mathrm{H}$ gel particles in untreated hydrating cement were determined to be $(\mathrm{CaO})_{1.7} \mathrm{SiO}_{2} \cdot 1.80 \mathrm{H}_{2} \mathrm{O}$ and $2.604 \mathrm{~g} / \mathrm{cc}$, respectively.[109] These values differed from previous reported ones for the C-S-H gel, likely because of the specific drying conditions used in different approaches. Other study focused on determining the pore volume fraction of hydrated cement compacts from SAXS data and their evolution with hydration time.[110] The changes in the microstructures due to the use of cement additives have also been investigated by SAXS and SANS (see Figure 10).[111] The reported results showed that the used PCE tends to increase the size of the disk-like C-S-H globules but has little influence on the thickness of the water and calcium silicate layers within the globules. It must also be noted in importance of SANS studies. As a key example, this technique has been used for monitoring the degree of homogeneity of a cement paste matrix with the final goal of immobilizing low- and intermediate-level radioactive waste.[112]

Finally, SAXS data have also very recently been used to validate 2D high-resolution observations by TEM. Under some approximations, and using the Fourier slice theorem, it has been shown that the spectral density from TEM is a good approximation of the SAXS pattern. This have been used for a deeper characterization of the $\mathrm{C}-\mathrm{S}-\mathrm{H}$ gel where the computed SAXS signal (from TEM) and the measured spectrum agree quite well within the limited overlapping q-range $\left(0.01\right.$ to $\left.0.04 \AA^{-1}\right)$.[113] 

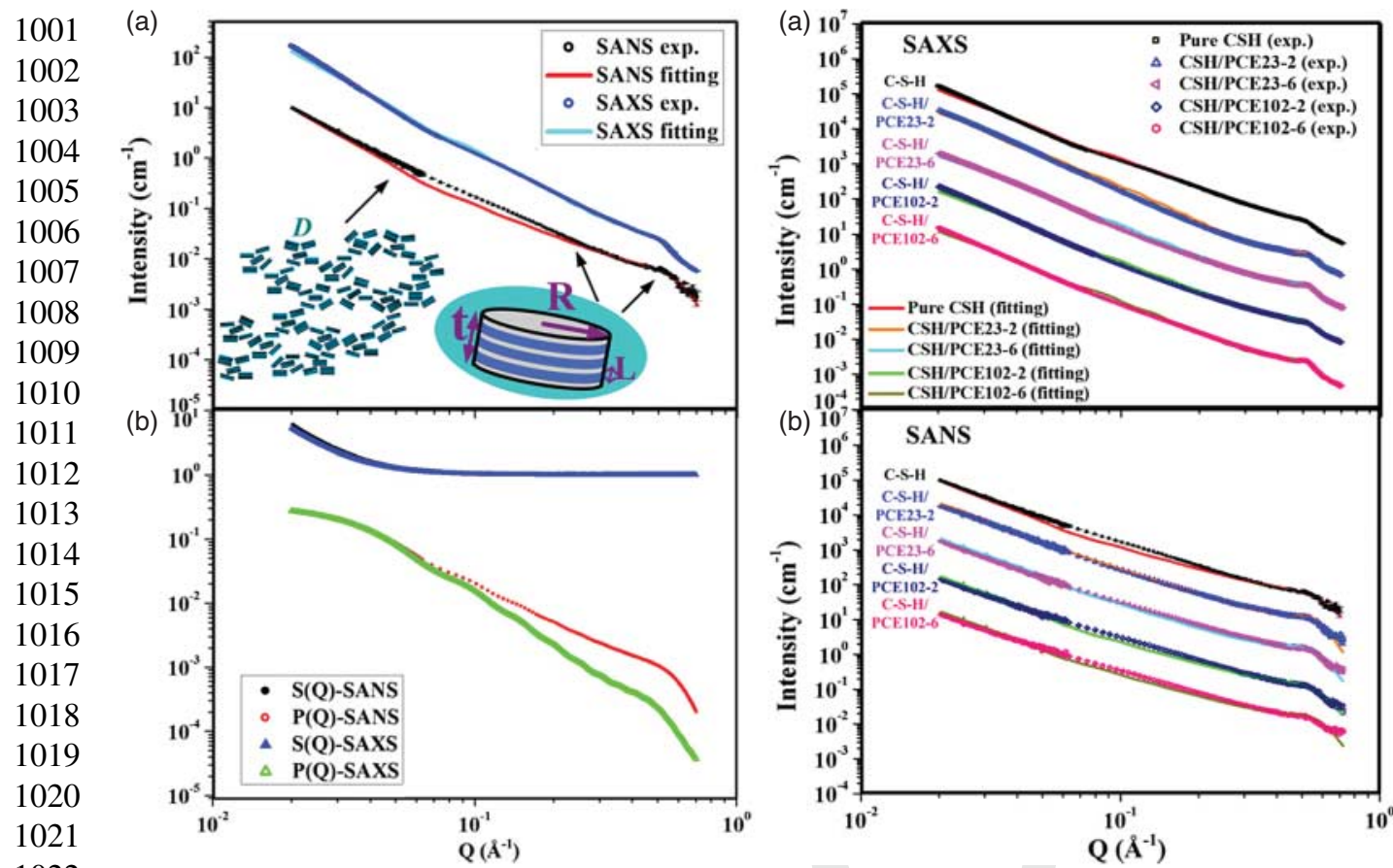

1022

1023

Figure 10. (Left panel) Model fitting results of a pure C-S-H sample. (a) Experimental data of SAXS (blue open circle) and SANS (black open circle) and the corresponding data fitting curves of SAXS (cyan line) and SANS (red line). (b) Inter-particle structure factor S(Q) of the SAXS data (blue solid triangle) and SANS data (black solid circle) and intra-particle structure factor P(Q) of the SAXS data (green open

1025 triangle) and SANS data (red open circle) used to fit the data in panel (a). (Right panel) Model fitting results for (a) SAXS data and (b) SANS data. Both panels show the experimental data for pure $\mathrm{C}-\mathrm{S}-\mathrm{H}$ (black open square), and C-S-H with different amounts of superplasticizer. For further details, the reader is directed to

1028

1029 the original publication. Reprinted from reference 109 with permission from Elsevier.

1030

1031

1032

\subsection{Imaging building materials at different length scales and with different photon energies}

1033

There are many different types of imaging methods based on different wavelengths (IR, soft

1034 $\mathrm{X}$-rays and hard X-rays) as well as on different experimental set-ups. Figure 11 displays a schematic representation of the three more common techniques: full-field microscopy, scanning transmission microscopy and coherent diffraction imaging. All these three set of techniques (with subgroups) have been employed for characterizing the rich hierarchical microstructure details of cement pastes. A recent publication has reviewed state-of-the art X-ray imaging techniques based on partially coherent synchrotron radiation including: full-field tomography, scanning transmission microscopy, ptychographic forward coherent diffraction imaging and scanning small-angle X-ray scattering [114] but it did not specifically deal with cement research. Another recent review [18] discussed the progress in the development of hard X-ray microscopy techniques for materials' characterization at the nanoscale. They reviewed state-of-the-art hard X-ray synchrotron nanoscale microscopy techniques which included 3D tomographic visualization, spectroscopic elemental and chemical mapping, microdiffraction-based structural analysis, and coherent methods for nanomaterial imaging.

For full-field imaging, see Figure 11 (top); the synchrotron beam is relatively large and the ability to resolve tiny details of the sample arises from either a magnified projection onto the $\mathrm{X}$-ray detector or from a magnifying lens. In the former approach, image resolution is limited by the pixel size of the detector and by the size of the $\mathrm{X}$-ray source; in the second case, resolution 
1051

1052

1054

1055

1056

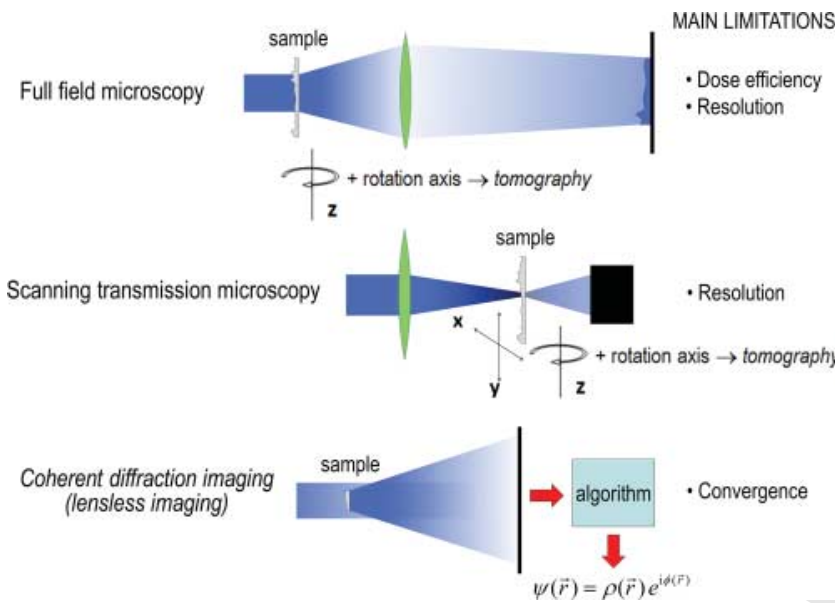

Figure 11. Scheme of the three main techniques for X-ray imaging highlighting some limitations. (Top) full-field microscopy, where the sample is fully bathed by the X-ray beam. (Intermediate) scanning transmission microscopy, where the sample is raster scanned by a focused beam. (Bottom) Coherent diffraction imaging, where the image is generated by an appropriate reconstruction algorithm. In the three cases, proper sample rotation allows recording tomographic data.

and image quality depend on the X-ray optics. The challenge to increase the resolution resides in producing better X-ray optics elements that combine high numerical aperture, high efficiency and low aberrations. This is assuming that radiation sample damage does not limit the achievable resolution.

For scanning imaging, see Figure 11 (intermediate); the beam is focused on a tiny spot that it is raster scanned to deliver 2D (radiographic) or 3D (tomographic) images. Furthermore, different properties can be measured (absorption, fluorescence, diffraction, etc.) which provide complementary information. For instance, STXM is a real-space imaging technique that utilizes focusing optics (it could be a Fresnel zone plate or a capillary) to deliver a small monochromatic X-ray beam onto a sample and it measures the intensity of the transmitted beam in raster mode, thereby filling an image array. STXM does not require an objective lens, and hence there is no attenuation of the beam between the sample and the detector, which means that the dose delivered to the sample is reduced compared to a full-field, lens-based approach. The procedure allows imaging with classical spectroscopic techniques; see below, at sample-tailored X-ray photon energies.

There is an alternative image-forming approach where the X-rays scattered by the sample are analysed and reconstructed by appropriate mathematical algorithms, see Figure 11 (bottom). Such lensless techniques are often grouped under the term: CDI or diffraction microscopy (not to be confused with X-ray diffraction micro-tomography, see below). It is widely believed that the CDI technique allows image resolution limited only by the tolerance of the samples to radiation damage. Furthermore, single-shot experiments at ultra-fast XFEL sources may even bypass this limitation. In a typical CDI experiment, a small sample is fully bathed with a plane wave (fullfield technique), and its far-field scattering pattern is recorded in oversampling conditions. For more information about CDI, the interested reader is directed to a recent review.[115] At this stage, two related techniques should be mentioned that depend on where the detector is placed. In BCDI, the far-field scattering pattern is collected at the right angle of a diffraction peak for a crystalline microparticle. In FCDI, the far-field scattering pattern is collected at the small angle scattering and the sample does not need to be crystalline. While the scattering process is well known and understood, inverting measurable intensity distributions to obtain an image of the 
1101 sample, often known as image retrieval, is a mathematically ill-posed problem where a unique

1102

1103

1104

1105

1106

1107

1108

1109

1110

1111

1112

1113

1114

1115

1116

1117

1118

1119

1120

1121

1122

1123

1124

1125

1126

1127

1128

1129

1130

1131

1132

1133

1134

1135

1136

1137

1138

1139

1140

1141

1142

1143

1144

1145

1146

1147

1148

1149

1150 solution has to be ensured. Image retrieval usually comprises many cycles of alternate iterative processes enforcing a priori knowledge on the sample, such as its finite size and consistency with measured data. Such a 'classical' CDI approach requires the samples to be isolated and has very low tolerance to perturbations by signals due to other scatters, f.i. from ice. Very importantly, there is an evolution of CDI where the samples are scanned by a small beam overlapping part of the illuminated samples (ptychographic approach) which favour/ensure the convergence of the reconstructing algorithms.

\subsubsection{Full-field soft X-ray nano-tomography}

Transmission soft X-ray full field microscopy was originally developed to study biological samples, but later has been applied to the study of the hydration processes of cement-based materials. Working with soft X-rays of an energy of $\approx 520(\mathrm{eV})$, which corresponds to a wavelength of $2.4 \mathrm{~nm}$, it enhances the contrast between the cement particles and developing hydrates which contains more oxygens 'water window'. Soft X-ray microscopy allows high-resolution imaging of hydrated samples over time and permits complete imaging of samples up to about $5 \mu \mathrm{m}$ thick. For building materials this limitation effectively means loading dilute suspensions with very high w/c ratios (a severe drawback for many types of studies). In order to prevent excessive dissolution of the cement grains, several works used saturated solutions of $\mathrm{CH}$ and/or $\mathrm{CS}_{2}$. However, saturated solutions cannot overcome the other artefact of dilute solutions, the increased availability of space in which hydration products are growing.

Initially 2D soft X-ray full-field microscopy, ACsX-nM, was used to directly image the hydration of $\mathrm{C}_{3} \mathrm{~S}$ and $\mathrm{OPC}$ in a saturated solution of $\mathrm{CH}$ and $\underline{\mathrm{CSH}}_{2}$ with time.[116] Figure 12(a) shows $\mathrm{a} \mathrm{C}_{3} \mathrm{~S}$ grain which has needle-like hydration products on its surface likely showing the of C-S-H gel formation after the induction period. Figure 12(b) and 12(c) shows the hydration evolution with time of OPC which clearly shows the formation of hexagonal prisms ettringite crystals. ACsX-nM has also been employed to study the differences in real-time hydration between pure (cubic) tricalcium aluminate and $\mathrm{Na}$-doped $\mathrm{C}_{3} \mathrm{~A}$ (orthorhombic) in aqueous solutions saturated in sulphates. The reactions involving cubic $\mathrm{C}_{3} \mathrm{~A}$ were more influenced by higher concentrations of sulphate ions, forming smaller ettringite needles at a slower pace than for orthorhombic $\mathrm{C}_{3} \mathrm{~A}$. It was also concluded that the rate of release of aluminate species into the solution was also accelerated by Na-doping.[117] The early-age hydration of ye'elimite phase (the main component of the calcium sulphoaluminate cements) has also been studied using this technique.[118] Diluted suspensions of this phase saturated in $\mathrm{CSH}_{2}$, and with variable amounts of $\mathrm{CH}$, were examined. The most voluminous hydration product observed was ettringite. Under these hydration conditions, AFt commonly displayed acicular, filiform and plenty of intergrowths with stellate habits (see Figure 13).

The previous examples used 2D image evolution (microscopy) for obtaining the required information. The current technology allows to rapidly record a set of $2 \mathrm{D}$ images rotating the sample and so tomograms can be acquired and reconstructed. Therefore, as images may have nanometer resolution, the term nano-tomography was coined. ACsX-nCT has been recently employed to characterize the microstructure of two hydrated cement pastes.[119] Furthermore, it was possible to perform a direct computation of the ultra-small angle-scattering spectra from a single projection image which agreed well with the experimental synchrotron SAXS data obtained for the same pastes. Finally, soft X-ray nanotomography has also been employed for characterizing 2000-year-old Roman seawater concrete.[101] The data analysis showed clusters of Al-tobermorite crystals displaying both platy and elongated 1-2 $\mu \mathrm{m}$ crystals typical of geological $11 \AA$-tobermorite. 
(a)
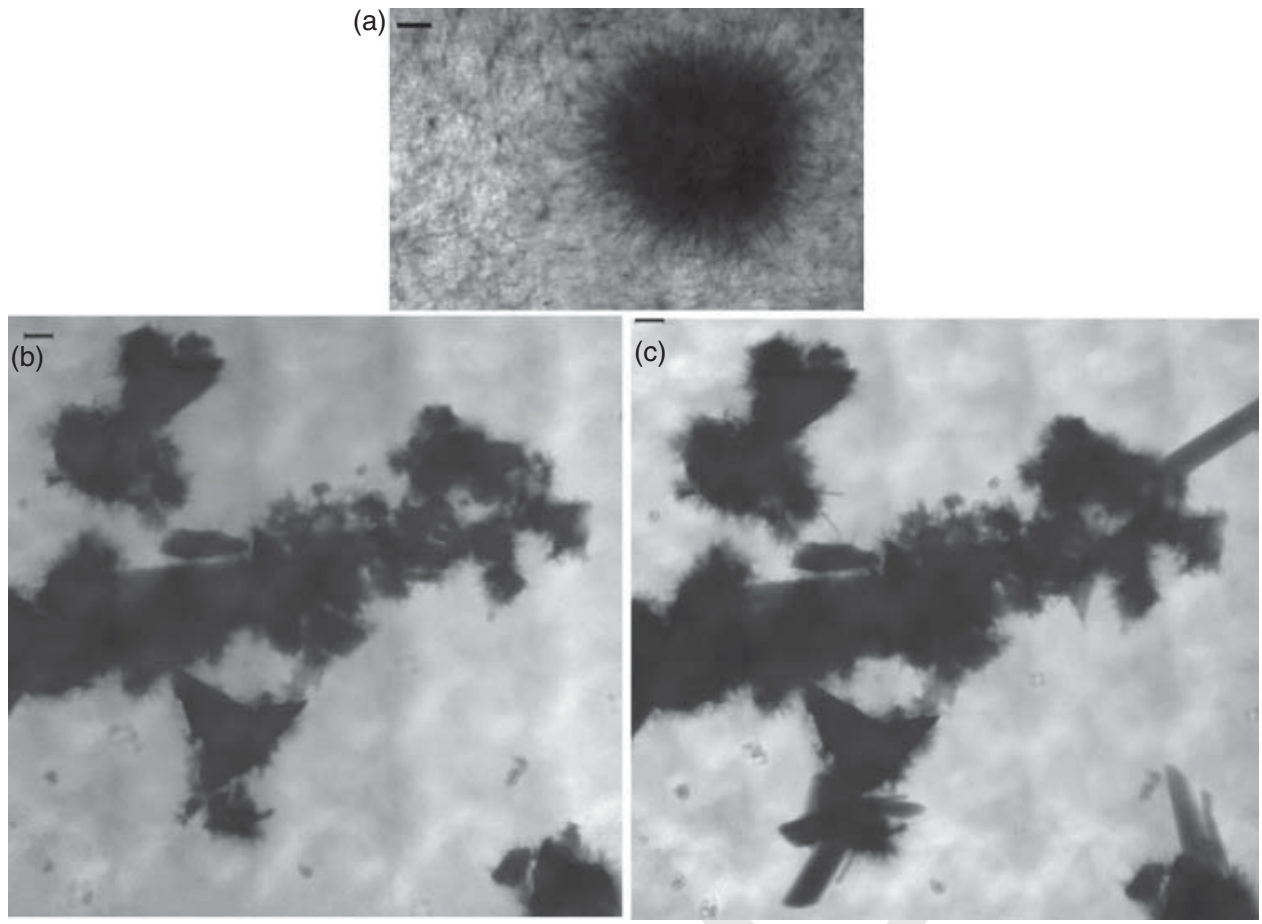

Figure 12. In-situ soft X-ray images, $A C s X-n M$, for (a) $\mathrm{C}_{3} \mathrm{~S}$ hydrating for $8 \mathrm{~h} 51 \mathrm{~min}$ in a diluted solution saturated with $\mathrm{CH}-\mathrm{CSH}_{2}$; (b) OPC sample hydrating for $15 \mathrm{~min}$ in a diluted solution saturated with $\mathrm{CH}-\mathrm{CSH}_{2}$; (c) as (b) but hydrating for $55 \mathrm{~min}$. Scale bars correspond to $1 \mu \mathrm{m}$. Reprinted from reference 114 with kind permission from Springer Science and Business Media.

\subsubsection{Full-field hard X-ray micro-tomography}

Full-field transmission hard X-ray computed micro-tomography (here summarized as AChX$\mu \mathrm{CT})$ is the high-resolution adaptation of the CAT technique employed in medical applications since the 1970s. The AC-hX- $\mu \mathrm{CT}$ imaging technique is based on the virtual reconstruction of the inner density distribution of a sample from $2 \mathrm{D} \mathrm{X}$-ray radiographs collected at many viewing angles, while the sample rotates relatively to the source-detector direction (see Figure 14). We can distinguish two different steps in data handling. Initially, the recorded data must be processed to obtain a digitalized version of the studied object. The final outcome of the reconstruction process is a series of images called slices that, when stacked together after proper alignment, provide a 3D map of the spatial variations of the X-ray linear attenuation coefficient $(\mu)$ within the investigated object. Here, the key result is that each slice is composed by a matrix of voxels (volume elements) whose grey values are proportional to the mean value of $\mu$ (see Figure 14, bottom) The maximum spatial resolution achievable can reach the sub-micrometre scale for standard applications and is related not only to the technical specifications of the experimental set-up (characteristics of the synchrotron X-ray source and used detector), but also and chiefly to the size of the sample. As a general rule, higher resolutions require smaller samples due to the limited field of view of current X-ray area detectors. In a second stage, the digitalized object must be analysed with the appropriate software(s) depending on the information to be obtained: pore size distribution and connectivity, tortuosity, size and shapes of some particles, leaching effects, etc.

The main advantage of $\mathrm{AC}-\mathrm{hX}-\mu \mathrm{CT}$ is that it provides three-dimensional visualization of the internal microstructure of untreated samples. This is key as several other techniques for microstructure analysis (MIP, SEM, TEM) are known to produce irreversible changes in the 
1201

1202

1203

1204

1205

1206

1207

1208

1209

1210

1211

1212

1213

1214

1215

1216

1217

1218

1219

1220

1221

1222

1223

1224

1225

1226

1227

1228

1229

1230

1231

1232

1233

1234

1235

1236

1237

1238

1239

1240

1241

1242

1243

1244

1245

1246

1247

1248

1249

1250
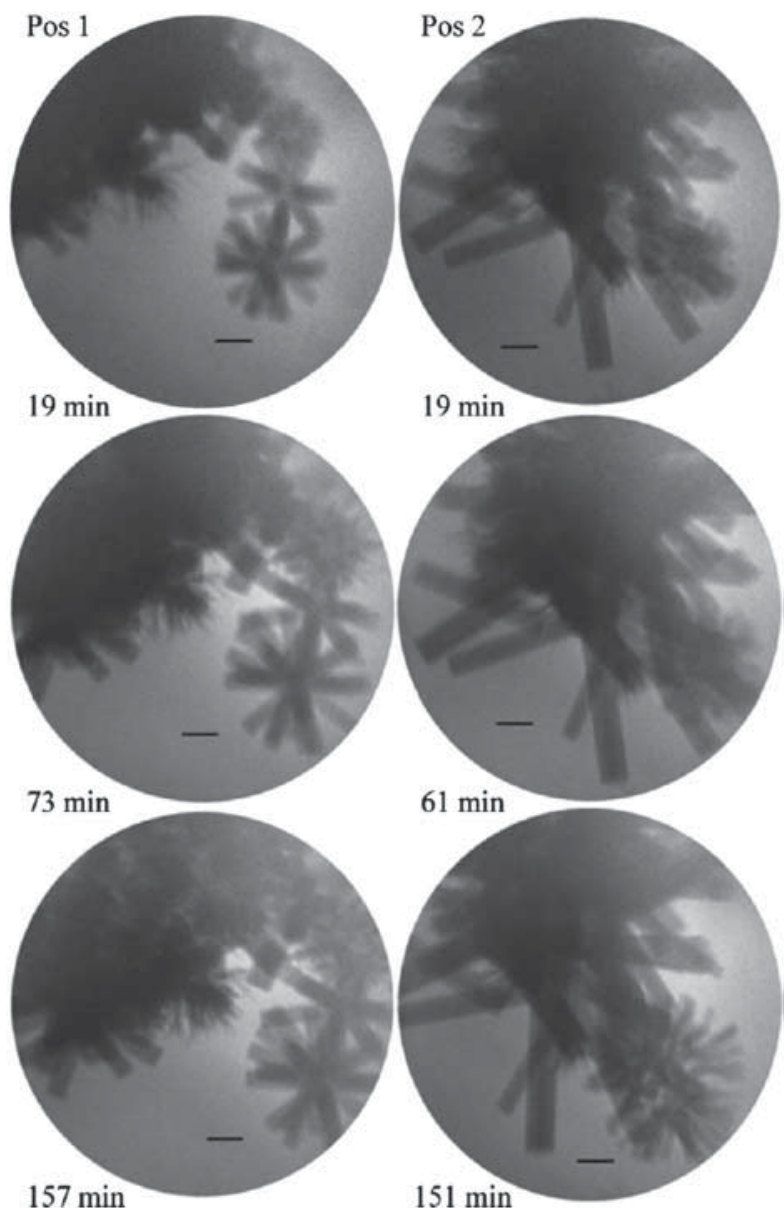

19 min
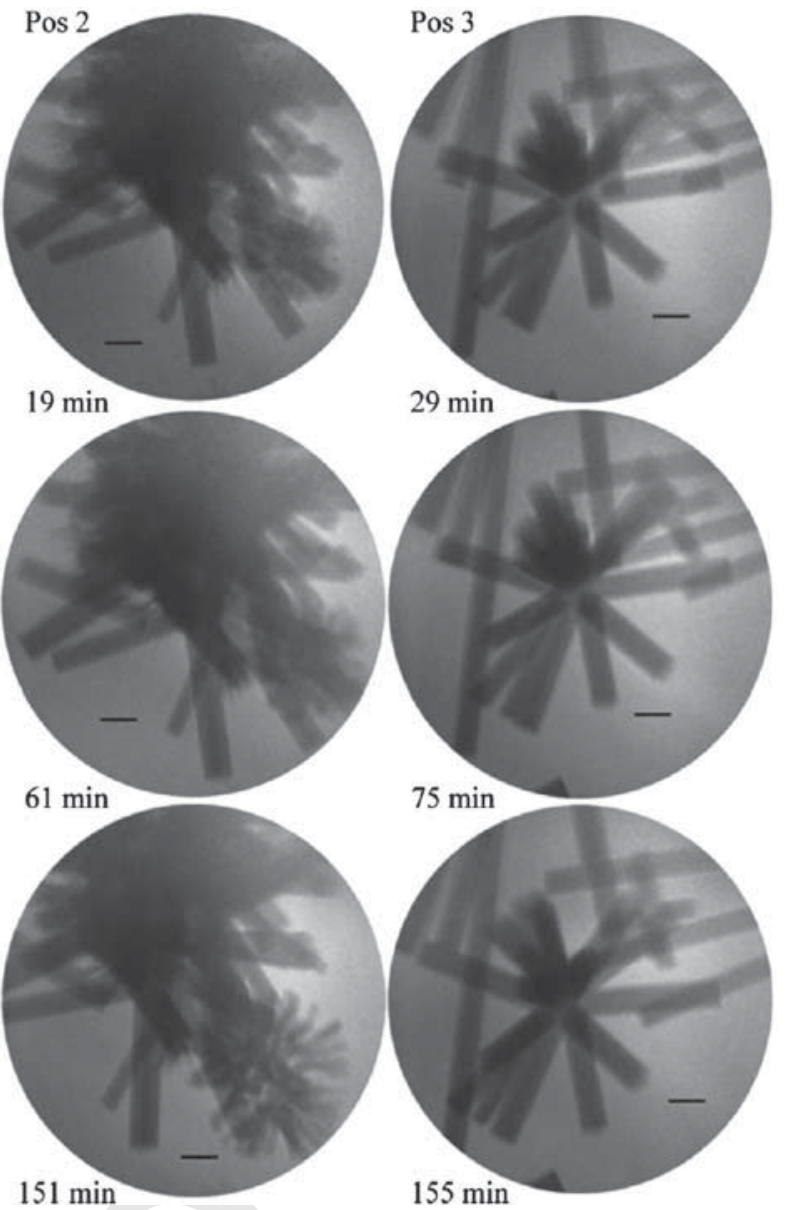

$29 \mathrm{~min}$

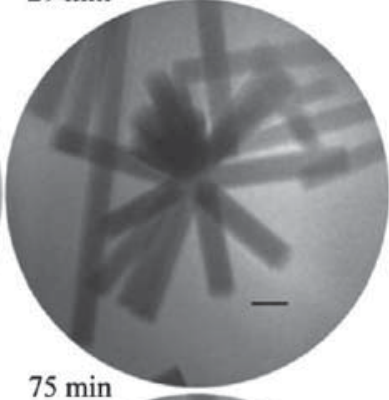

$75 \mathrm{~min}$

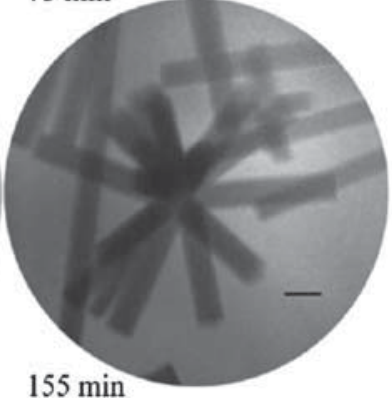

$155 \mathrm{~min}$

Figure 13. In-situ soft X-ray images, $\mathrm{ACsX}-\mathrm{nM}$, of hydrating $\mathrm{C}_{4} \mathrm{~A}_{3} \underline{\mathrm{S}}$ particles in a saturated $\mathrm{CH}_{-}-\underline{S}_{2}$ very diluted solution, showing the ettringite growth. Hydration time is indicated. Scale bars correspond to $1 \mu \mathrm{m}$. Reprinted from reference 116 with permission from Elsevier.

pore structure of cement pastes, particularly at small sizes. Furthermore, parameters such as connectivity and tortuosity are completely inaccessible by these techniques but they can be inferred from AC-hX- $\mu \mathrm{CT}$, although the obtained results can be resolution dependent, see below. Fast data acquisition times are very important to avoid heating of the sample with the possibility to alter the microstructure of the studied sample due to local dehydration processes. The main two disadvantages of AC-hX- $\mu \mathrm{CT}$ are: first, its still low spatial resolution, voxel size of $\approx 0.5 \mu \mathrm{m}^{3}$, relative to the sizes of capillary pores controlling transport properties in mature pastes. Second, sample preparation is delicate as narrow capillaries are required to acheive high resolution and in these conditions the w/c ratio and homogeneity of the pastes are difficult to ensure.

Perhaps it is worth mentioning that initial (independent) contributions from the Europeans, Japanese and Americans were reported within two years. In a seminal work of European researches, $[120] \mathrm{AC}-\mathrm{hX}-\mu \mathrm{CT}$ was used to study the connectivity and tortuosity of the pore network in OPC pastes. It was also shown that the degree of connectivity of the pore network was very sensitive to both the spatial resolution of the images and the evolution of contrast resolution during ageing of the cement. Some experimental conditions were: Lindemann Glass type capillaries with diameter of $600 \mu \mathrm{m}$ and a wall thickness of $10 \mu \mathrm{m}$; pastes with w/c ratio of 0.5 ; X-ray 
1251

1252
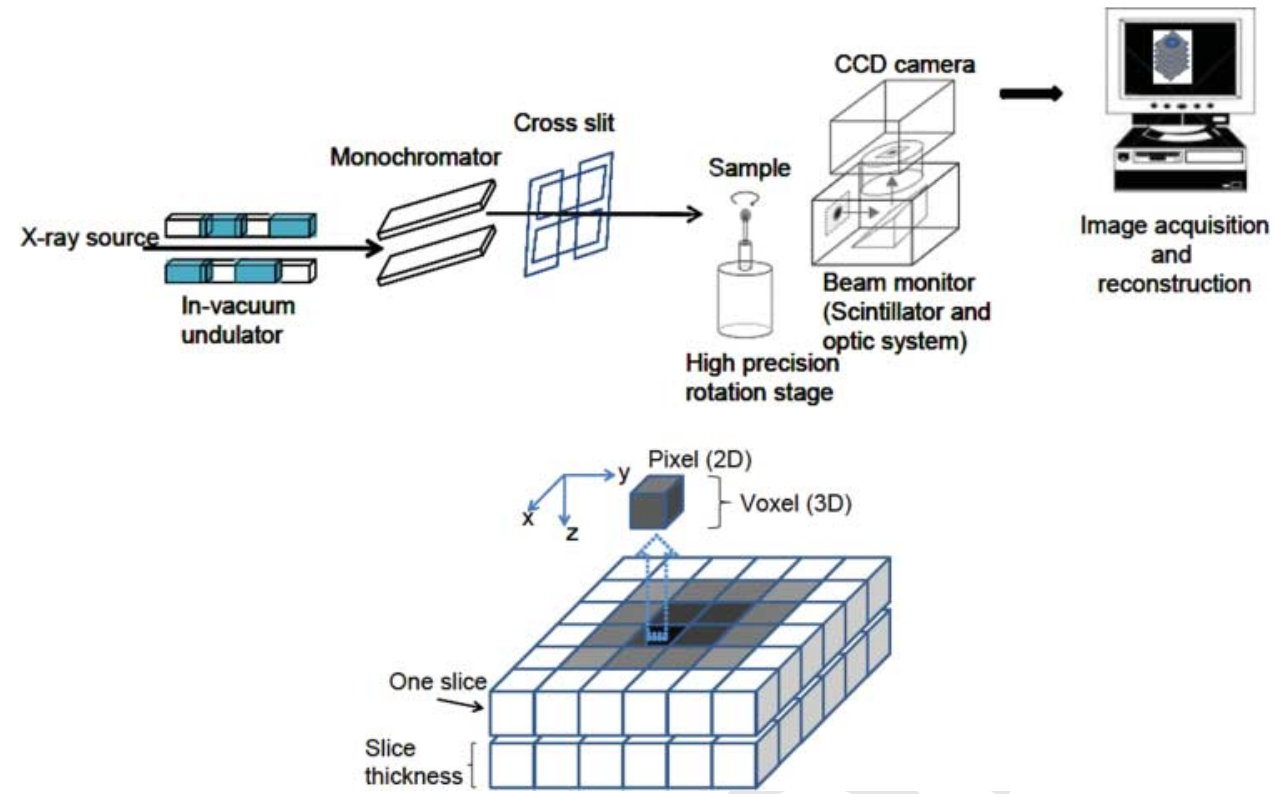

Figure 14. (Top) Typical system for absorption-constrast hard X-ray micro-computed tomography. (Bottom) Scheme describing pixel, voxel and slice, with each voxel being associated with an attenuation coefficient. From reference 119 (c) JCI - reprinted with permission.

energy variable between 12 and $15 \mathrm{keV} ; 1001$ projections with an angle step of $0.18^{\circ}$ and an exposure time of $3 \mathrm{~s}$; detector being a CCD camera (2048 pixels) equipped with a $1400 \mathrm{~mm}$ field of view and a $10 \times$ magnification optical objective. Japanese experts studied not only porosity but the degree of pore connectivity and tortuosity,[121,122] which are very important parameters to understand the mechanical performances and the durability of mortars and concretes. In these studies a voxel size of $0.5 \mu \mathrm{m}^{3}$ was achieved and pastes at different hydration ages $(2,7$ and 28 days) were characterized. These authors also used AC-hX- $\mu \mathrm{CT}$ for studying the internal microstructure of deteriorated cementitious matrices due to leaching.[123] Finally, American researches applied both $\mathrm{AC}-\mathrm{hX}-\mu \mathrm{CT}$ and $\mathrm{PC}-\mathrm{hX}-\mu \mathrm{CT}$ to study the durability of concrete by analysing in-situ ice formation in entrained air voids within hydrated cement paste.[124] It must be highlighted that at X-ray wavelengths, the index of refraction is about 10-100 times larger than the absorption index. Thus the phase contrast mode of operation is more sensitive than the absorption mode. However, $\mathrm{PC}-\mathrm{hX}-\mu \mathrm{CT}$ data are harder to interpret quantitatively than those arising from $\mathrm{AC}-\mathrm{hX}-\mu \mathrm{CT}$, unless phase retrieval procedures are implemented.

More recently, other works used these techniques for further characterization of building materials. For instance, AChX- $\mu \mathrm{CT}$ has been used $[125,126]$ to study ASR which is one of the most important weathering processes in cement chemistry. To optimize the phase-contrast effects, the sample-to-detector distance was set to $200 \mathrm{~mm}$. These authors found three different kinds of voids due to the effect of three different mechanisms: (i) cracks from ASR expansion, (ii) irregular-shaped voids due to the aggregate particles dissolution, and (iii) bubbles due to the cement paste preparation. AC-hX- $\mu \mathrm{CT}$ has also been used to compare the early hydration of three cementing materials: OPC, CSA and a mixture of these two types of cements.[127] A full tomogram took $5 \mathrm{~min}$ and data were taken from hydration times between 1 and $12 \mathrm{~h}$, the resolution being not high $(0.74 \times 0.74 \mu \mathrm{m}$ pixel size $)$. Some consequences of the hydration processes on the microstructure were followed including the porosity evolution with hydration time at early hydration ages. As an example, Figure 15 (left) shows the single slice evolution 
1301

1302

1303

1304

1305

1306

1307

1308

1309

1310

1311

1312

1313

1314

1315

1316

1317

1318

1319

1320

1321

1322

1323

1324

1325

1326

1327

1328

1329

1330

1331

1332

1333

1334

1335

1336

1337

1338

1339

1340

1341

1342

1343

1344

1345

1346

1347

1348

1349

1350
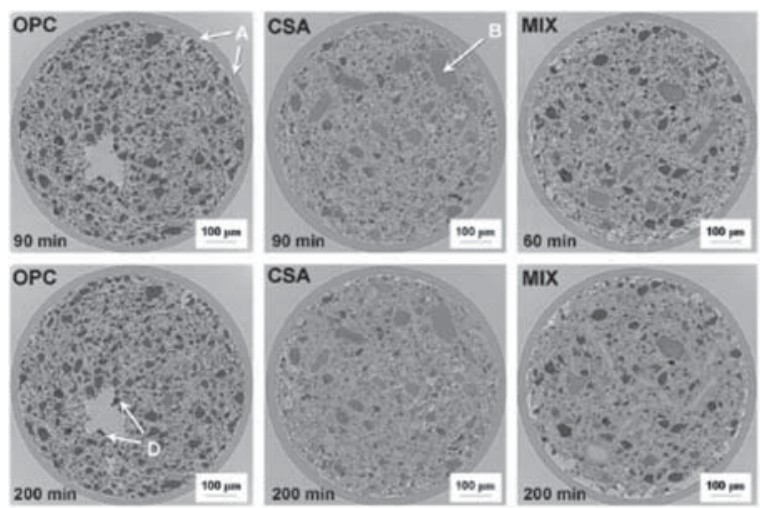

OPC

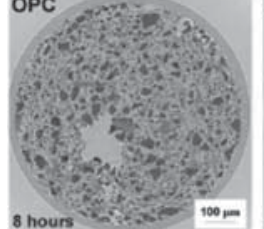

OPC

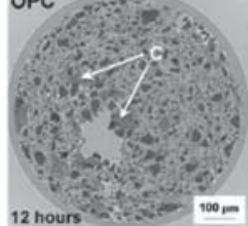

12 hours 10.2600
CSA

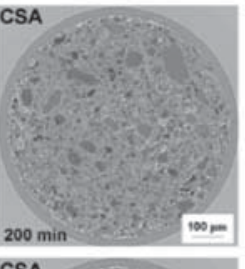

CSA

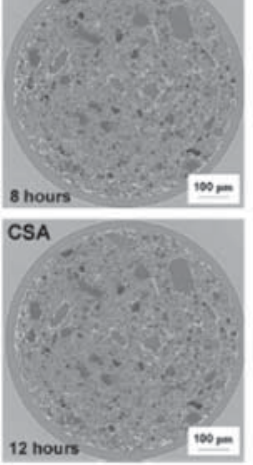

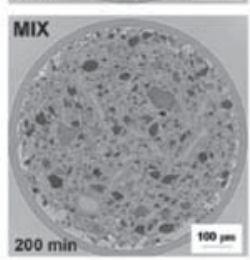
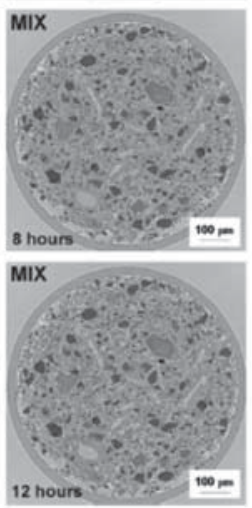
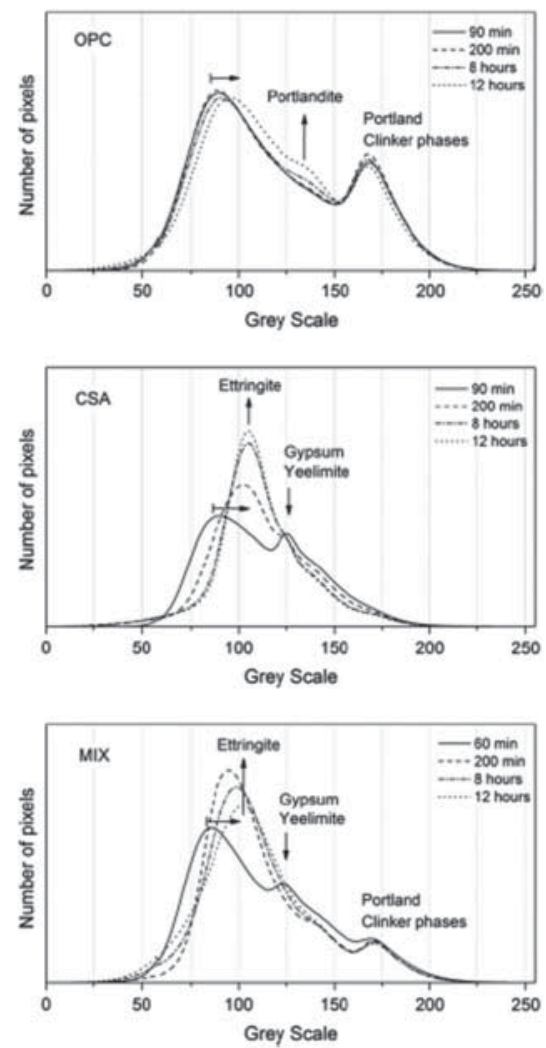

Figure 15. (Left) Single slice evolution for the three samples (OPC, CSA and a blended OPC/CSA cement) at different hydration times (A: Lindemann glass tube; B: gypsum; C: portlandite; $\mathrm{D}: \mathrm{C}_{4} \mathrm{AF}$ ). (Right) Evolution of the grey-level histograms during cement hydration. Reprinted from reference 125 with permission from Elsevier.

of the three samples (OPC, CSA and an OPC-CSA mixture) at selected hydration times. Data can be analysed in a quite sophisticated way but an initial test is to plot the evolution with hydration of the grey-level histograms extracted from a VoI (see Figure 15, right). These grey values correlate with the absorption coefficient and so with the hydration degree of the different components.[128] AC-hX- $\mu \mathrm{CT}$ has also been used to study emerging eco-cements like alkali-activated binders.[129] Insights into microstructural and pore structure characteristics were obtained including pore tortuosity calculated by a random walker method. AC-hX- $\mu \mathrm{CT}$ has also been used to compare the microstructure evolution of an OPC cement paste with and without a PCE superplasticizer.[130] Selected experimental details were: borosilicate glass capillaries with internal diameter of $600 \mu \mathrm{m}$; monochromatic beam of an energy of $14 \mathrm{keV}$; voxel size of $0.7 \mu \mathrm{m}^{3}, 30 \mathrm{~min}$ per single tomogram (about $800 \mathrm{~ms}$ per projection), and $20 \mathrm{~mm}$ between sample and detector which means that edge enhancement due to (propagation-based) phase contrast also contributed to the recorded signal. A very clear difference in the microstructure evolution between cement pastes with and without superplasticizers was shown.

There have been special applications of AC-hX- $\mu \mathrm{CT}$ in cements. For instance, it has been used with a white (filtered) synchrotron beam with energies ranging between 20 and $80 \mathrm{keV}$ [131] and final voxel size of $\approx 18 \mu \mathrm{m}^{3}$. The authors developed a method for extracting sub-voxel mineralogical and chemical information by combining advanced image segmentation with geochemical models of cement alteration. This method relies on determining 'effective linear activity 
coefficients' for the white beam to generate calibration curves that relate the image greyscales to material composition which was applied to the determination of diffusion profiles in altered wellbore cements. Another very recent special application was collecting AC-hX- $\mu \mathrm{CT}$ data on small cylinder specimens under load at varying degrees of damage.[132] Selected experimental details were: $5 \mathrm{~mm}$ of diameter of the specimens; monochromatic beam of an energy of $30 \mathrm{keV}$; voxel size of $6 \mu \mathrm{m}^{3}$, and $2.5 \mathrm{~h}$ for recording a single tomogram. AC-hX- $\mu \mathrm{CT}$ allowed characterizing microstructure and internal damage, which could then be related to bulk splitting strength and fracture energy. Results showed that aggregate surface roughness had little effect on strength but significant effect on fracture energy.

$\mathrm{AC}-\mathrm{hX}-\mathrm{nCT}$ has also been employed in cement studies. For attaining (dozens of) nanometer resolution, the commonly focusing optics used before the sample are capillary lenses and the field of view is considerably decreased when compared to AC-hX- $\mu \mathrm{CT}$. Nanotomographic reconstruction of a geopolymer binder, formed by hydration of fly ash, allowed very high resolution (voxel size of $30 \mathrm{~nm}^{3}$ ) observation of the pore structure of the aluminosilicate geopolymer gel.[133] However, it must be noted that this very high resolution was achieved by decreasing the FoV approximately to $10 \mu \mathrm{m}$. Finally, it also worth mentioning that AC-hX-nCT, voxel size of $64 \mathrm{~nm}^{3}$, has also been very recently obtained from a laboratory source.[134] The FoV in this high resolution configuration was $65 \mu \mathrm{m}$ in the three directions, with $12 \mathrm{~h}$ per tomogram. FZP optics was used to focus the transmitted beam on a scintillator plate in front of a $20 \times$ optical device, and the energy source was a rotating anode copper tube which produces a polychromatic beam with a maximum intensity of $8 \mathrm{keV}$.

\subsubsection{Scanning synchrotron radiation microscopies}

Synchrotron scanning microscopies comprise a set of techniques with a common feature, a small monochromatic beam impinged onto a sample which is scanned resulting in an image array. The image nature will depend upon the property being measured (transmitted X-ray beam, emitted $\mathrm{X}$-ray fluorescence, transmitted or reflected IR beam etc.). It must be also noted that many studies recorded more than one signal for the same sample set-up (for instance transmitted X-ray: image, plus energy variation of the recorded absorption: elemental sensitivity, etc.), thus having access to complementary information. Several techniques have been used for hydrated cement characterization depending upon the property being measured, and key papers are discussed below.

3.7.3.1. Scanning infrared spectro-microscopy Infrared spectro-microscopy at synchrotrons provides the opportunity to collect spatially resolved IR data for samples with a spatial resolution close to $3 \mu \mathrm{m}$ (depending on the wavelength region to be used). Obviously, there are laboratorybased IR spectro-microscopes but the brilliance of the infrared light produced at synchrotron radiation is much higher compared to that of thermal sources (about three orders of magnitude) and therefore it provides very good signal-to-noise ratio even when the microscope's apertures are set at the diffraction limit. This technique can operate in transmission, in total reflection and in attenuated total reflection. The choice of the experimental configuration mainly depends on the characteristics of the studied sample.

To the best of my knowledge, synchrotron IR spectro-microscopy has not been used in cement chemistry as widely as other synchrotron techniques in spite of its high degree of chemical selectivity by tuning to the specific vibration bands that can provide information about different phases, additives, etc. I can highlight the work on the effect of seeded nucleation on the formation and structural evolution of geopolymer gels.[135] This research showed that the nature of the seeds affects the structure of the growing gel by affecting the extent of phase separation, identified by the presence of a distinct silica-rich gel in addition to the main, alumina-richer gel 


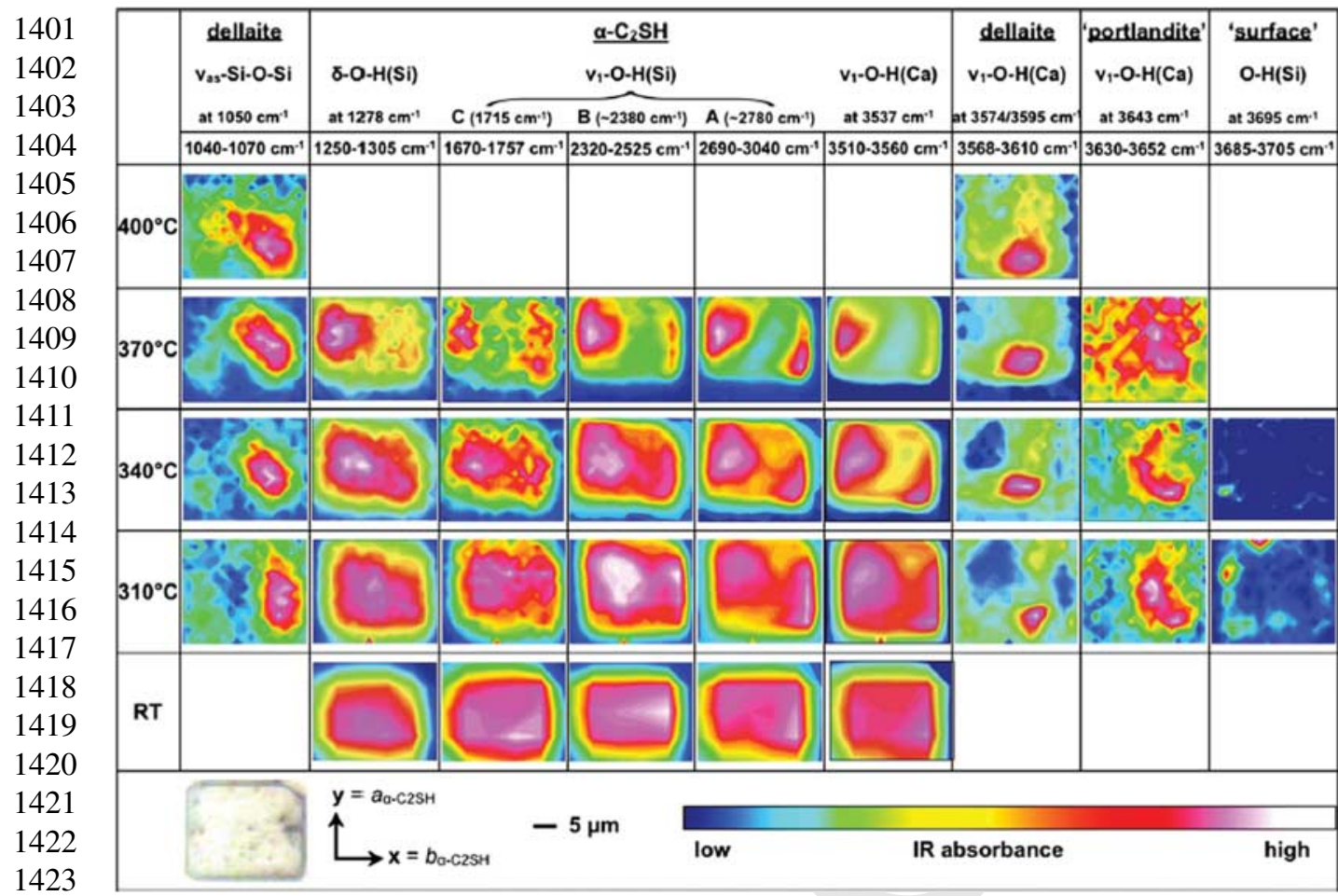

1424

1425

Figure 16. IR images of a $\alpha-\mathrm{C}_{2} \mathrm{SH}$ single crystal $(6 \times 5$ pixels, $5 \mu \mathrm{m}$ step size $)$ and after subsequent thermal treatment at different temperatures $(19 \times 16$ pixels, $1.5 \mu \mathrm{m}$ step size $)$. The images were created by integration of the intensity over a certain absorption band which is represented by the colour of a given pixel yielding an image with white, pink, red, yellow, green and blue (high to low intensity, respectively) For more information, the reader is directed to the original publication. Reprinted from reference 134 with 1429

phase. Laboratory data could not detect such differences likely due to their poorer resolution. On the other hand, synchrotron IR spectro-microscopy can be used to follow chemical reactions (f.i. 1433 on heating) by following the evolution of the vibration bands. This use has been very elegantly 1434 employed to follow the evolution of a single crystal (grain) of $\alpha-\mathrm{C}_{2} \mathrm{SH}$ on heating.[136] The 1435 exact transformation mechanism of dehydration remained controversial but this work showed conclusive evidences of the formation of Dellaite at about $350^{\circ} \mathrm{C}$. Figure 16 shows diffractionlimited IR images of a thin $\alpha-\mathrm{C}_{2} \mathrm{SH}$ crystallite, thickness $\approx 3 \mu \mathrm{m}$, showing the spatially resolved intensity evolution with temperature of selected vibration bands to highlight the appearance and disappearance of the phases. transmitted X-rays are measured in the detector resulting in spatially resolved images because of the scan of the sample. If coherence properties of the beam are not used, soft X-rays are preferred as the contrast between different parts of a (heterogeneous) sample is enhanced mainly for soft condensed matter. The chemical information of the sample can be simultaneously obtained by acquiring a signal at a given position for multiple photon energies.

Using soft X-rays (energy ranging between 200 and $2000 \mathrm{eV}$ ), the effect of polymers on the 

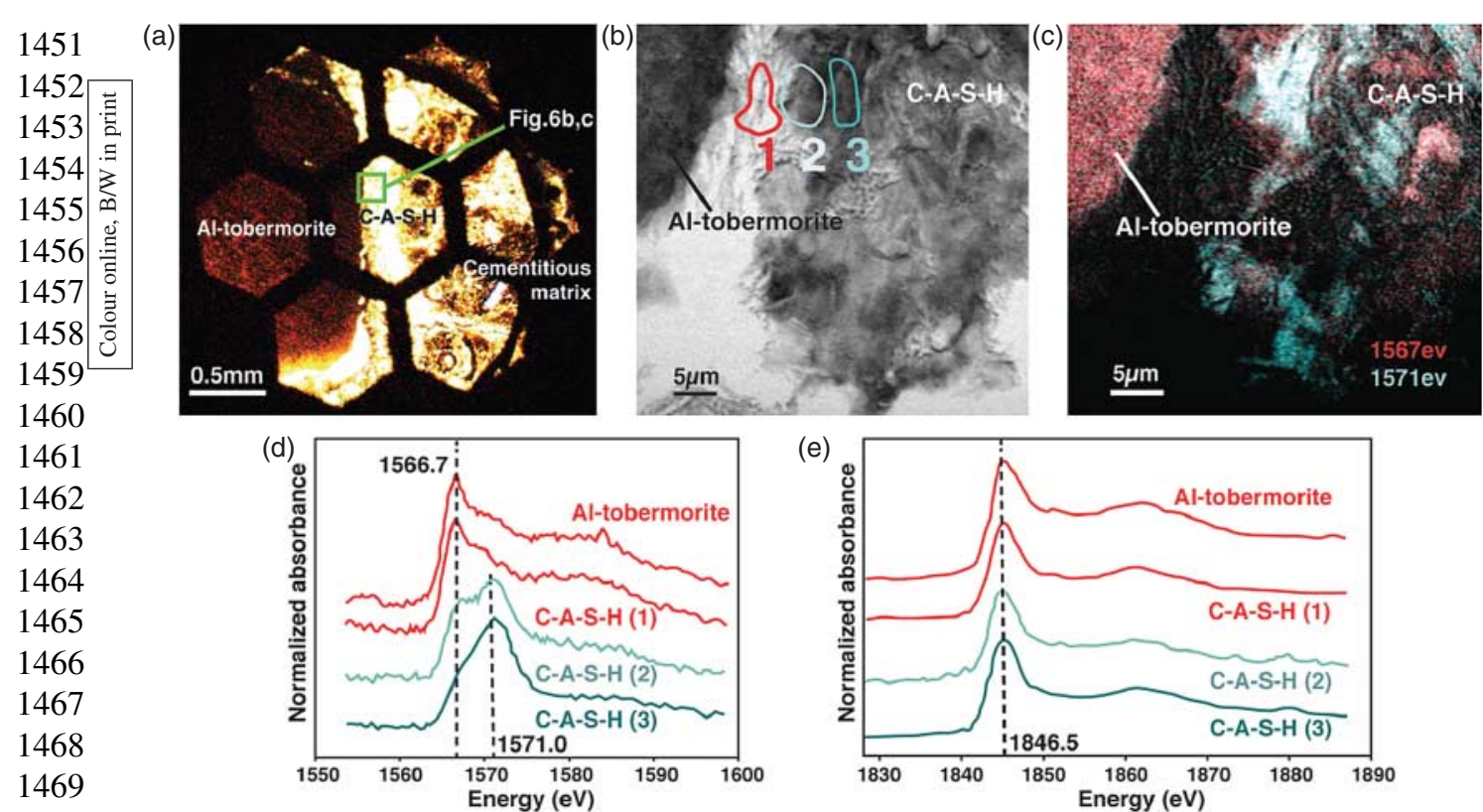

(e)

1462

1463

1464

1465

1466

1467

1468

1469

1470

1471

1472

1473

1474

1475

1476

1477

1478

1479

1480

1481

1482

1483

1484

1485

1486

1487

1488

1489

1490

1491

1492

1493

1494

1495

1496

1497

1498

1499

1500
Figure 17. Bonding environments of $\mathrm{Al}^{3+}$ and $\mathrm{Si}^{4+}$ for Al-tobermorite and $\mathrm{C}-\mathrm{A}-\mathrm{S}-\mathrm{H}$ in a 2000-year-old Roman seawater concrete. (a) Optical image of relict lime clast showing crystalline Al-tobermorite core, complex C-A-S-H perimetral rim and pumiceous cementitious matrix. (b) STXM absorption contrast image at $1550 \mathrm{eV}$ Al-edge. (c) STXM map of tetrahedral-Al at $1567 \mathrm{eV}$ (red), octahedral-Al at $1571 \mathrm{eV}$ (cyan), and mixed Al[IV] and Al[VI] (white). (d) Typical aluminium K-edge, (e) silicon K-edge NEXAFS spectra for Al-tobermorite and $\mathrm{C}-\mathrm{A}-\mathrm{S}-\mathrm{H}$, showing typical spectra at sites (1), (2), and (3) of part b. For more details, the reader is directed to the original publication. Reprinted from reference 136 with permission from the Mineralogical Society of America.

spectra for the $\mathrm{C}, \mathrm{Ca}$ and $\mathrm{Si}$ edges were obtained. The authors reported a different behaviour for the absorption and carbonation of polyethylene glycol and hexadecyltrimethylammonium polymers on C-S-H. STXM coupled with NEXAFS spectra for $\mathrm{C}, \mathrm{Ca}, \mathrm{Al}$ and $\mathrm{Si}$ edges were used to better characterize Al-tobermorite-rich Roman seawater concrete.[138] The microstructure of a 2000-year-old concrete block submerged under the Mediterranean Sea was comprehensively characterized including the spatial arrangements of Al-tobermorite and the poorly crystalline calcium-aluminium-silicate-hydrate $(\mathrm{C}-\mathrm{A}-\mathrm{S}-\mathrm{H})$ binder $_{\mathbf{A}}$ (see Figure 17). Finally, scanning transmission soft X-ray microscopy and full-field hard X-ray micro-tomography were used to study the interactions and microstructure of an OPC paste reinforced with polymeric fibres.[139]

\subsubsection{Scanning fluorescence X-ray microscopy and tomography In scanning fluorescence} microscopy, a hard X-ray beam (energy can be close to $10 \mathrm{keV}$ ) is also focused by the appropriate optics (commonly FZP). Emitted characteristic X-ray fluorescence radiation is detected with the suitable energy dispersive detector (f.i. a multi-channel silicon drift detector). Scanning the sample with small steps (they can be as small as $20-30 \mathrm{~nm}$ ) provides the high resolution multi-element images with the elemental compositions (derived from the integrated area of the recorded fluorescence signal).

SFXM was used to characterize the nanoscale distribution of elements within fly ash geopolymers, the binders obtained by alkaline activation of fly ash mainly formed by aluminosilicate gel(s).[140] Hydroxide-activated geopolymer gel was highly heterogeneous with high-content Ca particles within the geopolymer binder matrix. Conversely, silicate-activated geopolymer gel showed a much more homogeneous geopolymer gel binder structure surrounding the unreacted 
1501

1502

1503

1504

1505

1506

1507

1508

1509

1510

1511

1512

1513

1514

1515

1516

1517

1518

1519

1520

1521

1522

1523

1524

1525

1526

1527

1528

1529

1530

1531

1532

1533

1534

1535

1536

1537

1538

1539

1540

1541

1542

1543

1544

1545

1546

1547

1548

1549

1550
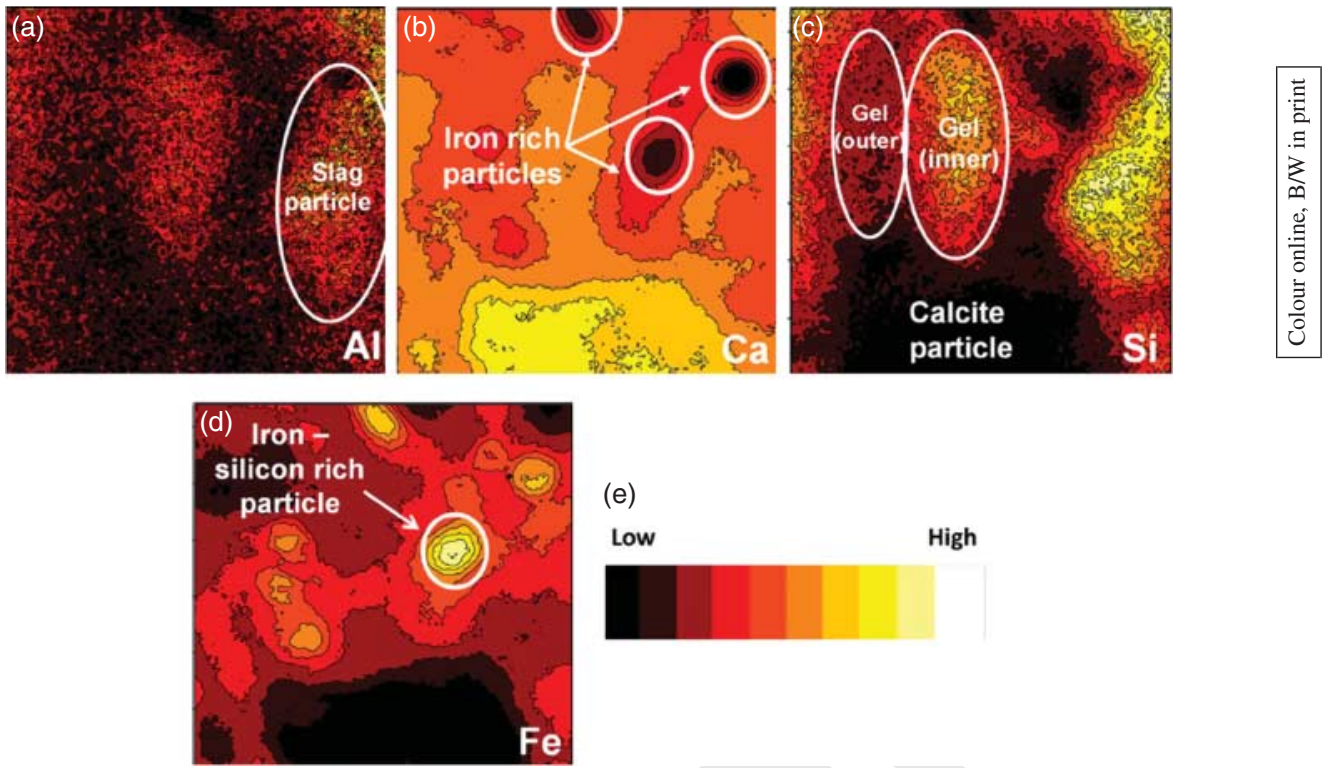

Figure 18. X-ray fluorescence micrographs of a sodium silicate-activated binder $(80 \%$ slag/20\% metakaolin), cured for $28 \mathrm{~d}$. The maps were obtained with a step size of $67 \mathrm{~nm}$, in a scanning region of $8 \mu \mathrm{m} \times 8 \mu \mathrm{m}$. Reprinted from reference 139 with permission from John Wiley and Sons.

fly ash particles. Several transition metals $(\mathrm{Cr}, \mathrm{Fe} . .$.$) were mapped. In a related recent$ work,[141] SFXM has been used to quantify the effects of the activator concentration on the microstructure of alkali silicate-activated slag/metakaolin pastes. The space-resolution properties of this technique (a $10.5 \mathrm{keV}$ beam focused down to $60 \mathrm{~nm}$ ) allowed to distinguish two coexisting gels: calcium aluminosilicate hydrate $(\mathrm{C}-\mathrm{A}-\mathrm{S}-\mathrm{H})$ and sodium/calcium aluminosilicate hydrate $[(\mathrm{C}, \mathrm{N})-\mathrm{A}-\mathrm{S}-\mathrm{H}]$ type gels. As an example of an outcome of this type of studies, Figure 18 shows X-ray fluorescence micrographs for selected elements in this system. Finally, this technique has also been applied to study alkali-activated slag binders.[142] A key observation was that iron-rich, titanium-rich and manganese/silicon-rich particles remain stable under the reducing conditions prevailing during alkaline activation. There was no evidence of chemical interaction between these particles and the geopolymer binder.

On the other hand, the combination of techniques always provides a better picture of the studied sample/processes. One selected example is the combined use of soft X-ray SFXM and micro-XANES spectroscopy to determine the spatial distribution of $\mathrm{Al}$ and $\mathrm{S}$ and to identify the Al- and S-bearing species in compact hardened OPC paste hydrated at 50 ${ }^{\circ}$. [143] SFXM data were obtained by focusing a $3.9 \mathrm{keV}$ beam (energy just below the Ca absorption edge) to a size of approximately $3 \times 3 \mu \mathrm{m}$, and by measuring the emitted fluorescence X-rays with a single-element silicon drift detector. The $\mathrm{Al}$ and $\mathrm{S} \mathrm{K}$-edges micro-XANES spectra were recorded in fluorescence yield mode using the single-element drift diode detector. The depth of X-ray penetration was slightly less near the $\mathrm{Al} \mathrm{K}$-edge $(\sim 3.6 \mu \mathrm{m}$ at $1559.6 \mathrm{eV})$ than the $\mathrm{S} \mathrm{K}$-edge ( $\sim 9.4 \mu \mathrm{m}$ at $2472 \mathrm{eV}$ ). The relatively large escape depths, similar to the penetration depths, mean that the size of the sample probed could be tens of $\mu \mathrm{m}^{2}$, possibly containing several species. A second selected example is the combined use of hard X-ray SFXM and micro-diffraction to study the phase assemblage and microstructure of the hydration products formed in blended OPC cements with high-volume fly ash.[144] The reported data showed that the $\mathrm{C}-\mathrm{S}-\mathrm{H}$ formed in the system containing $50 \%$ of fly ash had a similar structure as $\mathrm{C}-\mathrm{S}-\mathrm{H}(\mathrm{I})$ with comparatively lower $\mathrm{Ca} / \mathrm{Si}$ ratio than the one produced in the OPC system. Moreover, coexistence of $\mathrm{C}-\mathrm{S}-\mathrm{H}(\mathrm{I})$ and 
strätlingite was observed in the system containing $80 \%$ of fly ash, confirming that the amount of alumina and silicate phases provided by the fly ash is a major factor for the formation of stratlingite (and C-S-H).

One selected example on the combined use of hard X-ray SFXM and micro-EXAFS and micro-XANES spectroscopies is the work on the Ni uptake by OPC pastes including the influence of the inherent heterogeneity of the cement matrix on the Ni speciation.[145] Some key experimental details were: beam size of $5 \times 5 \mu \mathrm{m}$, a fixed beam energy of $10 \mathrm{keV}$ for the $\mu$ XRF study and a variable beam energy (close to the Ni K-edge, $8.3 \mathrm{keV}$ ) for the $\mu$-XAS study. Both $\mu$-XRF and $\mu$-XAS data were collected at room temperature in fluorescence mode using a seven-element Ge-solid-state detector. Unfortunately, the thicknesses of the thin sections were not reported.

\subsubsection{Scanning diffraction hard X-ray microscopy In section 3.3, the uses of synchrotron} powder diffraction for quantifying crystalline phases and to follow phase evolutions are discussed. These works used a large beam (usually larger than a millimetre) yielding an accurate average picture but without spatial resolution. However, for heterogeneous materials, like cement binders, and for some applications, it is invaluable to have the spatial distribution of the different phases (for instance the changes/alteration with depth due to sulphate attack). This can be obtained by focusing the beam down to several micrometre size and scanning the sample in the appropriate direction. The technique, SDXM, works in transmission but not only is beam focusing important (for instance using K-B mirrors) but sample preparation is also very important. For this technique to be useful, a relatively thin (unaltered) cross-section must be prepared along the appropriate direction (see Figure 19). Typical thicknesses for the flat slices used in these studies ranged from 100 to $500 \mu \mathrm{m}$. This technique is commonly known simply as synchrotron microdiffraction.

SDXM, aka synchrotron microdiffraction, was used to quantify the orientation distribution of fibrous ettringite crystals after sulphate attack in fractured concretes.[146] Sample preparation is key and a summary of the process follows. A flat surface was impregnated with epoxy resin and then mounted on a glass slide. Then, using a diamond saw, and with kerosene as cooling agent, a $50 \mu \mathrm{m}$ thin slice was prepared also sealed with epoxy. Finally, the slice was removed from the glass slide and used for the synchrotron characterization (beam energy: $8 \mathrm{keV}$, beam

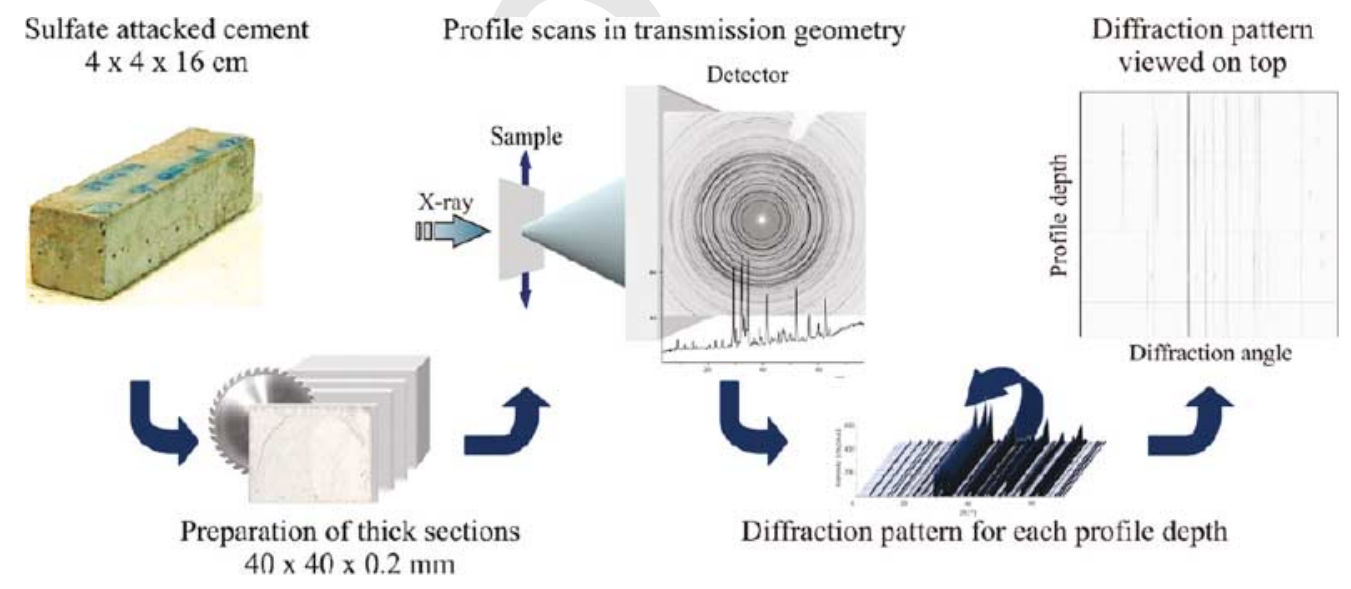

Figure 19. Schematic representation of the sample preparation and experimental method for scanning hard X-ray diffraction microscopy, aka synchrotron microdiffraction. Reprinted with permission from reference 145. Copyright $\{2011\}$ American Chemical Society. 
1601 size: $2 \times 2 \mu \mathrm{m}$ ). The analysis revealed that the $\mathrm{c}$ axes of the trigonal ettringite crystallites were

1602 preferentially oriented perpendicular to the fracture surfaces. SDXM was also employed to deter1603 mine, with spatial resolution, the changes in the phase composition due to sulphate attack [147] 1604 for establishing the durability of cementitious materials under these conditions. Key experimental 1605 details were, beam energy: $11.6 \mathrm{keV}$, beam size: $10 \mu \mathrm{m}$, sample thickness: $200 \mu \mathrm{m}$. Furthermore, 1606 the sulphate attacks are affected by the presence of SCM. In two subsequent works from the 1607 same group, the microstructural profile analyses of concrete deterioration after sulphate attack 1608 of OPC blended with fly ash [148] and with natural pozzolana, granulated blast furnace slag or 1609 fly ash [149] were deeply investigated. In the first work,[148] OPC was mixed with $30 \mathrm{wt} \%$ of 1610 class $\mathrm{F}$ fly ash and hydrated with w/c ratio of 0.5 for 28 days. Afterwards, the sulphate attack 1611 was carried out under laboratory conditions for 6 months. Then, the samples were embedded 1612 in epoxy resin and polished to thicknesses of $200 \mu \mathrm{m}$. During all preparation steps the sam1613 ples were cooled with petroleum to avoid dissolution of water-soluble phases. Key experimental 1614 details were, beam energy: $14.5 \mathrm{keV}$, beam size: $10 \mu \mathrm{m}$. In the second work,[149] the sample 1615 specimens were embedded in sulphate-bearing soil $\left(\approx 1 \mathrm{wt} \% \mathrm{SO}_{4}^{2-}\right)$ for 19 years. The samples 1616 were also embedded in epoxy resin for the preparation of cross-sections which were made par1617 allel to the direction of the sulphate ingress. Selected experimental details were, beam energy: $161812.4 \mathrm{keV}$, sample thicknesses: $500 \mu \mathrm{m}$. The beam size was not reported but it was mentioned that 1619 the achieved spatial resolution was $30 \mu \mathrm{m}$.

1620 Finally, synchrotron microdiffraction can be used to map the phase distributions in any com1621 plex binders after successful sample preparation. For instance, this technique has been very 1622 recently applied to study pyroclastic aggregate concrete of Trajan's Markets (1900 years old) as 1623 well as their reproductions (experimental archaeology): hydrated lime-volcanic ash mortar that 1624 binds decimeter-sized tuff and brick aggregates.[150] The mortar reproduction gains fracture 1625 toughness over $180 \mathrm{~d}$ through progressive coalescence of C-A-S-H gel binder and crystal1626 lization of strätlingite and katoite at $\geq 90$ days, after pozzolanic consumption of hydrated lime 1627 was complete. Key experimental details were, beam energy: $10 \mathrm{keV}$, beam size: $8 \times 2 \mu \mathrm{m}$, and 1628 1629 sample thickness: $300 \mu \mathrm{m}$.

1631

3.7.3.5. Scanning diffraction hard X-ray micro-tomography SDX- $\mu \mathrm{CT}$ [151] is a combination of diffraction (crystalline phase sensitive) and imaging (through tomographic reconstruction) 1632 techniques which allows determining the three-dimensional spatial distribution of different 1633 phases within heterogeneous samples. The reconstruction scheme for the SDX- $\mu$ CT technique is 1634 depicted in Figure 20. Unless the previous technique, SXDM, flat thin sections are not needed. 1635 Furthermore, the appropriate rescaling of the voxel intensity to the total intensity of sample scat1636 tering makes it possible to obtain the absolute quantification of the phase proportions in each 1637 voxel. SDX- $\mu \mathrm{CT}$ was initially used for 3D monitoring of the evolution of the microstructure 1638 and phase formation non-invasively.[152-154] For this particular set of experiments, the authors 1639 used a monochromatic beam $(E=18 \mathrm{keV})$ with a size of $2 \times 4 \mu \mathrm{m}^{2}$. Although this technique 1640 gives good insight into the three-dimensional phase arrangement at intermediate and later hydration ages, the long acquisition times ( $\sim 8 \mathrm{~h}$ for a slice of $500 \mu \mathrm{m}$ diameter and $2 \mu \mathrm{m}$ thickness) do not allow the phase mapping at early stages of hydration, as reaction kinetics are too fast for the microstructure to be resolved. Subsequently, AC- $\mu \mathrm{CT}$ was used at early ages ( $7 \mathrm{~h}$ of hydration) and SDX- $\mu \mathrm{CT}$ at later ages (7 days of hydration) for obtaining better insight into the phase and microstructure developments in hydrating pastes.[155]

SDX- $\mu \mathrm{CT}$, combined with numerical simulations for $\mathrm{C}-\mathrm{S}-\mathrm{H}$ precipitation, was used to investigate the $\mathrm{C}-\mathrm{S}-\mathrm{H}$ topological distribution and modes of precipitation.[156] This technique have been recently used to map the phases present in two hydrating OPC cement pastes (one sam1649 ple hydrated with pure water and a second one hydrated in the presence of nucleation seeds). The quantitative description of the phase spatial distribution by radial distribution functions 


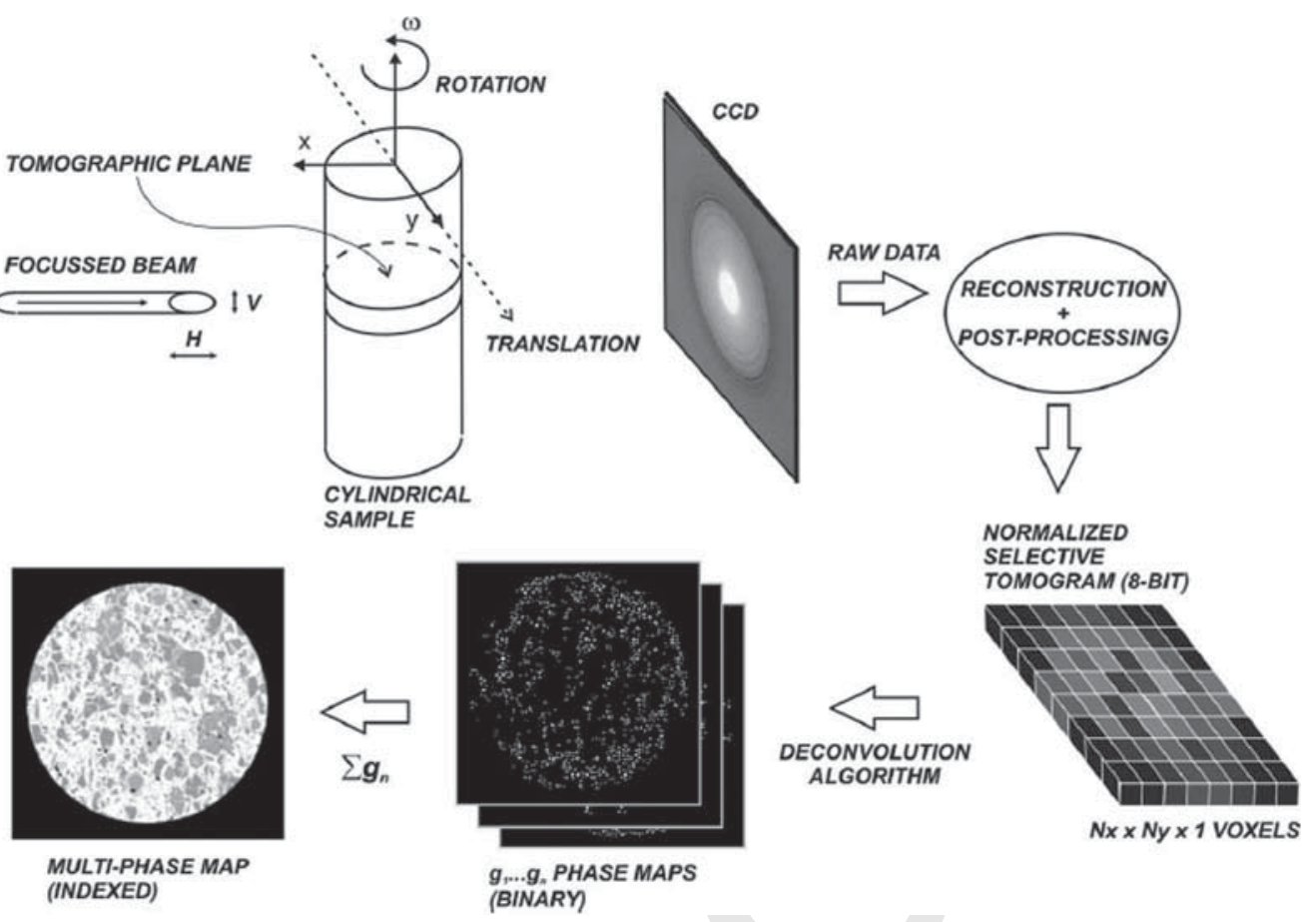

Figure 20. Schematic representation of the experimental set-up and workflow (data acquisition and data processing) for scanning diffraction hard X-ray micro-tomography. Reprinted from reference 151 with permission from International Union of Crystallography.

allows the discrimination of different nucleation mechanisms.[157] SDX- $\mu$ CT has also been very recently used to map the $\mathrm{C}-\mathrm{S}-\mathrm{H}$ precipitation in the absence and presence of superplasticizer (see Figure $21_{2}$ left). The observed spatial correlation between $\mathrm{C}-\mathrm{S}-\mathrm{H}$ and unhydrated cement particle surfaces indicated that, in the absence of PCE superplasticizers, $\mathrm{C}-\mathrm{S}-\mathrm{H}$ forms by a process of heterogeneous nucleation, on the surface of the dissolving cement particles (see Figure 21 , right). Conversely, the lack of significant spatial correlation between $\mathrm{C}-\mathrm{S}-\mathrm{H}$ and the surface of unhydrated particles, when PCE is added to the system, revealed that $\mathrm{C}-\mathrm{S}-\mathrm{H}$ precipitates randomly throughout the available space in the paste.[158]

\subsubsection{Hard X-ray coherent diffraction imaging}

As it was mentioned above, there is an alternative to image-forming optics where the $\mathrm{X}$ rays scattered by the sample are reconstructed by appropriate algorithms. These set of techniques are commonly named CDI techniques, and the two most common ones are discussed below.

3.7.4.1. Hard X-ray Bragg coherent diffraction nano-tomography BCDI is also a noninvasive imaging technique which can yield three-dimensional images of individual crystals on the nano-scale through inversion of the diffraction data by a computational method, but it also highly sensitive to crystal defects and strain fields inside crystals seen as phase evolution. The experimental set-up (see Figure 22) is compatible with cement hydrations as very recently reported.[159] In this study, the early hydration (up to 3 days) of microcrystals of calcium monoaluminate, CA, was investigated in situ by following the 3D Bragg diffraction electron density and strain evolution (see Figure 23). The variation of Bragg density within the crystal was attributed 
1701

1702

1703

1704

1705

1706

1707

1708

1709

1710

1711

1712

1713

1714

1715

1716

1717

1718

1719

1720

1721

1722

1723

1724

1725

1726

1727

1728

1729

1730

1731

1732

1733

1734

1735

1736

1737

1738

1739

1740

1741

1742

1743

1744

1745

1746

1747

1748

1749

1750
UNHYDRATED CEMENT

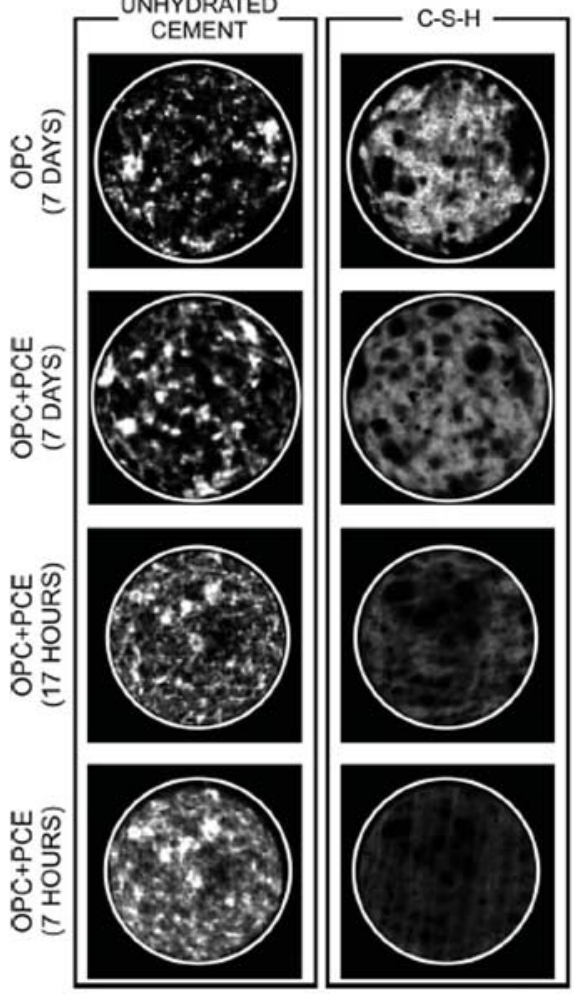

UNHYDRATED
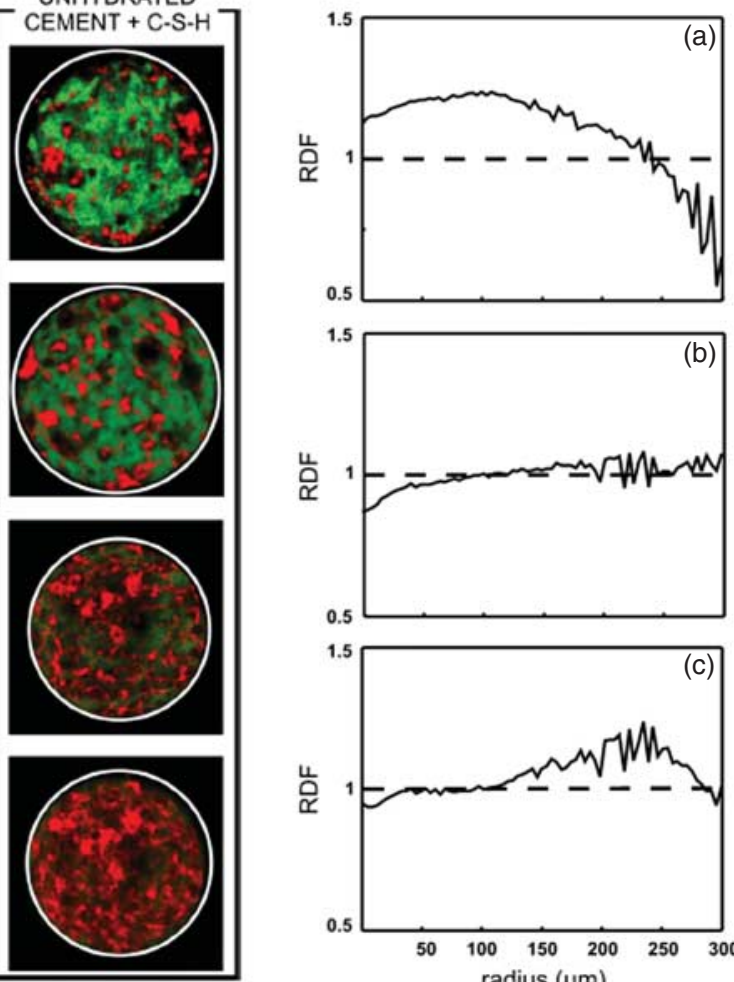
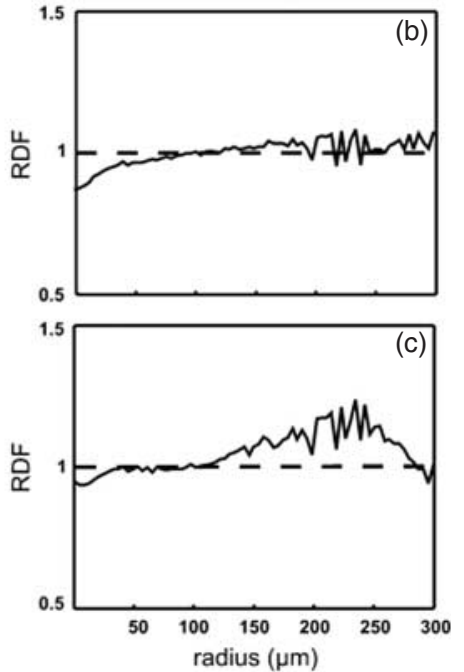

Figure 21. Scanning diffraction X-ray micro-tomography results. (Left) Phase maps displaying the space distribution of the unhydrated cement particles (red), $\mathrm{C}-\mathrm{S}-\mathrm{H}$ (green) and the combination of the two within a virtual slice through an OPC paste sample hydrating in water and in the presence of a PCE superplasticizer. The colour intensity is proportional to the volume fraction of the given phases in each voxel. The white circle represents the enclosing glass capillary (internal diameter $400 \mu \mathrm{m}$ ). (Right) Radial distribution functions relative to the spatial distribution of $\mathrm{C}-\mathrm{S}-\mathrm{H}$ with respect to the position of the unhydrated particle surfaces, as calculated for: (a) the phase maps of the OPC sample without PCE, at 7 days of hydration; (b) the phase maps of the OPC sample with PCE, at 7 days of hydration; (c) the difference phase map of the OPC sample with PCE at shorter times $(7-17 \mathrm{~h})$. Reprinted with permission from reference 156. Copyright $\{2015\}$ American Chemical Society.

to the change of the degree of crystal ordering, which could occur through ion transfer during hydration. The observed strain, coming from interfacial mismatch effect between high Bragg density and low Bragg density parts in the crystal, remained throughout the experiment. The first Bragg density change during hydration process was due to a big loss of Bragg density and was seen as removal of density, but not phase. The work provided new evidence supporting the through-solution reaction mechanism of calcium monoaluminate.

\subsubsection{Hard X-ray ptychographic forward coherent diffraction nano-tomography PFCDI-} $\mathrm{nCT}$ is a non-invasive imaging technique based on the (partly) coherent properties of synchrotron radiation and it allows the three-dimensional mapping of the electron density in the studied sample. This variant of CDI does not require crystalline ordering and its quantitativeness combined with a resolution close to $100 \mathrm{~nm}$ (for a field of view of about $60-100 \mu \mathrm{m}$ ) makes it very appropriate for studying the hierarchical microstructures in complex materials including cement pastes. The term 'ptychography' stems from the Greek word for a fold, related to the Latin origin of the term convolution. Instead of fully illuminating a small sample with a featureless plane wave, 


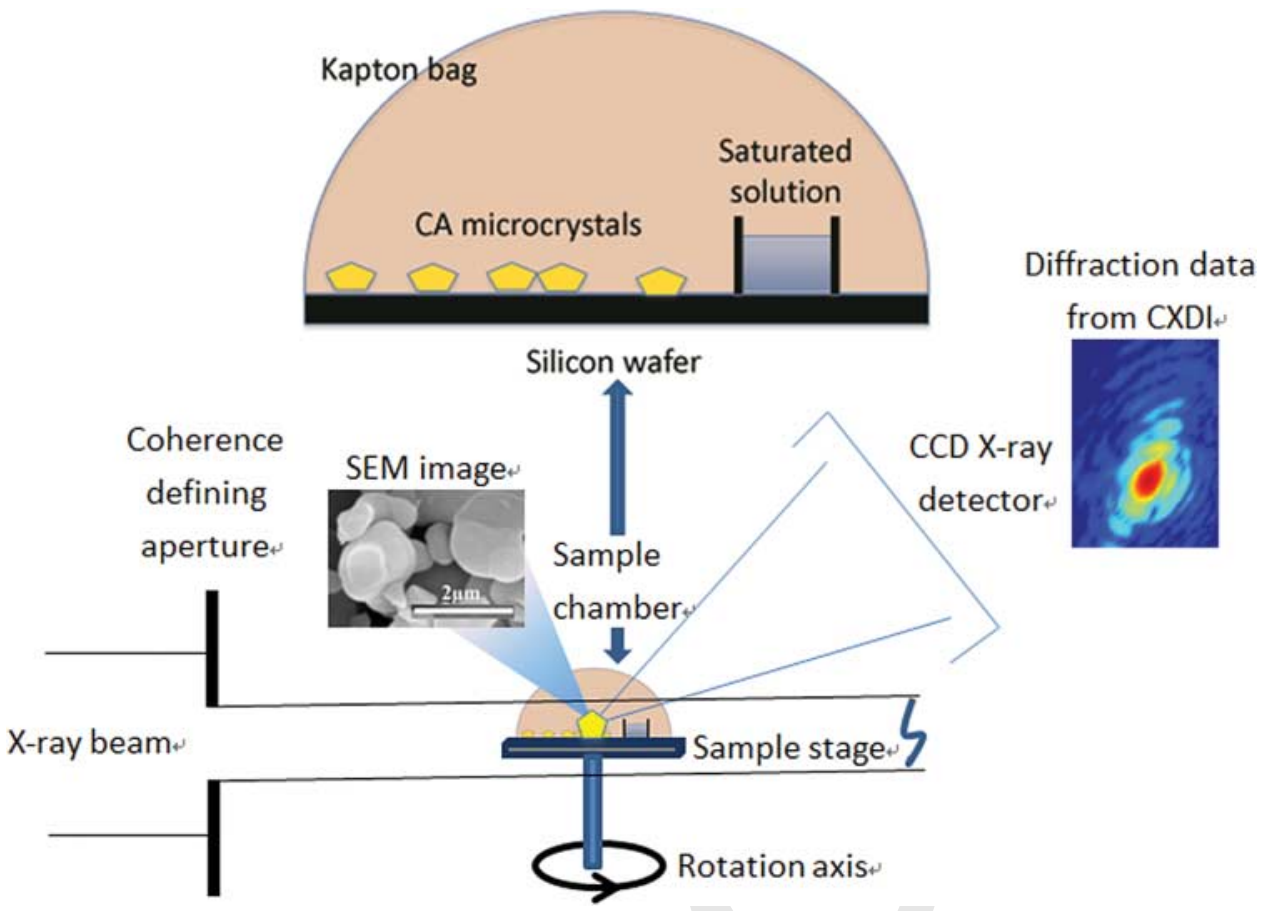

Figure 22. Schematic representation of the experimental set-up for hard X-ray Bragg coherent diffraction nano-tomography. Reprinted with permission from reference 157. Copyright $\{2015\}$ American Chemical Society.

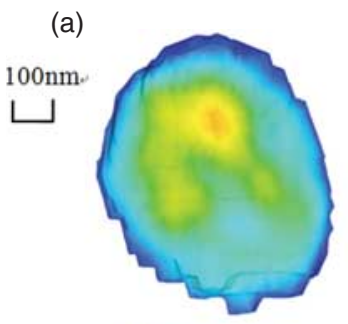

(c)

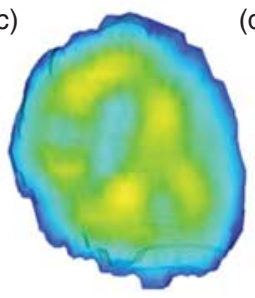

(d)

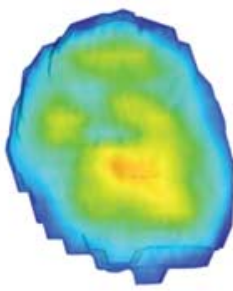

(b)

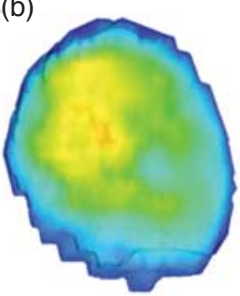

(e)

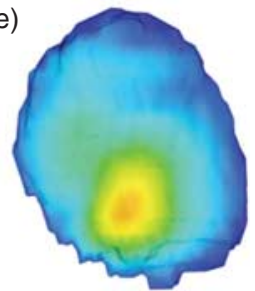

\section{Bragg Diffraction Electron Density}

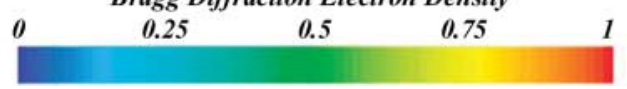

Figure 23. Cross-sections through the reconstructed 3D images of the CA crystal showing the internal Bragg density variations during 3 days of hydration measured by BCDI. (a) unhydrated CA. (b) $\mathrm{CA}$ hydrated for $2 \mathrm{~h}$. (c) CA hydrated for $24 \mathrm{~h}$. (d) CA hydrated for $52 \mathrm{~h}$. (e) CA hydrated for $67 \mathrm{~h}$. Reprinted with permission from reference 157. Copyright $\{2015\}$ American Chemical Society. 
1801

1802

1803

1804

1805

1806

1807

1808

1809

1810

1811

1812

1813

1814

1815

1816

1817

1818

1819

1820

1821

1822

1823

1824

1825

1826

1827

1828

1829

1830

1831

1832

1833

1834

1835

1836

1837

1838

1839

1840

1841

1842

1843

1844

1845

1846

1847

1848

1849

1850 (a)

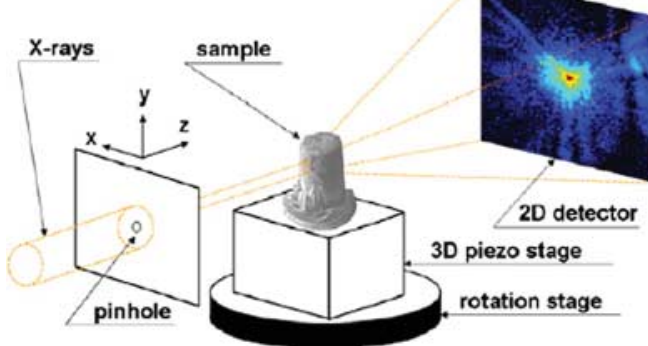

(b)

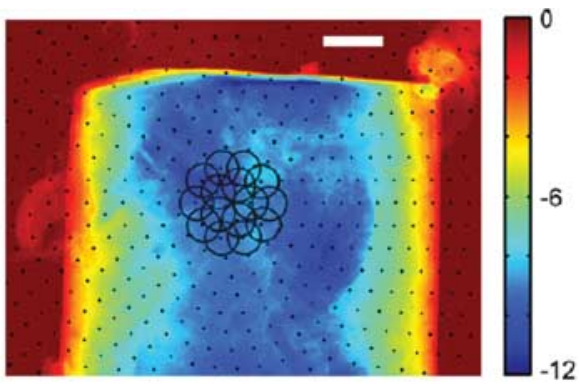

Figure 24. (a) Schematic representation of the experimental set-up for hard X-ray ptychographic forward coherent nano-tomography. At each incidence angle, coherent diffraction patterns are recorded by a pixelated detector for a number of overlapping scanning positions, which allows the projected complex-valued transmission function to be reconstructed. (b) Example of a single reconstructed phase projection of the epoxy resin impregnated hardened cement paste sample. The black dots indicate the scanning positions at which diffraction patterns were recorded, and the black circles represent the approximate shape of the beam - shown for the first two shells of the circular scan only. The scale bar corresponds to $5 \mu \mathrm{m}$. Reprinted from reference 158 with permission from Elsevier.

it used a small X-ray beam to raster scan an extended sample. The deconvolution of the effects Q10 due to the sample from those due to the structured illumination can be ensured if the sample is scanned in sufficiently fine, overlapping steps (see Figure 24). Ptychography became practical only by combining it with iterative phase retrieval algorithms which reduced the sampling requirements drastically.

PFCDI-nCT was applied to image hydrating cement pastes.[160] Figure 24 illustrates the experimental set-up (a) as well as the result (b) for imaging a sample of resin-impregnated, hardened cement paste. The data from multiple known scan positions are inverted to yield a 2D image, whose resolution is limited by the maximum scattering angle where there is signal and by the positioning accuracy of the sample. When combined with a rotation stage/strategy, a 3D tomographic image can be obtained. Furthermore, the high accuracy in measuring the electron density allows accurate segmentation of the data. In a very recent work,[161] PFCDI-nCT has been applied to the microstructural characterization of $\mathrm{C}-\mathrm{S}-\mathrm{H}$ formed by hydrating $\mathrm{C}_{3} \mathrm{~S}$. The 3D spatial resolution of the phase contrast images was close to $130 \mathrm{~nm}$, whereas the resolution of the absorption images was poorer, $\approx 250 \mathrm{~nm}$ (see Figure 25). It has been observed that the $\mathrm{C}-\mathrm{S}-\mathrm{H}$ density can depend on the particles' states of hydration. For fully hydrated particles, the estimated density of the outer-product $\mathrm{C}-\mathrm{S}-\mathrm{H}$ was larger than that of the inner-product $\mathrm{C}-\mathrm{S}-\mathrm{H}$, whereas for the partially hydrated particles, the densities of the apparent outer and the inner products were very similar. The density values of $\mathrm{C}-\mathrm{S}-\mathrm{H}$ ranged from $1.72 \mathrm{gcm}^{-3}$ to $1.96 \mathrm{gcm}^{-3}$, and its water content ranges from 4.3 to $7.6 \mathrm{~mol}$, assuming a fixed $\mathrm{C} / \mathrm{S}$ molar ratio of 1.75 .

\section{Outlook}

It is difficult to forecast the main research lines in cements using synchrotron tools as these evolve quite rapidly. In any case, there are challenges in the chemistry of cements where developments in the synchrotron characterization techniques may play a leading role. I highlight my shortlist below:

1. Most cement binders are based on amorphous gels or they contain large contents of amorphous materials. We all know that the characterization of amorphous materials is always complicated due to the lack of long-range order and periodicity, and also because of their 
1851

1852

1853

1854

1855

1856

1857

1858

1859

1860

1861

1862

1863

1864

1865

1866

1867

1868

1869

1870

1871

1872

1873

1874

1875

1876

1877

1878

1879

1880

1881

1882

1883

1884

1885

1886

1887

1888

1889

1890

1891

1892

1893

1894

1895

1896

1897

1898

1899

1900 (a)

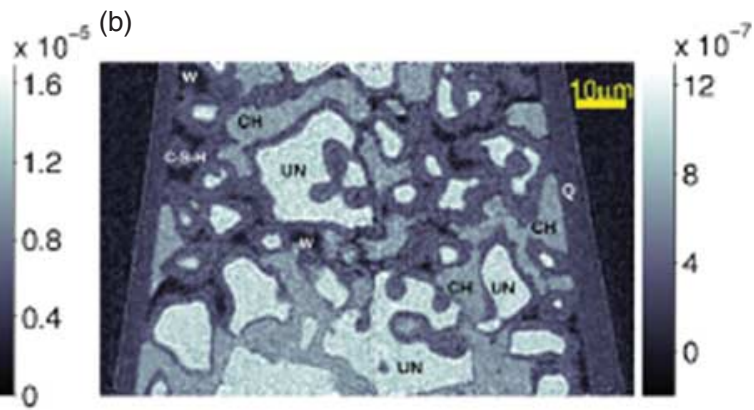

(c)

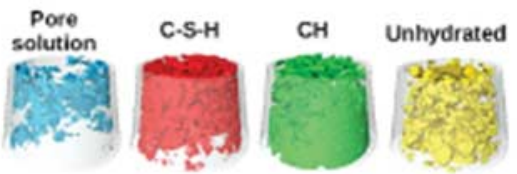

(d)

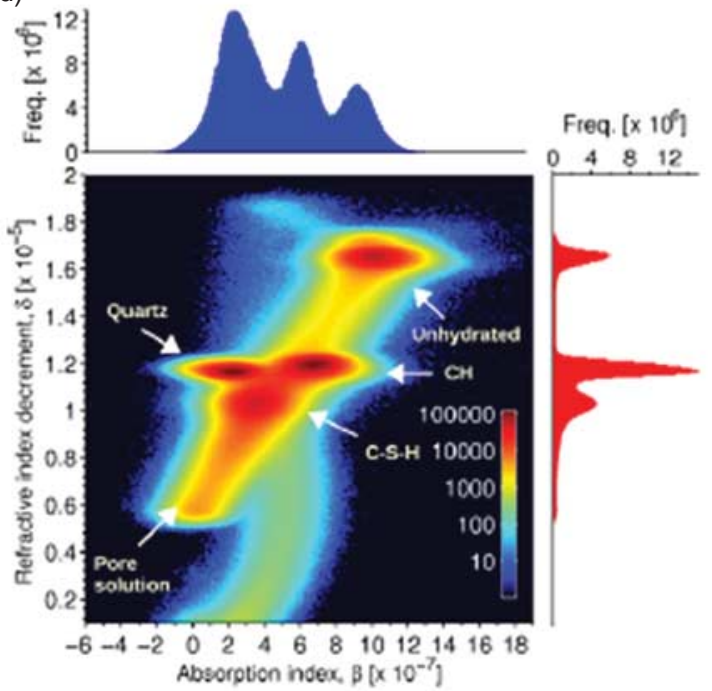

(e)

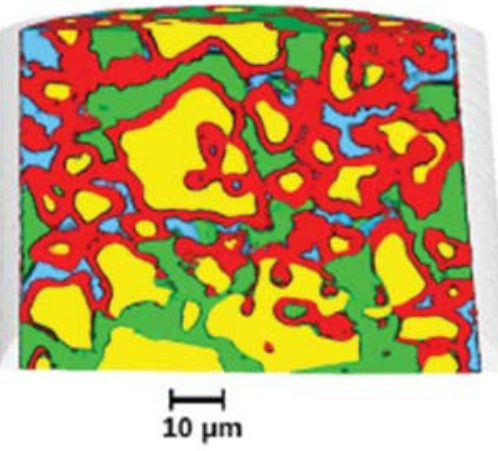

$(\mathrm{f})$
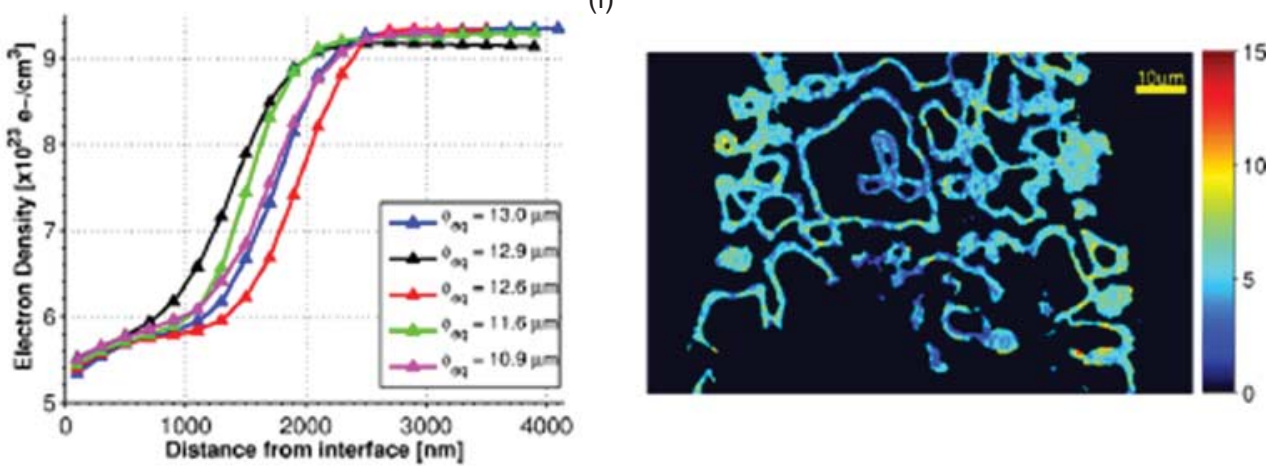

Figure 25. Vertical slices of the (a) phase-contrast and (b) absorption-contrast nano-tomograms of the hydrated cement paste, $\mathrm{UN}$ : Unhydrated $\mathrm{C}_{3} \mathrm{~S}, \mathrm{CH}, \mathrm{C}-\mathrm{S}-\mathrm{H}, \mathrm{Q}$ (quartz capillary) and $\mathrm{W}$ (pore solution). (c) 3D renderings of the volume showing how the phases are located with respect to each other. (d) Bivariate histogram of absorption and phase. (e) Radial electron density profile of the particles as a function of distance from surface inward. The effective particle diameters are shown in the legend. (f) Site-specific water content of the $\mathrm{C}-\mathrm{S}-\mathrm{H}$ at the same slice shown in (a) and (b) with a resolution of $1 \mu \mathrm{m}$, where the colorbar is given in units of mol of water. Reprinted from reference 159 which is an open access article published under a Creative Commons Non-Commercial No Derivative Works (CC-BY-NC-ND) Attribution License. 
large chemical variability. Advances in synchrotron tools will tackle these issues starting with the determination of chemical compositions and density values of these gels with very high spatial resolution by further development of the appropriate (combination) of imaging techniques.

2. The microstructure quantitative study of cement pastes is very important to understand and predict their mechanical behaviour as well as chemical durability. In this arena, synchrotron tools are very well suited as they do not require special sample preparation or sample environments that alter the microstructures. Here the challenge is to continue developing the imaging techniques, and the sample preparation procedures, for entry into the resolution range lower than $100 \mathrm{~nm}$. A very good resolution, well below 100nm, without a trade-off of field-of-view is important to properly characterize key pore microstructure details: connectivity and tortuosity. It will be also important to quantify the changes in the microstructure provoked by the uses of SCM which can vary quite a lot (fly ashes, slags, partially burned clays, etc.). For this type of application, one of the techniques with the brightest future, in my opinion, is hard X-ray ptychographic forward coherent diffraction nano-tomography.

3. Most crystalline materials in cement chemistry have known crystal structures. However, some hydrates have still unknown crystal structures. For instance, $\mathrm{C}_{2} \mathrm{AH}_{8}$ has been known for more than a century and its crystal structure is still not reported although it is known that it belongs to the AFm type structure. This is due to the combination of its chemical instability (it loses water very easily) with the lack of single crystals and that it is so far crystallized with additional coexisting phases. Here, microcrystal structure determination tools could be key to determine the crystal structure of this type of compounds from powder with grains smaller than $5 \mu \mathrm{m}$ but using single-crystal-like techniques.

4. The footprint of cement production is high and should be reduced, but retaining the life standards. Therefore the development of eco-cements is important to decrease anthropogenic $\mathrm{CO}_{2}$ emissions but maintaining the quality of our buildings and constructions. This can be tackled in a number of ways including the partial replacement of OPC by SCM but also by developing new binders, not based in OPC, like alkaline-activated materials and sulphobelite cements. In this direction, synchrotron techniques are being used, and will be used more intensively in the future, to shorten the time between chemistry formulation developments and their market appearances. This usage is very important as durability of new binder must be ensured and to do this, the understanding and quantification of their microstructures are vital.

5. Finally, it is worth mentioning that under-construction and planned diffraction-limited storage rings (fourth-generation synchrotron sources) will produce smaller beams with higher flux/brilliance of much higher coherence. These properties will directly impact the points described above and several others. The interested reader is directed to the special issue of Journal of Synchrotron Radiation published in September of 2014 which was fully devoted to the technical developments and science to be carried out in these last-generation synchrotrons.

\section{Acknowledgments}

I am grateful to all my coauthors, collaborators, colleagues and PhD students, for all our work together during more than two decades. I thank the University of Malaga and ALBA Synchrotron Light Source for the support and the stirring environments. I acknowledge the Spanish science funding agencies (they change the name quite often) for funding my studentship, to do the $\mathrm{PhD}$ and the three summer research stays at Oxford University, to the last ongoing research project. To all synchrotrons I have been allowed to enjoy carrying out experiments: SRS, ESRF, Max-Lab, DLS, APS, SLS and ALBA. Finally, this work has been supported by the Spanish MINECO through the BIA2014-57658-C2-1-R research grant. 


\section{Disclosure statement}

No potential conflict of interest was reported by the author.

\section{Notes on contributor}

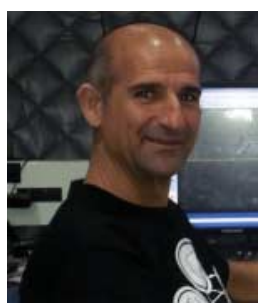

Miguel A. G. Aranda received his Ph.D. from the University of Malaga (Spain) in 1992 in the field of Rietveld analysis for structure determination. During his $\mathrm{Ph} . \mathrm{D}$. he carried out three summer research stays at Chemical Crystallography Laboratory (University of Oxford). He carried out his postdoctoral training at the University of Cambridge with Paul Attfield to work on the crystal structure of $\mathrm{Cu}$ based high-Tc superconductors using synchrotron and neutron powder diffraction. He came back in 1994 as Assistant Professor to the University of Malaga where he also was Associate Professor and Professor. In January 2013, he moved to ALBA Synchrotron Light Source as Scientific Director. He has research experience in cements and building materials but also in other fields like: ceramics, pigments, cultural heritage and archaeometry as well as strongly electron-correlated transition-metal oxides, solid-oxide fuel cells and metal-organic-framework materials. His hobbies include walking in the hills, snorkelling, travelling and enjoying good wine and food.

\section{References}

[1] Mehta PK, Monteiro PJM. Concrete: microstructure, properties, and materials. New York: McGrawHill; 2013.

[2] Damtoft JS, Lukasik J, Herfort D, Sorrentino D, Gartner EM. Sustainable development and climate change initiatives. Cem. Concr. Res. 2008;38:115-127.

[3] U.S.: geological survey, mineral commodity summaries, January; 2009.

[4] Taylor HFW. Cement chemistry. London: Academic Press; 1990.

[5] Matschei T, Lothenbach B, Glasser FP. The AFm phase in Portland cement. Cem Concr Res. 2007;37:118-130.

[6] Balonis M, Glasser FP. The density of cement phases. Cem Concr Res. 2009;39:733-739.

[7] Richardson IG. Model structures for C-(A)-S-H(I). Acta Cryst. 2014;B70:903-923.

[8] Willmott P. An introduction to synchrotron radiation. Techniques and applications. Chichester: John Wiley \& Son; 2011.

[9] Mobilio S, Boscherini F, Meneghini, C, editors. Synchrotron radiation basics, methods and applications. Berlin: Springer; 2015.

[10] Schlachter AS, Robinson AH, Bienenstock A, Mills D, Shenoy G, Winick H. Synchrotron radiation. In: AccessScience. McGraw-Hill Education; 2014. Available from:http://www.accessscience.com/ content/synchrotron-radiation/675200

[11] Bertrand L, Robinet L, Thoury M, Janssens K, Cohen SX, Schöder S. Cultural heritage and archaeology materials studied by synchrotron spectroscopy and imaging. Cem Concr Comp. 2012;106:377-396.

[12] Bertrand L, Cotte M, Stampanoni M, Thoury M, Marone F, Schöder S. Development and trends in synchrotron studies of ancient and historical materials. Phys Rep. 2012;519:51-96.

[13] Helliwell JR. The evolution of synchrotron radiation and the growth of its importance in crystallography. Cryst Rev. 2012;18:33-93.

[14] Patterson BD. Crystallography using an X-ray free-electron laser. Cryst Rev. 2014;20:242-294.

[15] Monteiro PJM, Kirchheim AP, Chae S, et al. Characterizing the nano and micro structure of concrete to improve its durability. Cem Concr Comp. 2009;31:577-584.

[16] Chae SR, Moon J, Yoon S, et al. Advanced nanoscale characterization of cement based materials using X-Ray synchrotron radiation: a review. Int J Concr Struct Mater. 2013;7:95-110.

[17] Provis JL, Hajimohammadi A, White CE, et al. Nanostructural characterization of geopolymers by advanced beamline techniques. Cem Concr Comp. 2013;36:56-64.

[18] Holt M, Harder R, Winarski R, Rose V. Nanoscale hard X-ray microscopy methods for materials studies. Annu Rev Mater Res. 2013;43:183-211.

[19] De la Torre AG, Bruque S, Campo J, Aranda MAG. The superstructure of C3S from synchrotron and neutron powder diffraction and its role in quantitative phase analyses. Cem Concr Res. 2002;32:1347-1356. 
2001

2002

2003

2004

2005

2006

2007

2008

2009

2010

2011

2012

2013

2014

2015

2016

2017

2018

2019

2020

2021

2022

2023

2024

2025

2026

2027

2028

2029

2030

2031

2032

2033

2034

2035

2036

2037

2038

2039

2040

2041

2042

2043

2044

2045

2046

2047

2048

2049

2050

[20] Petterson VK, Hunter BA, Ray A. Tricalcium Silicate $T_{1}$ and $T_{2}$ polymorphic investigations: rietveld refinement at various temperatures using synchrotron powder diffraction. J Am Ceram Soc. 2004;87:1625-1634.

[21] Petterson VK. A Rietveld refinement investigation of a Mg-stabilized triclinic tricalcium silicate using synchrotron X-ray powder diffraction data. Powder Diff. 2004;19:356-358.

[22] De la Torre AG, Lopez-Olmo MG, Alvarez-Rua C, Garcia-Granda S, Aranda MAG. Structure and microstructure of gypsum and its relevance to Rietveld quantitative phase analyses. Powder Diff. 2004;19:240-246.

[23] Garver K, Beuchle G, Bornefeld M, Black L, Stemmermann P. Cell dimensions and composition of nanocrystalline calcium silicate hydrate solid solutions. part 1: synchrotron-based X-ray diffraction. J Am Ceram Soc. 2008;91:3005-3014.

[24] Battocchio F, Monteiro PJM, Wenk HR. Rietveld refinement of the structures of 1.0 C-S-H and 1.5 C-S-H. Cem Concr Res. 2012;42:1534-1548.

[25] Renaudin G, Filinchuk Y, Neubauer J, Goetz-Neunhoeffer F. A comparative structural study of wet and dried ettringite. Cem Concr Res. 2010;40:370-375.

[26] Dilnesa BZ, Lothenbach B, Renaudin G, Wichser A, Kulik D. Synthesis and characterization of hydrogarnet $\mathrm{Ca}_{3}\left(\mathrm{Al}_{\mathrm{x}} \mathrm{Fe}_{1-\mathrm{x}}\right)_{2}\left(\mathrm{SiO}_{4}\right)_{\mathrm{y}}(\mathrm{OH})_{4(3-\mathrm{y})}$. Cem Concr Res. 2014;59:96-111.

[27] Cuesta A, De La Torre AG, Losilla ER, Santacruz I, Aranda MAG. Pseudocubic crystal structure and phase transition in doped Ye'elimite. Cryst Growth Des. 2014;14:5158-5163.

[28] Dilnesa BZ, Lothenbach B, Le Saout Get al. Iron in carbonate containing AFm phases. Cem Concr Res. 2011;41:311-323.

[29] Runcevski T, Dinnebier RE, Magdysyuk OV, Pollmann H. Crystal structures of calcium hemicarboaluminate and carbonated calcium hemicarboaluminate from synchrotron powder diffraction data. Acta Cryst. 2012;B68:493-500.

[30] Mesbah A, Francois M, Cau-dit-Coumes Cet al. Crystal structure of Kuzel's salt $3 \mathrm{CaO} \cdot \mathrm{Al}_{2} \mathrm{O}_{3}$. $\$ 1 / 2 \mathrm{CaSO}_{4} \cdot 1 / 2 \mathrm{CaCl}_{2} \cdot 11 \mathrm{H}_{2} \mathrm{O}$ determined by synchrotron powder diffraction. Cem Concr Res. 2011;41:504-509.

[31] Meral C, Benmore CJ, Monteiro PJM. The study of disorder and nanocrystallinity in C-S-H, supplementary cementitious materials and geopolymers using pair distribution function analysis. Cem Concr Res. 2011;41:696-710.

[32] Skinner LB, Chae SR, Benmore CJ, Wenk HR, Monteiro PJM. Nanostructure of calcium silicate hydrates in cements. Phys Rev Lett. 2010;104:195502.

[33] Soyer-Uzun S, Chae SR, Benmore CJ, Wenk HR, Monteiro PJM. Compositional evolution of calcium silicate hydrate (C-S-H) structures by total X-ray scattering. J Am Ceram Soc. 2012;95:793798.

[34] Benmore CJ, Monteiro PJM. The structure of alkali silicate gel by total scattering methods. Cem Concr Res. 2010;40:892-897.

[35] Mei Q, Benmore CJ, Sharma R, Yarger JL. Intermediate range order in vitreous silica from a partial structure factor analysis. Physical Review B. 2008;78:1-7.

[36] Bell JL, Sarin P, Driemeyer PE, Haggerty RP, Chupas PJ, Kriven WM. X-ray pair distribution function analysis of a metakaolin-based, $\mathrm{KAlSi}_{2} \mathrm{O}_{6} \cdot 5.5 \mathrm{H}_{2} \mathrm{O}$ inorganic polymer (geopolymer). J Mat Chem. 2008;18:5974-5981.

[37] White CE, Page K, Henson NJ, Provis JL. In situ synchrotron X-ray pair distribution function analysis of the early stages of gel formation in metakaolin-based geopolymers. Appl Clay Sci. 2013;73:17-25.

[38] Bell JL, Sarin P, Provis JL, et al. Atomic structure of a cesium aluminosilicate geopolymer: a pair distribution function study. Chem Mat. 2008;20:4768-4776.

[39] White CE, Provis JL, Bloomer B, Henson NJ, Page K. In situ X-ray pair distribution function analysis of geopolymer gel nanostructure formation kinetics. Phys Chem Chem Phys. 2013;15:8573-8582.

[40] White CE, Daemen LL, Hartl M, Page K. Intrinsic differences in atomic ordering of calcium (alumino)silicate hydrates in conventional and alkali-activated cements. Cem Concr Res. 2015;67:66-73.

[41] Dilnesa BZ, Wieland E, Lothenbach B, Dahn R, Scrivener KL. Fe-containing phases in hydrated cements. Cem Concr Res. 2014;58:45-55.

[42] Vespa M, Wieland E, Dahn R, Lothenbach B. Identification of the thermodynamically stable Fecontaining phase in aged cement pastes. J Am Ceram Soc. 2015;98. online. doi:10.1111/jace.13542

[43] Mendes A, Gates WP, Sanjayan JG, Collins F. NMR, XRD, IR and synchrotron NEXAFS spectroscopic studies of OPC and OPC/slag cement paste hydrates. Mater Struct. 2011;44:1773-1791.

[44] Grangeon S, Claret F, Lerouge C, et al. On the nature of structural disorder in calcium silicate hydrates with a calcium/silicon ratio similar to tobermorite. Cem Concr Res. 2013;52:31-37.

[45] Poo-arporn Y, Thachepan S, Palangsuntikul R. Investigation of damaged interior walls using synchrotron-based XPS and XANES. J Synchr Rad. 2015;22:86-90. 
[46] Le Saout G, Kocaba V, Scrivener K. Application of the Rietveld method to the analysis of anhydrous cements. Cem Concr Res. 2011;41:133-148.

[47] Aranda MAG, De La Torre AG, Leon-Reina L. Rietveld quantitative phase analysis of OPC clinkers, cements and hydration products. Rev Miner Geochem. 2012;74:169-209.

[48] Aranda MAG, De La Torre AG, Leon-Reina L. Powder diffraction characterization of cements. In: Gilmore C, Kaduk J, Schenk H. International tables for crystallography. Volume $\mathrm{H}$ - powder diffraction. 2016. (in the press). ISBN: 9781118416280

[49] Taylor JC, Aldridge LP. Full-profile Rietveld quantitative XRD analysis of Portland cement: standard XRD profiles for the major phase tricalcium silicate $\left(\mathrm{C}_{3} \mathrm{~S}: 3 \mathrm{CaO} \cdot \mathrm{SiO}_{2}\right)$. Powder Diffr. 1993;8:138144.

[50] De la Torre AG, Cabeza A, Calvente A, Bruque S, Aranda MAG. Full phase analysis of Portland clinker by penetrating synchrotron powder diffraction. Anal Chem. 2001;73:151-156.

[51] De la Torre AG, Aranda MAG. Accuracy in Rietveld quantitative phase analysis of Portland cements. J Appl Cryst. 2003;36:1169-1176.

[52] De la Torre AG, De Vera RN, Cuberos AJM, Aranda MAG. Crystal structure of low magnesiumcontent alite: application to Rietveld quantitative phase analysis. Cem Concr Res. 2008;38:12611269.

[53] Petersson VK, Ray AS, Hunter BA. A comparative study of Rietveld phase analysis of cement clinker using neutron, laboratory X-ray, and synchrotron data. Powder Diffr. 2006;21:12-18.

[54] De la Torre AG, Losilla ER, Cabeza A, Aranda MAG. High-resolution synchrotron powder diffraction analysis of ordinary Portland cements: phase coexistence of alite. Nucl Instr Meth Phys Res B. 2005;238:87-91.

[55] De la Torre AG, Cabeza A, Losilla ER, Aranda MAG. Quantitative phase analysis of ordinary Portland cements using synchrotron radiation powder diffraction. Z Kristallogr Suppl. 2006;23: $587-592$.

[56] Guirado F, Galí, S. Quantitative Rietveld analysis of CAC clinker phases using synchrotron radiation. Cem Concr Res. 2006;36:2021-2032.

[57] Morsli K, De la Torre AG, Zahir M, Aranda MAG. Mineralogical phase analysis of alkali and sulfate bearing belite rich laboratory clinkers. Cem Concr Res. 2007;37:639-646.

[58] Schlegel MC, Sarfraz A, Muller A, Panne U, Emmerling F. First seconds in a building's life- in situ synchrotron X-ray diffraction study of cement hydration on the millisecond timescale. Angew Chem Int Ed. 2012;51:4993-4996.

[59] Christensen AN, Jensen TR, Scarlett NVY, Madsen IC, Hanson JC. Hydrolysis of pure and sodium substituted calcium aluminates and cement clinker components investigated by in situ synchrotron X-ray powder diffraction. J Am Ceram Soc. 2004;87:1488-1493.

[60] Meller N, Hall C, Jupe AC, et al. The paste hydration of brownmillerite with and without gypsum: a time resolved synchrotron diffraction study at $30,70,100$ and $150^{\circ} \mathrm{C}$. J Mater Chem. 2004;14:428435.

[61] Merlini M, Artioli G, Cerulli T, Cella F, Bravo A. Tricalcium aluminate hydration in additivated systems. A crystallographic study by SR-XRPD. Cem. Concr. Res. 2008;38:477-486.

[62] Cuesta A, Alvarez-Pinazo G, Sanfélix I, et al. Hydration mechanisms of two polymorphs of synthetic ye'elimite. Cem Concr Res. 2014;63:127-136.

[63] Cuesta A, Santacruz I, Sanfelix SG, Fauth F, Aranda MAG, De La Torre AG. Hydration of C4AF in the presence of other phases: a synchrotron X-ray powder diffraction study. Const Build Mater. 2015 (submitted)

[64] Williams PJ, Biernacki JJ, Bai J, Rawn CJ. Assessment of a synchrotron X-ray method for quantitative analysis of calcium hydroxide. Cem Concr Res. 2003;33:1553-1559.

[65] Gualtieri ML, Romagnoli M, Miselli P, Cannio M, Gualtieri AF. Full quantitative phase analysis of hydrated lime using the Rietveld method. Cem Concr Res. 2012;42:1273-1279.

[66] Weyer HJ, Muller I, Schmitt B, Bosbach D, Putnis A. Time-resolved monitoring of cement hydration: influence of cellulose ethers on hydration kinetics. Nucl Instr and Meth in Phys Res B. 2005;238:102-106.

[67] Merlini M, Artioli G, Meneghini C, Cerulli T, Bravo A, Cella F. The early hydration and the set of Portland cements: in situ X-ray powder diffraction studies. Powder Diff. 2007;22:201-208.

[68] Cuberos AJM, De la Torre AG, Martín-Sedeño MC, et al. Phase development in conventional and active belite cement pastes by Rietveld analysis and chemical constraints. Cem Concr Res. 2009;39:833-842.

[69] Martín-Sedeño MC, Cuberos AJM, De la Torre AG, et al. Aluminum-rich belite sulfoaluminate cements: clinkering and early age hydration. Cem Concr Res. 2010;40:359-369. 
2101

2102

2103

2104

2105

2106

2107

2108

2109

2110

2111

2112

2113

2114

2115

2116

2117

2118

2119

2120

2121

2122

2123

2124

2125

2126

2127

2128

2129

2130

2131

2132

2133

2134

2135

2136

2137

2138

2139

2140

2141

2142

2143

2144

2145

2146

2147

2148

2149

2150

[70] Cuberos AJM, De la Torre AG, Alvarez-Pinazo G, et al. Active iron-rich belite sulfoaluminate cements: clinkering and hydration. Cem Concr Res. 2010;40:359-369.

[71] Alvarez-Pinazo G, Cuesta A, Garcia-Mate M, et al. In-situ early-age hydration study of sulfobelite cements by synchrotron powder diffraction. Cem Concr Res. 2014;56:12-19.

[72] Marinoni N, Pavese A, Voltolini M, Merlini M. Long-term leaching test in concretes: an X-ray powder diffraction study. Cem Concr Comp. 2008;30:700-705.

[73] Snellings R, Mertens G, Cizer O, Elsen J. Early age hydration and pozzolanic reaction in natural zeolite blended cements: reaction kinetics and products by in situ synchrotron X-ray powder diffraction. Cem Concr Res. 2010;40:1704-1713.

[74] Snellings R, Mertens G, Adriaens R, Elsen J. In situ synchrotron X-ray powder diffraction study of the early age hydration of cements blended with zeolitite and quartzite fines and water-reducing agent. Applied Clay Science. 2013;72:124-131.

[75] Oh JE, Moon J, Oh SG, Clark SM, Monteiro PJM. Microstructural and compositional change of $\mathrm{NaOH}$-activated high calcium fly ash by incorporating Na-aluminate and co-existence of geopolymeric gel and C-S-H(I). Cem Concr Res. 2012;42:673-685.

[76] Moon J, Bae S, Celik K, et al. Characterization of natural pozzolan-based geopolymeric binders. Cem Concr Comp. 2014;53:97-104.

[77] Christensen AN, Olesen M, Cerenius Y, Jensen TJ. Formation and transformation of five different phases in the $\mathrm{CaSO}_{4}-\mathrm{H}_{2} \mathrm{O}$ system: crystal structure of the subhydrate $\ddot{\mathrm{A}} \mathrm{A} c \mathrm{c}-\mathrm{CaSO}_{4} \cdot 0.5 \mathrm{H}_{2} \mathrm{O}$ and soluble anhydrite $\mathrm{CaSO}_{4}$. Chem Mater. 2008;20:2124-2132.

[78] Meller N, Kyritsis K, Hall C. The hydrothermal decomposition of calcium monosulfoaluminate 14hydrate to katoite hydrogarnet and ïAć-anhydrite: an in-situ synchrotron X-ray diffraction study. J Solid State Chem. 2009;182:2743-2747.

[79] Runcevski T, Dinnebier RE, Freyer D. Dehydration of the sorel cement phase $3 \mathrm{Mg}(\mathrm{OH}) 2 \cdot \mathrm{MgCl} 2$. $8 \mathrm{H} 2 \mathrm{O}$ studied by in situ Synchrotron X-ray powder diffraction and thermal analyses. Z Anorg Allg Chem. 2014;640:100-105.

[80] Gualtieri AF, Gualtieri ML, Meneghini C. In situ high-temperature synchrotron powder diffraction study of the thermal decomposition of cement-asbestos. Powder Diff. 2008;23: 323-328.

[81] Gualtieri AF, Gualtieri ML, Meneghini C. In situ synchrotron powder diffraction study of the thermal decomposition of cement-asbestos: preliminary results. Z Kristallogr Suppl. 2009;30: 353-358.

[82] De la Torre AG, Morsli K, Zahir M, Aranda MAG. In situ synchrotron powder diffraction study of active belite clinkers. J Appl Cryst. 2007;40:999-1007.

[83] De la Torre AG, Cuberos AJM, Alvarez-Pinazo G, Cuesta A, Aranda MAG. In situ powder diffraction study of belite sulfoaluminate clinkering. J Synchr Rad. 2011;18:506-514.

[84] Christensen AN, Jensen TJ, Hanson JC. Formation of ettringite, $\mathrm{Ca}_{6} \mathrm{Al}_{2}\left(\mathrm{SO}_{4}\right)_{3}(\mathrm{OH})_{12} \cdot 26 \mathrm{H}_{2} \mathrm{O}, \mathrm{AFt}$, and monosulfate, $\mathrm{Ca}_{4} \mathrm{Al}_{2} \mathrm{O}_{6}\left(\mathrm{SO}_{4}\right) \cdot 14 \mathrm{H}_{2} \mathrm{O}, \mathrm{AFm}-14$, in hydrothermal hydration of Portland cement and of calcium aluminum oxide-calcium sulfate dihydrate mixtures studied by in situ synchrotron X-ray powder diffraction. J Solid State Chem. 2004;177:1944-1951.

[85] Jensen TJ, Christensen AN, Hanson JC. Hydrothermal transformation of the calcium aluminum oxide hydrates $\mathrm{CaAl}_{2} \mathrm{O}_{4} \cdot 10 \mathrm{H}_{2} \mathrm{O}$ and $\mathrm{Ca}_{2} \mathrm{Al}_{2} \mathrm{O}_{5} \cdot 8 \mathrm{H}_{2} \mathrm{O}$ to $\mathrm{Ca}_{3} \mathrm{Al}_{2}(\mathrm{OH})_{12}$ investigated by in situ synchrotron X-ray powder diffraction. Cem Concr Res. 2005;35:2300-2309.

[86] Kikuma J, Tsunashima M, Ishikawa T, et al. Hydrothermal formation of tobermorite studied by in situ X-ray diffraction under autoclave condition. J Synchr Rad. 2009;16:683-686.

[87] Kikuma J, Tsunashima M, Ishikawa T, et al. Effects of quartz particle size and water-to-solid ratio on hydrothermal synthesis of tobermorite studied by in-situ time-resolved X-ray diffraction. J Solid State Chem. 2011;184:2066-2074.

[88] Matsui K, Kikuma J, Tsunashima M, et al. In situ time-resolved X-ray diffraction of tobermorite formation in autoclaved aerated concrete: Influence of silica source reactivity and $\mathrm{Al}$ addition. Cem Concr Res. 2011;41:510-519.

[89] Kikuma J, Tsunashima M, Ishikawa T, Matsuno S, Ogawa A, Matsui K. Development of an in situ Xray diffraction system for hydrothermal reactions and its application to autoclaved aerated concrete formation. Powder Diff. 2011;26:126-128.

[90] Matsui K, Ogawa A, Kikuma J, Tsunashima M, Ishikawa T, Matsuno S. In situ time-resolved X-ray diffraction of tobermorite formation process under hydrothermal condition: influence of reactive Al compound. Powder Diff. 2011;26:134-137.

[91] Jupe AC, Wilkinson AP. Sample cell for powder x-ray diffraction at up to 500 bars and $200^{\circ} \mathrm{C}$. Rev. Sci. Instrum. 2006;77:113901-1-113901-4. 
[92] Jupe AC, Wilkinson AP, Luke K, Funkhouser GP. Slurry consistency and in situ synchrotron X-ray diffraction during the early hydration of portland cements with calcium chloride. J Am Ceram Soc. 2007;90:2595-2602.

[93] Jupe AC, Wilkinson AP, Luke K, Funkhouser GP. Class H cement hydration at $180^{\circ} \mathrm{C}$ and high pressure in the presence of added silica. Cem Concr Res. 2008;38:660-666.

[94] Jupe AC, Wilkinson AP, Luke K, Funkhouser GP. Oil-Well Cement and C3S hydration under high pressure as seen by in situ X-ray diffraction, temperatures $\leq 80^{\circ} \mathrm{C}$ with no additives. $\mathrm{J}$ Am Ceram Soc. 2011;94:1591-1597.

[95] Jupe AC, Wilkinson AP, Funkhouser GP. The effect of pressure on tricalcium silicate hydration at different temperatures and in the presence of retarding additives. Cem Concr Res. 2012;42:10831087.

[96] Jupe AC, Wilkinson AP, Funkhouser GP. Simultaneous study of mechanical property development and early hydration chemistry in Portland cement slurries using X-ray diffraction and ultrasound reflection. Cem Concr Res. 2012;42:1166-1173.

[97] Clark SM, Colas B, Kunz M, Speziale S, Monteiro PJM. Effect of pressure on the crystal structure of ettringite. Cem Concr Res. 2008;38:19-26.

[98] Oh JE, Clark SM, Monteiro PJM. Does the Al substitution in $\mathrm{C}-\mathrm{S}-\mathrm{H}(\mathrm{I})$ change its mechanical property? Cem Concr Res. 2011;41:102-106.

[99] Oh JE, Clark SM, Wenk HR, Monteiro PJM. Experimental determination of bulk modulus of $14 \AA$ A tobermorite using high pressure synchrotron X-ray diffraction. Cem Concr Res. 2012;42:397403.

[100] Moon J, Yoon S, Monteiro PJM. Mechanical properties of jennite: a theoretical and experimental study. Cem Concr Res. 2015;71:106-114.

[101] Jackson MD, Moon J, Gotti E, et al. Material and elastic properties of Al-Tobermorite in ancient roman seawater concrete. J Am Ceram Soc. 2013;96:2598-2606.

[102] Moon J, Oh JE, Balonis M, Glasser FP, Monteiro PJM. Pressure induced reactions amongst calcium aluminate hydrate phases. Cem Concr Res. 2011;41:571-578.

[103] Moon J, Oh JE, Balonis M, Glasser FP, Monteiro PJM. High pressure study of low compressibility tetracalcium aluminum carbonate hydrates $3 \mathrm{CaO} \cdot \mathrm{Al}_{2} \mathrm{O}_{3} \cdot \mathrm{CaCO}_{3} \cdot 11 \mathrm{H}_{2} \mathrm{O}$. Cem Concr Res. 2012;42:105-110.

[104] Moon J, Speziale S, Meral C, Kalkan B, Clark SM, Monteiro PJM. Determination of the elastic properties of amorphous materials: case study of alkali-silica reaction gel. Cem Concr Res. 2013;54:55-60.

[105] Moon J, Yoon S, Wentzcovitch RM, Clark SM, Monteiro PJM. Elastic properties of Tricalcium Aluminate from high-pressure experiments and first-principles calculations. J Am Ceram Soc. 2012;95:2972-2978.

[106] Hargis CW, Moon J, Lothenbach B, Winnefeld F, Wenk HR, Monteiro PJM. Calcium Sulfoaluminate Sodalite $\left(\mathrm{Ca}_{4} \mathrm{Al}_{6} \mathrm{O}_{12} \mathrm{SO}_{4}\right)$ crystal structure evaluation and bulk modulus determination. J Am Ceram Soc. 2014;97:892-898.

[107] Allen AJ, Thomas JJ. Analysis of C-S-H gel and cement paste by small-angle neutron scattering. Cem Concr Res. 2007;37:319-324.

[108] Glatter O, Kratky O, editors. Small-angle X-ray scattering. London: Academic Press; 1982.

[109] Allen AJ, Thomas JJ, Jennings HM. Composition and density of nanoscale calcium-silicate-hydrate in cement. Nature Mater. 2007;6:311-316.

[110] Yeqing S, Min D, Anqun L. Structural evolution of hydrated cement compacts. Materials and Structures. 2011;44:1735-1743.

[111] Chiang WS, Fratini E, Ridi F, et al. Microstructural changes of globules in calcium-silicate-hydrate gels with and without additives determined by small-angle neutron and X-ray scattering. J Colloid Interface Sci. 2013;398:67-73.

[112] Das A, Mazumder S, Sen D, et al. Small-angle neutron scattering as a probe to decide the maximum limit of chemical waste immobilization in a cement matrix. J Appl Cryst. 2014;47:421-429.

[113] Taylor R, Sakdinawat A, Chae SR, et al. Developments in TEM Nanotomography of Calcium Silicate Hydrate. J Am Ceram Soc. 2015;98. online. doi:10.1111/jace.13585

[114] Stampanoni M, Menzel A, Watts B, Mader KS, Bunk O. Coherent X-ray imaging: bridging the gap between atomic and micro-scale investigations. Chimia. 2014;68:66-72.

[115] Miao J, Ishikawa T, Robinson IK, Murnane MM. Beyond crystallography: diffractive imaging using coherent x-ray light sources. Science. 2015;348:530-535.

[116] Juenger MCG, Lamour VHR, Monteiro PJM, Gartner EM, Denbeaux GP. Direct observation of cement hydration by soft X-ray transmission microscopy. J Mater Sci Lett. 2003;22:13351337. 
2201 [117] Kirchheim AP, Dal Molin LC, Fischer P, Emwas AH, Provis JL, Monteiro PJM. Real-time high-

2202

2203

2204

2205

2206

2207

2208

2209

2210

2211

2212

2213

2214

2215

2216

2217

2218

2219

2220

2221

2222

2223

2224

2225

2226

2227

2228

2229

2230

2231

2232

2233

2234

2235

2236

2237

2238

2239

2240

2241

2242

2243

2244

2245

2246

2247

2248

2249

2250

resolution $\mathrm{X}$-ray imaging and nuclear magnetic resonance study of the hydration of pure and NaDoped $\mathrm{C}_{3} \mathrm{~A}$ in the presence of sulfates. Inorg Chem. 2011;50:1203-1212.

[118] Hargis CW, Kirchheim AP, Monteiro PJM, Gartner EM. Early age hydration of calcium sulfoaluminate (synthetic ye'elimite, $\mathrm{C}_{4} \mathrm{~A}_{3} \mathrm{~S}$ ) in the presence of gypsum and varying amounts of calcium hydroxide. Cem Concr Res. 2013;48:105-115.

[119] Brisard S, Chae RS, Bihannic I, et al. Morphological quantification of hierarchical geomaterials by X-ray nano-CT bridges the gap from nano to micro length scales. Am Min. 2012;97:480-483.

[120] Gallucci E., Scrivener K, Groso A, Stampanoni M, Margaritondo G. 3D experimental investigation of the microstructure of cement pastes using synchrotron X-ray microtomography $(\mu \mathrm{CT})$. Cem Concr Res. 2007;37:360-368.

[121] Promentilla MAB, Sugiyama T, Hitomi T, Takeda N. Characterizing the 3D pore structure of hardened cement paste with synchrotron microtomography. J Adv Concr Technol. 2008;6:273-286.

[122] Promentilla MAB, Sugiyama T, Hitomi T, Takeda N. Quantification of tortuosity in hardened cement pastes using synchrotron-based X-ray computed microtomography. Cem Concr Res. 2009;39:548557.

[123] Sugiyama T, Promentilla MAB, Hitomi T, Takeda N. Application of synchrotron microtomography for pore structure characterization ofdeteriorated cementitious materials due to leaching. Cem Concr Res. 2010;40:1265-1270.

[124] Monteiro PJM, Kirchheim AP, Chae S, et al. Characterizing the nano and micro structure of concrete to improve its durability. Cem Concr Comp. 2009;31:577-584.

[125] Voltolini M, Marinoni N, Mancini L. Synchrotron X-ray computed microtomography investigation of a mortar affected by alkali-silica reaction: a quantitative characterization of its microstructural features. J Mater Sci. 2011;46:6633-6641.

[126] Marinoni N, Voltolini M, Mancini L, Cella F. Influence of aggregate mineralogy on alkali-silica reaction studied by X-ray powder diffraction and imaging techniques. J Mater Sci. 2012;47:28452855.

[127] Gastaldi D, Canonico F, Capelli L, et al. In situ tomographic investigation on the early hydration behaviors of cementing systems. Const Build Mater. 2012;29:284-290.

[128] Helfen L, Dehn F, Mikulik P, Baumbach T. Three-dimensional imaging of cement microstructure evolution during hydration. Adv Cem Res. 2005;17:103-111.

[129] Provis JL, Myers RJ, White CE, Rose V, van Deventer JSJ. X-ray microtomography shows pore structure and tortuosity in alkali-activated binders. Cem Concr Res. 2012;42:855-864.

[130] Parisatto M, Dalconi MC, Valentini L, et al. Examining microstructural evolution of Portland cements by in-situ synchrotron micro-tomography. J Mater Sci. 2015;50:1805-1817.

[131] Mason HE, Walsh SDC, DuFrane VL, Carroll SA. Determination of diffusion profiles in altered wellbore cement using x-ray computed tomography methods. Environ Sci Technol. 2014;48:70947100.

[132] de Wolski SC, Bolander JE, Landis EN. An In-situ X-ray microtomography study of split cylinder fracture in cement-based materials. Exp Mech. 2014;54:1227-1235.

[133] Provis JL, Rose V, Winarski RP, van Deventer JSJ. Hard X-ray nanotomography of amorphous aluminosilicate cements. Scripta Mater. 2011;65:316-319.

[134] Bossa N, Chaurand P, Vicente J, et al. Micro- and nano-X-ray computed-tomography: a step forward in the characterization of the pore network of a leached cement paste. Cem Concr Res. 2015;67:138147.

[135] Hajimohammadi A, Provis JL, van Deventer JSJ. Time-resolved and spatially-resolved infrared spectroscopic observation of seeded nucleation controlling geopolymer gel formation. J Colloid Interface Sci. 2011;357:384-392.

[136] Garbev K, Gasharova B, Stemmermann PA. Modular concept of crystal structure applied to the thermal transformation of ïAza- $\mathrm{C}_{2}$ SH. J Am Ceram Soc. 2014;97:2286-2297.

[137] Ha J, Chae S, Chou KW, Tyliszczak T, Monteiro PJM. Effect of polymers on the nanostructure and on the carbonation of calcium silicate hydrates: a scanning transmission X-ray microscopy study. $\mathrm{J}$ Mat Sci. 2012;47:976-989.

[138] Jackson MD, Chae SR, Mulcahy SR, et al. Unlocking the secrets of Al-tobermorite in roman seawater concrete. Am Miner. 2013;98:1669-1687.

[139] Hernández-Cruz D, Hargis CW, Bae S, et al. Multiscale characterization of chemical-mechanical interactions between polymer fibers and cementitious matrix. Cem Concr Comp. 2014;48:9-18.

[140] Provis JL, Rose V, Bernal SA, van Deventer JSJ. High-resolution nanoprobe X-ray fluorescence characterization of heterogeneous calcium and heavy metal distributions in alkali-activated fly ash. Langmuir. 2009;25:11897-11904. 
[141] Bernal SA, Provis JL, Rose V, de Gutierrez RM. High-Resolution X-ray diffraction and fluorescence microscopy characterization of alkali-activated slag-metakaolin binders. J Am Ceram Soc. 2013;96:1951-1957.

[142] Bernal SA, Rose V, Provis JL. The fate of iron in blast furnace slag particles during alkali-activation. Mater Chem and Phys. 2014;146:1-5.

[143] Wieland E, Dähn R, Vespa M, Lothenbach B. Micro-spectroscopic investigation of Al and S speciation in hardened cement paste. Cem Concr Res. 2010;40:885-891.

[144] Bae S, Meral C, Oh J, Moon J, Kunz M, Monteiro PJM. Characterization of morphology and hydration products of high-volume fly ash paste by monochromatic scanning x-ray micro-diffraction ( $\mu$-SXRD). Cem Concr Res. 2014;59:155-164.

[145] Vespa M, Dahn R, Gallucci E, Grolimund D, Wieland E, Scheidegger AM. Microscale investigations of Ni uptake by cement using a combination of scanning electron microscopy and synchrotron-based techniques. Environ Sci Technol. 2006;40:7702-7709.

[146] Wenk HR, Monteiro PJM, Kunz M, et al. Preferred orientation of ettringite in concrete fractures. J Appl Cryst. 2009;42:429-432.

[147] Schlegel MC, Muller U, Panne U, Emmerling F. Deciphering the sulfate attack of cementitious materials by high-resolution micro-X-ray diffraction. Anal Chem. 2011;83:3744-3749.

[148] Schlegel MC, Muller U, Malaga K, Panne U, Emmerling F. Spatially resolved investigation of complex multi-phase systems using $\mu$ XRF, SEM-EDX and high resolution SyXRD. Cem Concr Comp. 2013;37:241-245.

[149] Stroh J, Schlegel MC, Irassar EF, Meng B, Emmerling F. Applying high resolution SyXRD analysis on sulfate attacked concrete field samples. Cem Concr Res. 2014;66:19-26.

[150] Jackson MD, Landis EN, Brune PF, et al. Mechanical resilience and cementitious processes in imperial roman architectural mortar. PNAS. 2014;111:18484-18489.

[151] Bleuet P, Welcomme E, Dooryhée E, Susini J, Hodeau JL, Walter P. Probing the structure of heterogeneous diluted materials by diffraction tomography. Nat Mater. 2008;7:468-472.

[152] Artioli G, Cerulli T, Cruciani G, et al. X-ray diffraction microtomography (XRD-CT), a novel tool for non-invasive mapping of phase development in cement materials. Anal Bioanal Chem. 2010;397:2131-2136.

[153] Valentini L, Dalconi MC, Parisatto M, Cruciani G, Artioli G. Towards three-dimensional quantitative reconstruction of cement microstructure by X-ray diffraction microtomography. J Appl Cryst. 2011;44:272-280.

[154] Voltolini M, Dalconi MC, Artioli G, et al. Understanding cement hydration at the microscale: new opportunities from 'pencil-beam' synchrotron X-ray diffraction tomography. J Appl Cryst. 2013;46:142-152.

[155] Artioli G, Dalconi MC, Parisatto M, Valentini L, Voltolini M, Ferrari G. 3D imaging of complex materials: the case of cements. Int J Mat Res. 2012;103:145-150.

[156] Valentini L, Artioli G, Voltolini M, Dalconi MC. Multifractal analysis of Calcium Silicate Hydrate (C-S-H) mapped by x-ray diffraction microtomography. J Am Ceram Soc. 2012;95:2647-2652.

[157] Artioli G, Valentini L, Dalconi MC, et al. Imaging of nano-seeded nucleation in cement pastes by X-ray diffraction tomography. Int J Mat Res. 2014;105:628-631.

[158] Artioli G, Valentini L, Voltolini M, Dalconi MC, Ferrari G, Russo V. Direct imaging of nucleation mechanisms by synchrotron diffraction micro-tomography: superplasticizer-induced change of C - S - H nucleation in cement. Cryst Growth Des. 2015;15:20-23.

[159] Liu X, Aranda MAG, Chen B, Wang P, Harder R, Robinson I. In situ bragg coherent diffraction imaging study of a cement phase microcrystal during hydration. Cryst Growth Des. 2015;15:30873091.

[160] Trtik P, Diaz A, Guizar-Sicairos M, Menzel A, Bunk O. Density mapping of hardened cement paste using ptychographic X-ray computed tomography. Cem Concr Comp. 2013;36:71-77.

[161] da Silva JC, Trtik P, Diaz A, et al. Mass density and water content of saturated never-dried calcium silicate hydrates. Langmuir. 2015;31:3779-3783. 